\title{
Taxonomy of Papuasian Onthophagus: twenty new species and their relatives (Coleoptera: Scarabaeidae: Scarabaeinae)
}

\author{
J. Krikken \& J. Huijbregts
}

\begin{abstract}
The species composition of the genus Onthophagus Latreille, 1802 in Papuasia (New Guinea and adjacent islands) is discussed. Twenty new species from Papuasia are described and illustrated, several being accommodated in multi-species operational groups; a synoptic guide and keys to the species are given. The following new species are proposed: Onthophagus (eliptaminus group): O. kokoiorus, O. solomonensis; Onthophagus (pedisequus group): O. mokwamensis; Onthophagus (quadripustulatus group): O. tarasovi; Onthophagus (tauroides group): O. opacotaurus, O. pseudocostifer; Onthophagus (coprimorphus group): O. ioranus, O. ubaidillahi; Onthophagus (declivis group): O. francoisgenieri; Onthophagus (labdacus group): O. alaindrumonti, $O$. andrewsmithi; Onthophagus (platalea group): O. yifer; Onthophagus (asper group): O. papurugosus. The following new species have no obvious close Papuasian relatives: Onthophagus hagenmontis, O. ioramaculatus, O. papuater, O. papuplicatus, $O$. peotoxus, O. sylvipapuanus, O. toxopeus. A lectotype is designated for Onthophagus costifer Gillet, 1930, in the tauroides group. A list of all named Papuasian species of Onthophagus is given.

Keywords: Coleoptera, Scarabaeidae, Onthophagus, New Guinea, keys, list of species, new species.

J. Krikken*, NCB Naturalis, PO Box 9517, NL-2300 RA Leiden, The Netherlands. jan.krikken@naturalis.nl

J. Huijbregts, NCB Naturalis, PO Box 9517, NL-2300 RA Leiden, The Netherlands. hans.huijbregts@naturalis.nl
\end{abstract}

\section{Introduction}

The Papuasian region, from the Aru and Waigeo Islands to the Solomons, has a rich fauna of the subcosmopolitan dung beetle genus Onthophagus Latreille, 1802, particularly on the main island of New Guinea. This paper is the first in a series reporting on new and otherwise interesting species from this region. Our recent Onthophagus studies have focused on the fauna of Sundaland and Wallacea, particularly Sulawesi, but always with an eye to the Papuasian islands. The Sulawesi Onthophagus fauna is strongly endemic above the species level, but can, with few exceptions, not be qualified as having Australasian affinities, i.e. not on morphological characters. On the Moluccas, on the other hand, although the islands have an Onthophagus fauna with low species numbers, showing a certain level of supraspecific endemism, Australasian elements seem more predominant (Huijbregts \& Krikken 2012). This applies, predictably, fully to New Guinea - at any rate, very few of the at least 145 Papuasian species currently known to us have obvious affinities to Oriental congeners. 
Synoptic papers relevant to Papuasian Onthophagus include Balthasar (1969, mainly New Guinea) and Matthews (1972, Australia), to which some additions have been published (Paulian 1972, Krikken 1977, New Guinea; Storey 1977, Storey \& Weir 1990, Australia; Huijbregts \& Krikken 2012, Moluccas). Notwithstanding serious flaws, Balthasar's (1969) key to the Papuasian species remains, for the time being, useful as an operational overview. He misinterpreted some of Gillet's (1930) species - as we did, before having studied the types. In his revision of Australian Onthophagus Matthews (l.c.) did not discuss any relationships with extralimital congeners, except for observing that he knew Australia and New Guinea to share five species; he did not cite the New Guinea papers of Balthasar and Gillet. Meanwhile, at least 14 of the current total of nearly 200 named indigenous Australian Onthophagus species are known to be shared with New Guinea (summary in Table 2). Storey \& Weir (1990) gave a figure of 191 species for Australia; Cassis \& Weir (1992) mentioned 6 further non-indigenous species. Cassis \& Weir (l.c.) also mentioned two African species, O. gazella (Fabricius, 1787) and O. obliquus (Olivier, 1789), as introduced to New Guinea and other Melanesian islands. Published documentation on proposed and actual introductions of dung beetles and any ecosystem consequences - not only for New Guinea - continues to be limited (a recent review with emphasis on Australia is Ridsdill-Smith \& Edwards 2011).

Davis (for instance in Scholtz et al. 2009) implies Cenozoic Australian origins for the Papuasian scarabaeine fauna, but, whatever the detailed biogeographic patterns and their history, New Guinea has some odd endemics, including various Onthophagus species groups apparently absent from presentday Australia and vice versa. In other words, there appears to be more to the fauna of New Guinea than a simple Australian connection. Moreover, recent immigrants aside, a straightforward origin of the overall Australasian onthophagine fauna from the Oriental Region since the Oligocene (as suggested by Davis 1.c.) is disputable, to say the least - as already implied above. If indeed the body of the Australasian fauna would have originated from Oriental congeners, one would expect, also on morphological grounds, to find more relatives West of the Wallace Line, although, admittedly, the phylogenies from recent molecular analyses (like Emlen et al. 2005) hardly leave us with alternatives.

The morphological diversity of Papuasian onthophagines is considerable, as is evident from the illustrations in this paper. About 90 names are now on the species list (Table 2), and limited exploration on top of the minimum of 145 given above thus implies numerous additions, 20 being described in this paper. Several are here accommodated in operational groups, defined by taking into account (a) some of the key characters employed in the two synopses mentioned above, (b) a selection of conventional quasi-supraspecific characters (listed in Table 1 below), and (c) any additional, preferably unusual group attributes (i.e. including potential synapomorphies). Several of the character states coming under (a) and (b) have a checkered distribution over the respective species; in other words: clustering is poor. It even looks as if certain character states may be found in any combination with others (shape of frontovertexal and pronotal protrusions, size of eye foramina, configuration of clypeofrontal transition, etc.). Note, by the way, that individual polymorphism is common in these characters, further qualifying (usually diminishing) their practical taxonomic value. Apart from the application of molecular techniques, a serious study of morphological characters (for instance of the mouthparts and elements of the reproductive system) is likely to uncover synapomorphies supporting the reclassification of Papuasian Onthophagus (see, for instance, Tarasov \& Solodovnikov 2011). Access to the species groups treated in this paper is, to some extent, facilitated by a synoptic guide (Table 1) and an operational dichotomous key. Onthophagus species that cannot now be joined with other Papuasian relatives in a multi-species group are assembled under the heading Ungrouped species.

For the majority of the species the material at hand is limited in terms of locality records and specimen numbers, leading inevitably to presumptions about populational and individual polymorphism. Subtle geographic and altitudinal variation seems rife among Papuasian Onthophagus, raising questions about species-group ranking (species versus subspecies), and occasionally necessitating a provisional assessment awaiting more material. Additionally, some new species without obvious relatives, proposed in this paper, are just based on male singletons, but not describing them would impair our view on the Papuasian morphological diversity. Not all species, however, present these problems, some appearing homogeneous and widespread - one, for instance, occurring from Queensland through New Guinea to the Aru Islands (Onthophagus wombalano Matthews, 1972).

Older specimens usually lack ecological data, but most post-1970 specimen labels, other information aside, indicate attraction to dung or carrion. Altitudinal occurrence (particularly lowland versus upland, at about the $1000 \mathrm{~m}$ line), given on nearly all recent labels, is known to be a major factor in species distribution. The long-standing mountainous (ecological island) nature of New Guinea and the presence of peninsulas, and islands around the mainland, or 
Table 1. Synoptic guide roughly positioning the new species and their relatives

\section{Morphological characters and character states}

Reference: major males, consult illustrations.

1. Clypeal edge of male anteriorly (shape)

a. bidentate, bisinuate, or emarginate (may be slightly reflexed-lobe)

b. rounded, very slightly projecting, or simply truncate c. distinctly projecting and reflexed (irrespective of shape)

2. Clypeal surface of male in front of clypeofrontal transition (ornamentation)

a. without non-marginal protrusion(s)

b. with non-marginal protrusion(s)

3. Frontovertex of male (ornamentation)

a. without distinct protrusion(s)

b. with (at least) pair of protrusions or transverse ridge

c. with single median protrusion only

d. with ornamentation distinctly different from $b-c$

4. Clypeofrontal transition of male (ornamentation)

a. without transverse elevation

b. with arcuate (anteriorly convex) elevation

c. with (virtually) rectilinear elevation ending at genal suture away

from border

d. with (virtually) rectilinear transverse elevation reaching genal

border (continuing into clypeogenal ridge)

e. with isolated median elevation

5. Foramen of eye (shape, full-face view)

a. narrow (luniform or narrowly elliptic)

b. broad (elliptic to circular, separated by less than 5 eye-widths)

6. Pronotum of male (general shape)

a. convex, (virtually) unmodified

b. with distinct impression(s) and/or protrusion(s)

7. Pronotum (microsculpture)

a. smooth or punctate

b. granulate, asperate, or heavily rugulate(-punctate) throughout

8. Elytra (pilosity)

a. glabrous, or with inconspicuous micro-stubbles or micro-setae only (distinct at $>\times 40$ )

b. distinctly setose, at least with bristles, at least laterally (at $<\times 10$ )

9. Protibial apex of male (shape)

a. unmodified (apico-external denticle more or less oblique to tibial axis)

b. truncate (and/or apico-external denticles perpendicular to tibial axis)

c. distinctly modified (with apico-internal

thumb or otherwise)

10. Dorsal colour (general pattern)

a. virtually entire dorsum usually black or dark-brown

b. dorsum usually lighter, but virtually uniform (yellowish,

reddish, medium- or light-brown, head may be darker)

c. dorsum distinctly patterned

d. at least pronotum and/or elytra distinctly metallic

11. Usual total body length (in $\mathrm{mm}$ )

a. up to $6 \mathrm{~mm}$ (small)

b. 6-12 $\mathrm{mm}$ (medium-sized)

c. over $12 \mathrm{~mm}$ (large)

12. Remarkable attributes within group and/or faunal context (of more than 2 species)

a. absent

b. emphasized in key and/or under Identification of relevant species

for that matter, the underlying geographical history, seem to have participated in speciation - probably driving the evolution of the dung beetle fauna to this day.
Table 1. (Continued.)

\begin{tabular}{|c|c|c|c|c|c|c|c|c|c|c|c|}
\hline \multirow[t]{2}{*}{ species: Onthophagus } & \multicolumn{11}{|c|}{ characters: } \\
\hline & 1 & 23 & 34 & 5 & 6 & 7 & 8 & 9 & 10 & 11 & 12 \\
\hline \multicolumn{12}{|l|}{ eliptaminus group: } \\
\hline eliptaminus & c & $\mathrm{a} a$ & a $a$ & $\mathrm{a}$ & $\mathrm{b}$ & $\mathrm{a}$ & (b) & $\mathrm{a}$ & a & $\mathrm{b}$ & a \\
\hline kokoiorus & $\mathrm{c}$ & $\mathrm{a} a$ & a a & $\mathrm{a}$ & $\mathrm{b}$ & $a$ & $\mathrm{~b}$ & $\mathrm{a}$ & $a / b$ & $b$ & $\mathrm{a}$ \\
\hline signifer & c & a a & a $a$ & $\mathrm{a}$ & $\mathrm{b}$ & $\mathrm{a}$ & $\mathrm{b}$ & $\mathrm{a}$ & $\mathrm{c}$ & $\mathrm{b}$ & $\mathrm{a}$ \\
\hline solomonensis & $\mathrm{c}$ & a a & a a & $\mathrm{a}$ & $\mathrm{b}$ & a & $\mathrm{b}$ & $\mathrm{x}$ & c & $\mathrm{b}$ & b \\
\hline \multicolumn{12}{|l|}{ pedisequus group: } \\
\hline pedisequus & c & $\mathrm{a} a$ & a $a$ & $\mathrm{a}$ & $\mathrm{a}$ & $\mathrm{a}$ & $\mathrm{b}$ & c & $\mathrm{a}$ & $b$ & a \\
\hline mokwamensis & $\mathrm{c}$ & $\mathrm{a} a$ & a a & $\mathrm{a}$ & $\mathrm{a}$ & $\mathrm{a}$ & $\mathrm{b}$ & c & a & $\mathrm{b}$ & a \\
\hline parapedisequus & $\mathrm{c}$ & a a & a a & $\mathrm{a}$ & $\mathrm{a}$ & a & $\mathrm{b}$ & $\mathrm{b}$ & a & $\mathrm{b}$ & a \\
\hline \multicolumn{12}{|c|}{ quadripustulatus group: } \\
\hline quadripustulatus & $\mathrm{a}$ & $\mathrm{a} b$ & $\mathrm{~b}$ & $\mathrm{a}$ & a & $\mathrm{a}$ & $\mathrm{a}$ & $\mathrm{b}$ & c & a & a \\
\hline tarasovi & $\mathrm{a}$ & $a b$ & $\mathrm{~b}$ & $\mathrm{a}$ & $\mathrm{a}$ & $\mathrm{a}$ & $\mathrm{a}$ & $\mathrm{a}$ & c & $\mathrm{a}$ & b \\
\hline flavomaculatus & a & $\mathrm{a} \mathrm{b}$ & $\mathrm{b}$ & $\mathrm{a}$ & $\mathrm{a}$ & a & $\mathrm{b}$ & $\mathrm{a}$ & c & a & a \\
\hline \multicolumn{12}{|l|}{ tauroides group: } \\
\hline tauroides & $\mathrm{a}$ & $\mathrm{a} b$ & $\mathrm{a}$ & $\mathrm{b}$ & $\mathrm{b}$ & $\mathrm{a}$ & $\mathrm{a}$ & $\mathrm{a}$ & a & $\mathrm{b}-\mathrm{c}$ & a \\
\hline opacotaurus & $\mathrm{a}$ & $\mathrm{a} \mathrm{b}$ & $\mathrm{b}$ & $\mathrm{b}$ & $\mathrm{b}$ & $\mathrm{a}$ & $\mathrm{a}$ & $\mathrm{a}$ & $\mathrm{a}$ & $b-c$ & a \\
\hline costifer & $\mathrm{a}$ & $\mathrm{a} \mathrm{b}$ & (b) & $\mathrm{b}$ & $\mathrm{b}$ & $\mathrm{a}$ & $\mathrm{a}$ & $\mathrm{a}$ & $\mathrm{a}$ & b-c & a \\
\hline pseudocostifer & a & $\mathrm{a} b$ & (b) & $\mathrm{b}$ & $\mathrm{b}$ & $\mathrm{a}$ & $\mathrm{a}$ & $\mathrm{a}$ & a & $b-c$ & a \\
\hline \multicolumn{12}{|l|}{ coprimorphus group: } \\
\hline coprimorphus & $\mathrm{b}$ & $\mathrm{a} \mathrm{b}$ & $\mathrm{b}$ & $\mathrm{b}$ & $\mathrm{b}$ & $\mathrm{a}$ & $\mathrm{a}$ & $\mathrm{a}$ & a & $\mathrm{b}$ & a \\
\hline ioranus & $\mathrm{b}$ & $\mathrm{a} b$ & $\mathrm{~b}$ & $\mathrm{~b}$ & $\mathrm{~b}$ & $\mathrm{a}$ & $\mathrm{a}$ & $\mathrm{a}$ & $\mathrm{a}$ & $\mathrm{b}$ & a \\
\hline ubaidillahi & $\mathrm{b}$ & $\mathrm{a} \mathrm{b}$ & $\mathrm{b}$ & $\mathrm{b}$ & $\mathrm{b}$ & $\mathrm{a}$ & $\mathrm{a}$ & $\mathrm{a}$ & a & $\mathrm{b}$ & a \\
\hline \multicolumn{12}{|l|}{ declivis group: } \\
\hline francoisgenieri & $\mathrm{b}$ & $\mathrm{a} b$ & $\mathrm{~b}$ & $\mathrm{~b}$ & $\mathrm{~b}$ & $\mathrm{a}$ & $\mathrm{a}$ & a & a & c & a \\
\hline tarsius & $\mathrm{b}$ & $\mathrm{a} b$ & $\mathrm{~b}$ & $\mathrm{~b}$ & $\mathrm{~b}$ & $\mathrm{a}$ & $\mathrm{a}$ & $\mathrm{a}$ & a & $\mathrm{c}$ & a \\
\hline \multicolumn{12}{|l|}{ labdacus group: } \\
\hline alaindrumonti & $\mathrm{a}$ & a c & $c \quad b$ & $\mathrm{a}$ & $\mathrm{b}$ & a & $\mathrm{a}$ & $\mathrm{a}$ & a & $b-c$ & a \\
\hline andrewsmithi & $\mathrm{a}$ & $\mathrm{a} \mathrm{b}$ & $\mathrm{b}$ & $\mathrm{a}$ & $\mathrm{b}$ & $\mathrm{a}$ & $\mathrm{a}$ & $\mathrm{a}$ & $\mathrm{a}$ & $b-c$ & a \\
\hline labdacus & $\mathrm{a}$ & $\mathrm{a} b$ & (b) & $\mathrm{a}$ & $\mathrm{b}$ & $\mathrm{a}$ & $\mathrm{a}$ & $\mathrm{a}$ & $\mathrm{a}$ & $b-c$ & a \\
\hline \multicolumn{12}{|l|}{ platalea group: } \\
\hline yifer & c & a c & c a & $\mathrm{a}$ & $\mathrm{a}$ & $\mathrm{a}$ & $\mathrm{a}$ & $\mathrm{a}$ & $a+(d)$ & $\mathrm{b}$ & b \\
\hline platalea & c & a a & a a & $\mathrm{a}$ & $\mathrm{b}$ & $\mathrm{a}$ & $\mathrm{a}$ & a & $\mathrm{d}$ & $\mathrm{b}$ & a \\
\hline \multicolumn{12}{|l|}{ asper group: } \\
\hline papurugosus & $\mathrm{a}$ & $\mathrm{a} b$ & $\mathrm{~b}$ & $\mathrm{a}$ & (b) & $\mathrm{b}$ & $\mathrm{b}$ & $\mathrm{a}$ & $a+d$ & $\mathrm{a}$ & a \\
\hline ocelliger & a & $a b$ & $\mathrm{~b}$ & $\mathrm{a}$ & $\mathrm{a}$ & a & $\mathrm{b}$ & a & c & a & a \\
\hline \multicolumn{12}{|l|}{ ungrouped species: } \\
\hline ioramaculatus & $\mathrm{a}$ & $\mathrm{a} \mathrm{b}$ & $\mathrm{b} a$ & $\mathrm{a}$ & $\mathrm{a}$ & $\mathrm{a}$ & $\mathrm{a}$ & $\mathrm{a}$ & $\mathrm{c}$ & $a-b$ & b \\
\hline papuater & $\mathrm{a}$ & $\mathrm{a} b$ & $\mathrm{~b}$ & $\mathrm{a}$ & a & $\mathrm{a}$ & $\mathrm{a}$ & $\mathrm{a}$ & a & $\mathrm{b}$ & $b$ \\
\hline peotoxus & $\mathrm{a}$ & $\mathrm{a} b$ & $\mathrm{~b}$ & $\mathrm{a}$ & $b$ & $\mathrm{a}$ & $\mathrm{a}$ & $\mathrm{a}$ & $\mathrm{a}$ & $b$ & $\mathrm{~b}$ \\
\hline hagenmontis & $a-c$ & $\mathrm{a} b$ & $\mathrm{~b}$ & $\mathrm{a}$ & $\mathrm{b}$ & $\mathrm{a}$ & $\mathrm{a}$ & $\mathrm{a}$ & $\mathrm{a}$ & $\mathrm{b}$ & b \\
\hline papuplicatus & $\mathrm{a}$ & $\mathrm{a} b$ & $\mathrm{c}$ & $\mathrm{a}$ & $\mathrm{b}$ & $\mathrm{a}$ & $\mathrm{a}$ & $\mathrm{a}$ & $\mathrm{a}$ & $b-c$ & $\mathrm{~b}$ \\
\hline sylvipapuanus & c & $\mathrm{a} b$ & a a & $\mathrm{b}$ & $\mathrm{b}$ & $\mathrm{a}$ & $\mathrm{a}$ & $\mathrm{a}$ & $\mathrm{a}$ & $\mathrm{b}$ & $b$ \\
\hline \multirow[t]{2}{*}{ toxopeus } & c & $\mathrm{a} b$ & $\mathrm{~b} a$ & $\mathrm{a}$ & $b$ & $\mathrm{a}$ & $\mathrm{a}$ & $\mathrm{a}$ & $\mathrm{a}$ & $\mathrm{b}$ & $\mathrm{b}$ \\
\hline & 1 & 23 & 34 & 5 & 6 & 7 & 8 & 9 & 10 & 11 & 12 \\
\hline
\end{tabular}

- hyphen indicates occurrence of transitional state

+ indicates combination of more states in one individual

/ indicates occurrence of more states in a taxon

( ) enclose limited development of state in a taxon

Immature stages of indigenous Papuasian species have yet to be described. As for general ecology, many extralimital Onthophagus are known to be tunneling feeders and breeders under or near dung or carrion, and the majority of the Papuasians may be inferred to behave similarly. Based on their possible phylogeny c.q. group membership, some species may be predicted to have an unusual ecology, ranging, as in 
the Australian fauna, from mycetophagy on agarics to phoresy on mammals (Matthews 1972). A number of phoretic species (some were formerly combined with Macropocopris Arrow, 1920) have tarsal claws that are adapted for clinging to mammal fur, $O$. symbioticus (Arrow, 1920) and O. muticus Macleay, 1864 being New Guinea examples. Members of the group around Onthophagus papuensis Harold, 1877 may, like some of their relatives in the West of the archipelago, be associated with plants, for instance their fruits, tubers, decaying wood, and other vegetable material (Krikken \& Huijbregts 2011). Other trophic relationships undoubtedly have remained undetected, and the species concerned may well have escaped standard collecting routines. Note also that the incidence of large eye foramina is high among Papuasian Onthophagus, possibly indicative of a concordant nocturnal or crepuscular activity.

Groups of small, unicoloured black or brown Papuasian Onthophagus (i.e., with a body length under $6 \mathrm{~mm}$ ) will be treated in a forthcoming paper, and sequels on other sets of species are in preparation. A taxonomic overview of the fauna is envisaged, but its completion will take more time (input from other parties welcome). A list of the named Papuasian species of Onthophagus is given in Table 2 of this paper (questionable records omitted). The novelties treated herein are all formally placed in the nominate subgenus and included in Table 2. In view of the ongoing efforts to globally reclassify the components of the genus and other Onthophagini, many species may end up in different supraspecific units (genera, subgenera, species groups). In our view, however, without a thorough global analysis, the creation of more genus-group names without critical context should be avoided.

\section{Methods, terminology, material}

In the section References all post-Gillet (1930) and other pertinent papers regarding Papuasian Onthophagus are listed. Locality data given under Material examined (holotype data, all data in Appendix 1) follow the label text, at most with slight adaptations; pertinent non-label additions, translations and comments are in square brackets. Appendix 1 is limited to Papuasian material concretely used in the preparation of this paper, i.e. material of new species and their close relatives (including data not given in the main text). Note that the term West New Guinea as used here collectively denotes various administrative units on the Indonesian side; island groups apparently having a typically Papuasian fauna are included, like the Aru Islands.

The descriptive text focuses on the new Onthophagus species, and keys and other diagnostic informa- tion are complementary to the much more informative technical illustrations. In some illustrations the contrast of protrusions and microsculpture against a shining unicolour black surface may be limited, but this is compensated by illustrations showing different views, starting with eight plates giving habitus views of the new species and their relatives. All scale lines given with the body parts are $1 \mathrm{~mm}$. In order not to damage them by re-mounting and other handling, most specimens (particularly types) and their body parts have been photographed as is, using simple ring flash and/or LED ring devices avoiding unnatural colours. With few exceptions, the parameres of the Papuasian Onthophagus, although constant in species, show little structural diversification within groups, most having a simple, downward, tapering distal part (with protruding apex frequently slightly dilated in full-face view); some are plump at base, some strongly recurved and humped.

In the context of this paper many type specimens of pre-1970 Onthophagus species were studied (some being pictured here for comparison with their new relatives). Several of these had been provided, apparently as part of curatorial routine, with holotype and paratype labels where actually syntypes and/or non-typical specimens were involved. In this paper one lectotype is designated and described $(O$. costifer Gillet, 1930 in the tauroides group). Some authors mixed up West New Guinea (Irian Jaya) and Papua New Guinea localities (western versus eastern New Guinea), apparently being unfamiliar with topography and/or history (Paulian 1937, for instance, situated Sattelberg in the western half of New Guinea, which was then followed by Balthasar 1969). For the West New Guinea localities of collector L.J. Toxopeus, cf. Archbold et al. (1942), and Toxopeus (1940); for the 1920-1921 localities of collector W.C. van Heurn, mentioned by Gillet (1930), cf. map in Holthuis \& Husson (1973: 23), more references in van Steenis-Kruseman (1950, under H.J. Lam).

In the descriptions the qualification abundant for microsculptural units (like punctures) usually means: mostly separated by 2-5 diameters, dense: 1-2 diameters, crowded: less than 1 diameter; sparse: separated by at least 5 diameters, or limited to certain parts only. The type of punctation is usually qualified only if decidedly different from a simple punctation.

The term full-face view is applied where the surface of the element concerned is maximally parallel to the plane of the picture (as with the head). The prefix micro- usually stands for sculpture and pilosity distinct at magnifications $\times 40$ and higher; glabrous means that any pilosity is absent or indistinct at $\times 40$. The prefix hemi-, as occasionally used with punctures, means that the punctural edge 
Table 2. Alphabetical list of named indigenous Papuasian Onthophagus species

\begin{tabular}{|c|c|c|}
\hline O. acerus Gillet, 1930 & O. investigator Lansberge, 1885 & O. peotoxus sp. n. \\
\hline O. adelphus Gillet, 1930 & O. ioramaculatus sp. n. & O. phrixus Balthasar, 1969 Bism \\
\hline O. aemulus Gillet, 1930 & O. ioranus sp. $\mathrm{n}$. & O. picipennis Hope, $1841 \mathrm{AU}$ \\
\hline O. affinis Gillet, 1930 & O. irianus Balthasar, 1969 & O. planiceps Macleay, 1886 \\
\hline O. alaindrumonti sp. n. & O. iris Sharp, 1875 & O. platalea Arrow, 1941 \\
\hline O. andrewsmithi $\mathrm{sp} . \mathrm{n}$. & O. joliveti Paulian, 1972 & O. prehensilis (Arrow, 1920) AU \\
\hline O. aspericollis Lansberge, 1885 & O. koebelei Blackburn, $1903 \mathrm{AU}$ & O. propinquus Macleay, $1888 \mathrm{AU}$ \\
\hline O. atrox Harold, $1867 \mathrm{AU}$ & O. kokoiorus sp. n. & O. pseudocostifer sp. n. \\
\hline O. bennigseni Paulian, 1937 & O. kraatzeanus Lansberge, $1883 \mathrm{mx}$ & O. quadripustulatus (Fabricius, 1775) AU \\
\hline O. bomberaianus Balthasar, 1969 & O. Labdacus Balthasar, 1969 & O. reticollis Macleay, 1886 \\
\hline O. bufulus Arrow, 1941 & O. Laminatus Macleay, $1864 \mathrm{AU}$ & O. riparius Lansberge, 1885 \\
\hline O. busiris Balthasar, 1969 & O. latenasutus Arrow, 1941 & O. rubrimaculatus Macleay, $1864 \mathrm{AU}$ \\
\hline O. calamophilus Krikken, 1977 & O. lorianus Gillet, 1930 & O. rufosignatus Macleay, $1864 \mathrm{AU}$ \\
\hline O. catenatus Lansberge, 1883 & O. ludicrus Balthasar, 1969 & O. sciron Balthasar, $1969 \mathrm{MO}$ \\
\hline O. centurio Lansberge, 1885 & O. maculosipennis Gillet, 1930 & O. signifer Harold, 1877 \\
\hline O. cheesmanae Arrow, 1941 & O. malthinus Gillet, 1930 & O. sisyphoides Krikken, 1977 \\
\hline O. chremes Balthasar, 1969 & O. mayeri Harold, 1876 & O. solomonensis $\mathrm{sp} . \mathrm{n}$. Sol \\
\hline O. consentaneus Harold, $1867 \mathrm{AU}$ & O. mimikanus Balthasar, $1969 \mathrm{mx}$ & O. spinicornis Gillet, 1930 \\
\hline O. coprimorphus Gillet, 1930 & O. minotaurus Arrow, 1941 & O. sylvipapuanus sp. n. \\
\hline O. costifer Gillet, 1930 & O. mokwamensis sp. $\mathrm{n}$. & O. symbioticus (Arrow, 1920) AU \\
\hline O. cratippus Balthasar, 1969 & O. muticus Macleay, $1864 \mathrm{AU}$ & O. tarasovi sp. n. \\
\hline O. devexicornis Gillet, 1930 & O. nasicus Gillet, 1930 & O. tarsius Arrow, 1941 \\
\hline O. dignus Gillet, 1930 & O. nitefactus Harold, 1877 & O. tauroides Gillet, 1930 \\
\hline O. doriae Harold, 1877 & O. nodulifer Harold, 1867 AU & O. taxillus Balthasar, 1969 \\
\hline O. eliptaminus Balthasar, 1969 & O. novaeirlandiae Balthasar, 1969 Bism & O. telegonus Balthasar, 1969 \\
\hline O. flavomaculatus Gillet, 1930 & O. nymani Gillet, 1930 & O. telephus Balthasar, 1969 \\
\hline O. francoisgenieri $\mathrm{sp} . \mathrm{n}$. & O. ocelliger Harold, $1877 \mathrm{AU}$ & O. tetricus Harold, 1877 \\
\hline O. gagatinus Gillet, 1930 & O. opacotaurus sp. n. & O. toxopeus sp. n. \\
\hline O. geryon Balthasar, 1969 & O. orbicularis Lansberge, 1885 & O. triptolemus Balthasar, 1969 \\
\hline O. glaucinus Gillet, 1930 & O. orbus Boucomont, 1924 (n.nov.) mx & O. ubaidillabi sp. n. \\
\hline O. gorokae Paulian, 1972 & O. ornaticollis Gillet, 1930 & O. vicinus Harold, 1887 \\
\hline O. gothicus Gillet, 1930 & O. papuater sp. $\mathrm{n}$. & O. vulpinaris Schoenfeldt, 1907 \\
\hline O. hagenmontis sp. $\mathrm{n}$. & O. papuensis Harold, 1877 & O. wallacei Harold, 1871 \\
\hline O. hamaticornis Gillet, 1930 & O. papurugosus sp. $\mathrm{n}$. & O. wombalano Matthews, $1972 \mathrm{AU}$ \\
\hline O. heurni Gillet, 1930 & O. papuplicatus sp. $\mathrm{n}$. & O. yifer sp. n. \\
\hline O. hirtuosus Gillet, 1930 & O. parapedisequus Balthasar, 1969 & \\
\hline O. hoplothorax Gillet, 1930 & O. parryi Harold, 1869 & 111 spp. \\
\hline O. horribilis Balthasar, 1969 & O. pedisequus Balthasar, 1969 & \\
\hline
\end{tabular}

new species proposed in this paper listed in bold; additional papers with new species forthcoming

no indication of range $=$ occurring in Papuasian region (mainland New Guinea and nearby islands, incl. Aru Islands and Solomons)

AU - Papuasian species, also in Australia

MO - Papuasian species, also in Moluccas

Bism - Bismarck Is only

Sol - Solomon Is only

$\mathrm{mx}$ - male undescribed/unknown

is more or less effaced on one side (any associated seta decumbent to effaced side). Prefixes between parentheses, like (hemi)punctate, denote incomplete and/or mixed states (read: more or less). Occasionally the term sericeous is applied to a surface looking satin (slightly shiny, or with some lustre, not being completely matt/opaque, usually due to a slight microreticulation). The use of the term shiny means that from a surface light reflection of the body part(s) concerned is limited, being not generally brightly shining.

Body part measurements as given in the descriptions were taken through microscopes with a calibrated ocular micrometer scale, rounded off to $0.1 \mathrm{~mm}$ (in the smaller species to $0.05 \mathrm{~mm}$ ). Body lengths of specimens usually measured as is (head not necessarily fully extended), rounded off to $0.5 \mathrm{~mm}$. Metatarsomeral proportions roughly indicated by rounding off to nearest integer.

\section{Collections mentioned}

AMNH American Museum of Natural History, New York, USA

BMNH The Natural History Museum, London, UK

CMNC Canadian Museum of Nature, Ottawa, Canada

IRSNB Institut Royal des Sciences Naturelles de Belgique, Brussels, Belgium 
NMPC National Museum, Prague, Czech Republic

MBBJ Museum Zoologicum Bogoriense, Cibinong/Bogor, Indonesia

RMNH National Museum of Natural History/Naturalis Biodiversity Centre, Leiden, The Netherlands

SDEI Senckenberg Deutsches Entomologisches Institut, Müncheberg, Germany

\section{Key to groups and to ungrouped species (males)}

\section{How to use}

This is an introductory key to grouped and ungrouped Papuasian Onthophagus treated in this paper; use informative series, and beware of minor males, particularly singletons. More subkeys to species in the species group accounts further below. Consult the relevant illustrations.

1. Both apical edge of clypeus and anterior side of generally convex pronotum with single, long projection (a reflexed clypeal lobe and a forward pronotal prong, plate, or spike, forward over head). Forebody not conspicuously shining, not metallic. Head behind apical border lacking any elevation. Body length over $6 \mathrm{~mm} . . . \ldots \ldots \ldots \ldots$. ......... eliptaminus group (subkey, 4 spp.)

- Not such a projection on both these parts, or else other character states different ...... 2

2. Clypeogenal border widely evenly rounded from apicomedian lobe to distinctly angular genal tip, head behind clypeal apex lacking any elevations. Pronotum evenly convex, lacking projections. Tibiae all very slender, protibia distally curved inward, outer edge more or less retro-dentate. Body length over $6 \mathrm{~mm}$....... pedisequus group (subkey, $3 \mathrm{spp}$.)

- Combination of character states different....3

3. Elytra with pattern of well-defined symmetric patches on darker background (red, orange, or yellow on black-brown), or elytra generally much lighter than forebody (reddish, light-brown, yellow). Dorsum lacking abundant, very long setae. Pronotum generally convex (any protrusions limited). Body length usually up to ca $7 \mathrm{~mm}$. Clypeal apex not distinctly bidentate, always with protrusions on head surface (for instance, between eyes) $\ldots \ldots \ldots \ldots \ldots \ldots \ldots \ldots \ldots \ldots . \ldots \ldots$

- Elytra and forebody predominantly unicolour black or brown, or more or less metallic (elytra in one group peculiarly satin with metallic reflections). Dorsum, if not unicolour black or brown, with pattern more scattered, or vague, marbled, abundantly speckled, etc., or very small species with clypeal apex bidentate and without protrusions on head and pronotal surface ...6 6

4. Clypeal apex shallowly emarginate (usually bisinuate), without reflexed projection ..... 5

- Clypeal apex with distinct more or less upright projection (usually a reflexed lobe) $\ldots . .8$

5. Head at most with low (transverse) eleva$\operatorname{tion}(\mathrm{s}) \ldots \ldots \ldots \ldots \ldots \ldots \ldots \ldots \ldots$ ...... quadripustulatus group (subkey, 3 spp.)

- Head with pair of upright vertexal stalks, in major males distal section abruptly bent inward .................. ioramaculatus

6. Pronotum with well defined, broadly concave median depression over much of its length, flanked on either side by more or less erect ridge or tapering plate. Eyes large. Clypeal border widely, evenly rounded. Generally black or brown .............. ..... coprimorphus group (subkey, $3+1$ spp.)

- Lacking this combination of character states 7

7. Pronotum with very broad, flat pronotal disc, laterally delimited by sharp ridge, sloping up to backward, tapering posterior projection (may extend over elytral base). Clypeal border widely rounded, apex lacking lobe or other distinct projection. Large, body length over $12 \mathrm{~mm}$. Generally black or brown ...... declivis group (subkey, 2 spp.)

- Combination of character states different ... .8

8. Vertex with pair of long, slender, well separated horns, evenly arcuate laterad, upward over eyes; base of horns unconnected and lacking intervening protrusion, horns lacking accessory expansions (denticles, lobes etc.). Pronotum unevenly convex, but lacking well defined projections and/or cavities. Clypeal apex simply bisinuate or truncate. Body length usually $10-14 \mathrm{~mm} . . . \ldots \ldots$. ..........tauroides group (subkey, 4 spp.)

- Vertex different, horns (if present at all) different (for instance, dentate, more upright, or connected at base), or other character states not applicable (clypeal apex, detailed shape of pronotum, etc.) ............. 9

9. Pronotum (in both sexes) with double pair of anteriorly directed, well-pronounced, more or less conical protrusions. Clypeal apex broadly lobate-reflexed, bisinuate-bidentate. Frontovertex with distinct elevation(s). Labrum at most shallowly excised. Generally black or brown. Body length usu- 
ally $11-13 \mathrm{~mm} . \ldots \ldots \ldots \ldots \ldots \ldots \ldots$ ............labdacus group (subkey, 3 spp.)

- Pronotum lacking double pair of conical protrusions (if any paramedian protrusions present, these are set on much broader forward projection), or other character states not applicable .................. 10

10. Body predominantly brown-black, with metallic lustre, conspicuously (rugulate-)punctate-setose. Clypeal border anteriorly bisinuate. Pygidium ridged along base. Vertex and other parts of head surface with low, more or less transverse protrusions only. Small, not looking deplanateoval, body length less than $6 \mathrm{~mm}$......... ...............asper group (subkey, 2 spp.)

- Combination of character states different. .. 11

11. Pronotum with sharp, transverse, fold-like ridge (plica) topping steep anterior declivity, remaining surface generally convex. Vertex with pair of inwardly expanded horns. Generally robust, black or brown ........ .................. papuplicatus

- Pronotum without antediscal plica ...... 12

12. Head relatively broad, genae and clypeus rounded, clypeus with long spatuliform, upright projection, usually just behind apical edge. Frons may have projection, and pronotum may have long forward prong or spike. Pronotum (apart from any anteromedian projection) generally convex, punctation fine. Shining, black, forebody may have metallic lustre. Body length $6-8 \mathrm{~mm}$ ........... platalea group (subkey, 2 spp.)

- Combination of character states different. . 13

13. Head without long projections on margin and/or surface. Frons with slight, short interocular ridge. Dorsum entirely matt black. Pronotum evenly convex, somewhat deplanate, base widely evenly rounded.... ................................

- Combination of character states different... 14

14. Pronotum anteriorly with shallowly concave depression surrounded by set of three low conical protrusions. Frons with short interocular ridge. Dorsum unicolour black ..................... peotoxus

- Forebody without this ornamentation..... 15

15. Pronotal disc with two-sided anterior declivity, medially converging (dorsal view) to angular, forward protrusion with sharp upright crest. Elytra remarkably elongate. Dorsum unicolour black........ hagenmontis

- Combination of character states different .. 16
16. Head lacking clypeofrontal ridge, reflexed subtriangular lobe on clypeal apex with rounded tip. Pronotum broadly protruding forward from disc. Elytra relatively long. Dorsum unicolour black-brown ......... 17

- Combination of character states different ........................... other Papuasian (groups of) Onthophagus species

17. Anterior section of lateral border of pronotum concave(-sinuate) in dorsal view. Frons with slight interocular ridge, head surface lacking other elevation(s) ....... sylvipapuanus

- Anterior section of lateral border of pronotum evenly convex in dorsal view. Frons lacking interocular elevation, but with distinct pair of interconnected vertexal horns ........................ toxopeus

\section{Group and species accounts The Onthophagus eliptaminus group}

\section{Group characters}

The males in this group have an upright projection (usually a lobe or a narrow plate) on their clypeal apex, and a forward expansion of the pronotal disc, which may take the form of a long complanate plate, prong, or spike. Head surface of male without non-marginal protrusions, lateral borders variable, usually continuous at clypeogenal border, genal tip more or less angular. Eye foramina narrow, relatively small. Anterior section of lateral pronotal border evenly rounded in dorsal view. Pygidial base ridged. Male protibia elongate, with extensive proximal-external serration, and with four larger external denticles not simply oblique to the tibial axis (apical edge perpendicular-truncate or produced). Medium-sized, body length usually $6-10 \mathrm{~mm}$. Dorsum glabrous, or with short bristles or setae. Forebody not remarkably shining and metallic, as in the platalea group further below.

\section{Comments}

The four Papuasian species here included are reminiscent of the Australian group around $O$. dunningi Harold, 1869, comprising mycetophagous species (Matthews 1972, Bornemissza 1971), but the shape of the head and other characters proved too different to justify a merger, and consequently a separate operational group is here proposed. Apart from the four species mentioned below, the outlier $O$. phrixus Balthasar, 1969 (Bismarck Islands, cf. remarks under O. solomonensis below) and one or two other species are candidates for inclusion in the group, but the material available is just too scanty to judge the repercussions of polymorphism. The male of $O$. signifer 
Harold, 1877, hitherto reputedly unknown, is here illustrated, supporting its present group position. Balthasar (1969) implied a possible subgeneric relationship of $O$. eliptaminus with the species around $O$. pedisequus (the group treated hereafter, q.v.).

The type locality of $O$. eliptaminus is situated in Papua New Guinea (not Irian, as mentioned by Balthasar 1969, male paratype from NMPC pictured), but we have indeed seen material from upland West New Guinea, relatively close to the border with Papua New Guinea (Appendix 1).

\section{Included Papuasian species \\ O. eliptaminus Balthasar, 1969 - Papua New Guinea, West New Guinea \\ O. kokoiorus sp. n. - Papua New Guinea \\ O. signifer Harold, 1877 - Papua New Guinea \\ O. solomonensis sp. n. - Solomon Is}

\section{Key to species (males)}

1. Dorsum with elaborate symmetric colour pattern (dark with yellowish markings). Femora not yellow.................. 3

- Dorsum without elaborate colour pattern (largely or entirely unicolour brownish to black elytra, apices may be lighter). Mesoand metafemora largely yellow .......... 2

2. Pronotum strongly punctate. Elytra more or less asperate-setose ............ kokoiorus

- Pronotum very finely punctate. Elytral disc not asperate-setose, sides may be shortly setose ................... eliptaminus

3. Pronotum finely punctate. Elytral interstriae finely punctate and all flat or nearly so. Antediscal pronotal protrusion broad, (sub)bifid .................... signifer

- Pronotum densely, strongly punctate. Elytral interstriae 2 and 4 flat, finely punctate, 1, 3, 5 and laterals distinctly convex (costiform) and strongly, densely punctate. Pronotum with slender forward prong.... ........................

\section{Onthophagus kokoiorus sp. n.}

Figs 3-4, 59-63, 69, 202

\section{Material examined}

Holotype male (CMNC) from Papua New Guinea: Iora Creek, $17 \mathrm{~km} \mathrm{~S} \mathrm{Kokoda,} \mathrm{Kokoda} \mathrm{Trail,} 1400 \mathrm{~m}$, 3-6.viii.1976, O. Kukal, carrion, montane rainforest. Paratypes in Appendix 1.

\section{Identification}

Differing from the closely related $O$. eliptaminus by a stronger pronotal punctation (not sparse and fine), by its stronger, in the Kokoda Trail region almost completely asperate elytra (disc not smooth and shiny), and by microsculptural details on the ventral side. The long clypeal and pronotal prongs are characteristic of the males of both species. Both $O$. kokoiorus and eliptaminus have no long hair-pencils on their protibial apex. Elytral interstriae all equally, very slightly convex. Dorsal colour largely uniform black or (rufous) brown, at most with lighter markings limited to elytral tips; meso- and metafemora largely yellow. Female of $O$. kokoiorus with bidentate clypeal apex, lacking the conspicuous forebody projections, but elytra asperate, as in the male sex. Body length usually $8-10.5 \mathrm{~mm}$.

\section{Description (holotype, male)}

Body length ca $10 \mathrm{~mm}$. Habitus, irrespective of protrusions, generally high, convex. Colour generally uniformly light rufous brown, meso- and metacoxae and pygidium yellow, forebody shiny; most of elytra, pygidium, and abdominal venter matt (asperate, microreticulate). Pilosity whitish to pale yellow, abundant and distinct on elytra and pygidium, short, (sub)erect, bristle-like; apparently glabrous surfaces may have micro-stubbles in fine punctures.

Head light brown, shiny. Clypeal border very widely rounded, to long, upright, shining apicomedian projection, its tip dilated-emarginate; lateral margin of clypeus unmodified, surface abundantly, finely punctate; clypeogenal transition continuous at border, clypeogenal suture fine, curving onto frons. Clypeofrontal transition without any elevation, discal surface of clypeofrons virtually smooth, sparsely micropunctate only; head entirely glabrous. Genal border finely marginate, lateral tip subangular, rounded off. Frontovertex, posterior delimitation aside, without any elevation. Eye foramina narrow, ca 10 facet rows across widest point. Ratio interocular distance/maximum (transverse, single) eye width ca 8.5 .

Pronotum generally strongly convex (disc with very superficial midline impression), anterior declivity steep, smooth, concave (lateral view) beneath long, strongly complanate (relatively thin) anteromedian prong from disc, its tip (dorsal view) subbifurcate; anterior and lateral pronotal borders finely, distinctly marginate; anterior and posterior section of lateral border virtually straight in full-face view, widely rounded in dorsal view, anterolateral angle rounded; posterolateral angle rounded off to widely rounded, immarginate base. Most of pronotal surface with abundant to dense, fine, simple punctation, virtually absent on anterior declivity, beneath prong. 

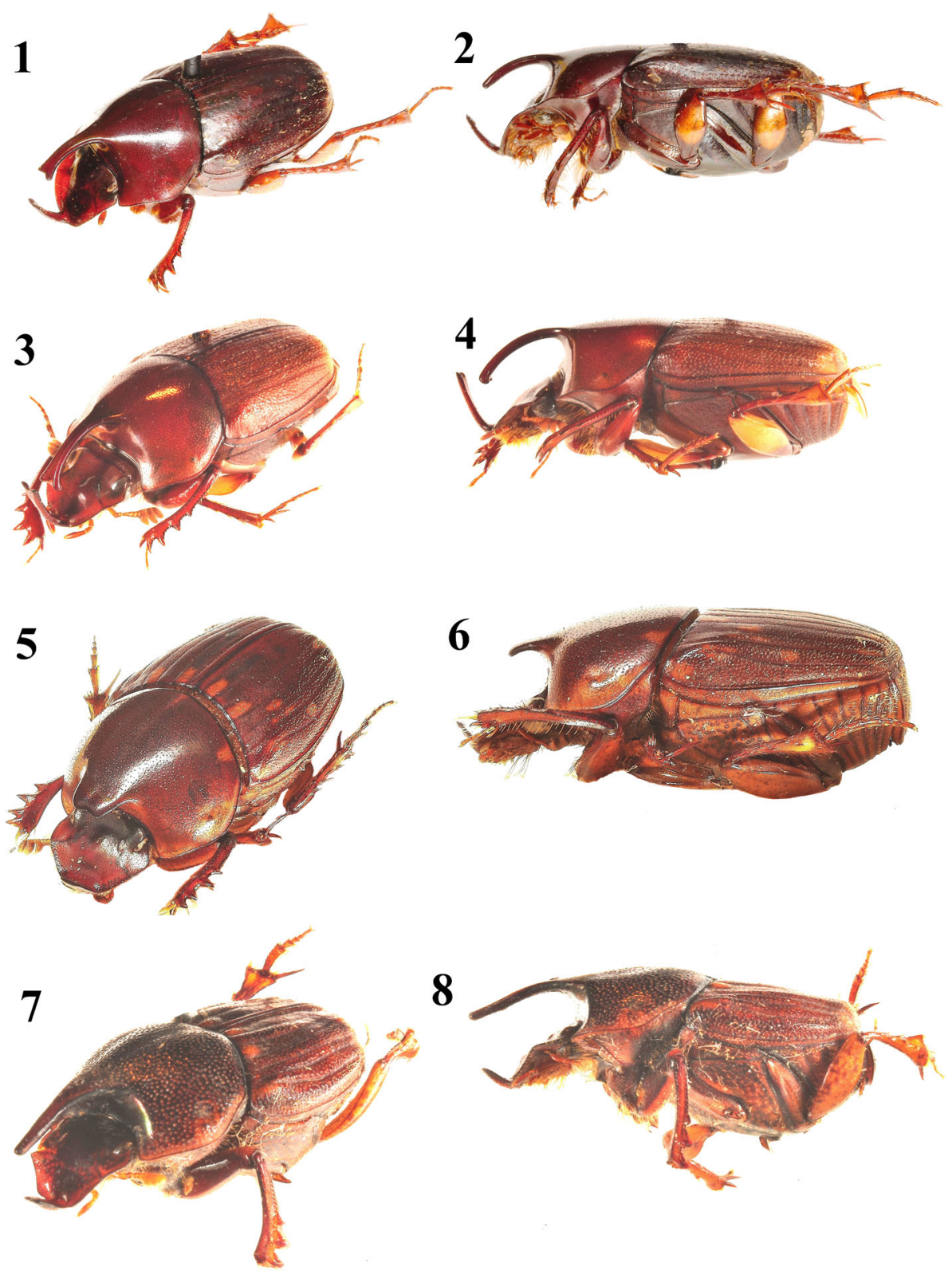

Figs 1-8. Habitus oblique and lateral views of Onthophagus (males), with approximate length. 1-2, O. eliptaminus, paratype $8 \mathrm{~mm}$, Eliptamin; 3-4, kokoiorus, holotype $10 \mathrm{~mm}$; 5-6, signifer, Finschhafen 7.5 mm; 7-8, solomonensis, holotype $7 \mathrm{~mm}$.

Colour of pronotum brown; disc and prong shining, sides with slight microreticulation.

Elytra broad, almost entirely asperate-punctate, matt (microreticulate), brown; base and apex of elytra unmodified, scutellum indistinct. Elytron with 8 distinct, straight to slightly curved, largely subparallel, narrow (micro-marginate) striae; stria 7 slightly sinuate in front, ending behind shining humeral umbone; strial punctures fine, widely separated (57 puncture diameters), slightly crenulating interstrial edges. Interstrial surfaces on disc virtually flat, all with numerous, evenly scattered, posteriorly directed, shiny asperities; bristles behind them (sub)erect, more or less curved, most of equal length 
(not exceeding length of asperities); broadest interstrial parts with up to ca 5 asperities over width between pairs of striae. Epipleuron matt, with effaced asperities.

Antennal club light-brown, scapus unmodified. Mentum shallowly emarginate in front. Propectoral sides light-brown, with simple coxal-marginal line; propectoral sides abundantly annulate-punctate. Anterior lobe of metasternum slightly transversely impressed behind setose mesosternum, with superficial midline impression caudad, most of metasternal disc brown, smooth, shiny, micropunctate, virtually glabrous; lateral metapectoral parts matt, distinctly, densely annulate-punctate. Abdominal ventrites brown, matt (strongly microreticulate), with fine, subasperate, bristle-bearing hemipunctures; sides and anal ventrite yellow-brown. Pygidium yellow, evenly, very slightly convex; surface matt, with numerous bristles in fine superficial hemipunctures; base with (widely arcuate) transverse ridge.

Protibia shining brown, distal half curved inward, with $3+1$ long external denticles (more or less separated by some fine serration); proximal serration extensive, consisting of ca 11 small denticles; 4 larger denticles at most slightly oblique to tibial axis, apex slightly produced, with short spiniform terminal spur, lacking longer pencil of fine setae; protibial underside with low longitidinal crest; protarsus slender, unmodified. Profemur brown, robust; shining underside finely punctate, almost glabrous. Meso- and metafemora with largely shining yellow underside (base brown), punctate, glabrous. Mesoand mesotibiae shining yellow-brown, slender, dilated distad to transverse sinuate-subelliptic crest, which is fringed with short fossorial spines below and longer setae and spines above; external side with very slight, spine-bearing fossorial protrusions. Tarsi slender, with fine sickle-shaped claws; meso- and metatarsomeres 1 robust, straight, unmodified. Terminal spurs on meso- and metatibiae long, tapering, tip slightly curved. Approximate length proportions metatibial terminal spur//metatarsomeres $1-5$ : 14//18/7/4/3/6.

Parameres plump, recurved-humped (lateral view), with pointed downward distal tip, Fig. 202.

Measurements in mm (dorsal view). Maximum width of head 2.8. Median length of pronotum 3.1, maximum width 4.6. Sutural length of elytra 4.0, maximum width combined 4.8 .

\section{Variation and sexual dimorphism}

Female lacks clypeal and pronotal projections, clypeal apex distinctly bidentate. Protibia of female less curved, with long, acuminate terminal spur. Colour varies, dorsum (rufous) brown in holotype, black with orange elytral apex in other specimens.
Asperate cover of elytral disc varies, being, for instance, much less close in the Mt Hagen specimens. Pronounced pronotal punctation apparently constant. Body size varies between 8 and $10.5 \mathrm{~mm}$.

\section{Distribution}

Papua New Guinea: SE region: Kokoda Trail; Western Highlands.

\section{Etymology}

Name is a contraction of the components of the name of the type locality of this species; to be treated as masculine noun.

\section{Onthophagus solomonensis sp. $\mathbf{n}$.}

Figs 7-8, 64-68, 203

\section{Material examined}

Holotype male only (partly damaged, BMNH): British Solomons, 193 [possibly incomplete year], R.J.A.W. Lever.

\section{Identification}

Differing from the other group members by the combination of its colouration (yellowish versus brownblack pattern), heavy punctation, variety in elytral interstrial convexity, etc. Lobe on clypeal apex long, tip truncate. Pronotum and elytra of $O$. solomonensis densely, strongly punctate. Elytra relatively short, several interstriae remarkably convex, strongly punctate (interstriae 1, 3, 5, laterals). Much of pectus yellow with darker marbled pattern. Long pronotal spike simply tapering, slender (not a broader, subbifid plate). Lateral border of head (full-face view) not evenly rounded from angular genal tip to clypeal apex. Protibial characters uncertain, due to damage. Parameres not humped-recurved, their tips unmodified. Medium-sized, body length ca $7 \mathrm{~mm}$.

\section{Description (holotype, male)}

Body length ca $7 \mathrm{~mm}$. Habitus, irrespective of protrusions, generally high, convex. Colour patterned, generally brown to black with lighter (yellowish) elements; much of underside yellow with marbled pattern of black; pygidium dark-brown and yellowish; head shiny, many other parts matt due to microsculpture, including strong punctation. Pilosity pale yellow, mostly short, (sub)erect, bristle-like, on some parts abundant, locally longer; apparently glabrous surfaces may have micro-stubbles.

Head with yellow-brown margins, disc strongly infuscated, shiny throughout (posterior part microreticulate). Clypeal border rounded in front, shallowly concave to clypeogenal suture; clypeal apex 
with long, upright, shining plate, top angles shortly rounded on either side; most of clypeofrontal and genal surface abundantly micropunctate, sparse and almost indistinct between eyes; clypeogenal transition almost continuous at border, clypeogenal suture fine. Clypeofrontal transition without any elevation; head entirely glabrous. Genal border finely marginate, lateral tip rounded. Frontovertex, posterior delimitation aside, without any elevation. Eye foramina small, narrow, ca 8 facet rows across widest point. Ratio interocular distance/maximum (transverse, single) eye width ca 15 .

Pronotum generally strongly convex (disc with obsolescent midline impression), anterior declivity steep, smooth, concave (lateral view) beneath long, strongly complanate (relatively thin), slender, tapering anteromedian spike from disc forward (its tip not dilated); anterior and lateral borders very finely marginate; anterior and posterior section of lateral border virtually straight in full-face views, widely rounded in dorsal view, anterolateral angle rounded; posterolateral angle rounded off to widely rounded, immarginate base. Most of pronotal surface with dense to crowded punctation, virtually absent on anterior declivity, beneath prong; punctures filled with appressed matter and short erect bristle (mostly not longer than puncture diameter). Colour of pronotum brown-black, generally matt, but shining between punctures; sides with some yellow.

Elytra broad, brown, with yellow markings; base and apex of elytra unmodified, scutellum indistinct. Elytron with 8 distinct, straight to slightly curved, narrow (micro-marginate) striae; stria 7 in front ending near shining, yellowish humeral umbone; strial punctures mostly 2-4 puncture diameters apart, slightly crenulating interstrial edges. Surface of interstriae 2 and 4 on disc virtually flat, matt (microreticulate), punctuation looking slightly effaced; other interstriae more or less convex, more shiny, all with dense to crowded, evenly scattered, distinct bristlebearing punctures (length of discal bristles mostly 12 puncture diameters, longer on lateral and distal declivities); base of interstriae 2 and 4 distinctly yellow, slightly convex, shiny; apex of elytra also with (moderately delimited) yellow markings; interstriae 6-8 more or less yellow-brown. Epipleuron matt, somewhat rugulate, yellow-brown.

Antennal club yellow, scapus unmodified. Mentum shallowly emarginate in front. Propectoral sides yellow in front, black-brown behind, with simple coxal-marginal line; surface with numerous seta-bearing punctures. Anterior lobe of metasternum slightly transversely impressed behind setose mesosternum, with shallow midline impression caudad, metasternal disc broadly impressed; lateral metapectoral parts matt, distinctly, densely annulate- punctate. Most of pectus matt (microreticulate), yellow with marbled blackish pattern, with numerous fine (locally asperate) seta-bearing (hemi)punctures. Abdominal ventrites blackish brown, matt (microreticulate), each with transverse row of fine, subasperate, bristle-bearing hemipunctures; abdominal sides lighter brown. Pygidium yellow to blackbrown, hardly convex; surface matt, crowded with large seta-bearing punctures; base with transverse ridge.

Protibia shining brown, slender, curved, presumably (tip broken off) with $3+1$ long external denticles (more or less separated by some fine serration); proximal serration extensive, consisting of ca 8 small denticles; protibial underside with low longitudinal crest; protarsi and spurs missing. Profemoral underside yellow with some brown, shiny, punctatesetose. Meso- and metafemora with largely shining yellow underside, speckled with brown, punctatesetose. Meso- and mesotibiae shining yellow, with some infuscation, slender, dilated distad to transversely subelliptic crest, which is fringed with short fossorial spines below and some longer setae and spines above; mesotibia slightly curved; external side of meso- and metatibiae with 3 slight, spine-bearing fossorial protrusions. Tarsi slender, with fine sickleshaped claws; meso- and metatarsomeres 1 long, almost straight, unmodified. Terminal spurs on mesoand metatibiae long, tapering, tip slightly curved. Approximate length proportions metatibial terminal spur//metatarsomeres 1-5: 12//15/6/4/3/6.

Parameres relatively slender, with tapering, slightly dilated tip, Fig. 203.

Measurements in $\mathrm{mm}$ (dorsal view). Maximum width of head 2.2. Median length of pronotum 2.9, maximum width 4.0. Sutural length of elytra 2.9, maximum width combined 4.1.

\section{Variation and sexual dimorphism}

Only male holotype known.

\section{Distribution}

Solomon Islands.

\section{Comments}

In spite of being based on a single damaged male, $O$. solomonensis is unusual enough to be easily recognizable from the information given here.

The colouration and pronotal shape of $O$. phrixus Balthasar, 1969 from New Britain are somewhat reminiscent of solomonensis, but that species is smaller (4.5-5.5 $\mathrm{mm}$ given in original description, male paratype seen in NMPC) and the other features mentioned above are quite different; the lack 
of a longer lobe on the clypeal apex would exclude phrixus from the eliptaminus group as here conceived.

\section{Etymology}

Named after the type region, in its English spelling. This is the only indigenous Onthophagus species from the Solomon Islands known to us.

\section{The Onthophagus pedisequus group}

\section{Group characters}

Including remarkably deplanate-elongate species, with more or less modified male protibiae, and very slender meso- and metatibiae; clypeal apex with reflexed median lobe; genae with distinctly angular tip. Head without non-marginal elevations, lateral border evenly rounded from clypeal apex to genal tip. Eye foramina narrowly elliptic. Lateral borders of pronotum (in dorsal view) evenly rounded, disc lacking protrusions. Legs long, slender; protibia elongate, distally curved inward, external denticles more or less perpendicular to tibial axis (or even "retro-dentate"). Pygidial base ridged. Colour pattern (lighter markings), if present at all, very limited. Dorsum punctate, any setae short, bristle-like. Medium-sized, body length usually 7-9 $\mathrm{mm}$.

\section{Comments}

Balthasar (1969) described two members in this group (types of both species from NMPC pictured here) - note their evenly, slightly convex pronotum, lacking protrusions. A congener with male protibiae similar to those of $O$. parapedisequus, but with an anteromedian pronotal protrusion, $O$. telegonus Balthasar, 1969, is here excluded. For all these species Balthasar (l.c.) suggested a relationship with the species united in the eliptaminus group (q.v.), and indeed telegonus may be considered intermediate.

\section{Included Papuasian species}

O. mokwamensis sp. n. - West New Guinea

O. parapedisequus Balthasar, 1969 - Papua New Guinea

O. pedisequus Balthasar, 1969 - Papua New Guinea, West New Guinea

\section{Key to species (males)}

1. External denticles on protibia with apex shifted proximad (retro-dentate), protibial apex expanded, terminal spur spiniform, reduced. Clypeal apex with upright lobe, tip slightly emarginate (bisinuate-bidentate) .....2

- Apico-external denticle perpendicular to protibial axis, but apex not shifted backward, terminal spur elongate-acuminate, curved. Clypeal apex with narrow upright lobe, tip rounded. Dorsum shining....... $\ldots \ldots \ldots \ldots \ldots \ldots$ parapedisequus

2. Dorsum generally matt, clypeus and pronotum very closely, evenly, distinctly punctate throughout, elytra largely microreticulate ......................mokwamensis

- Dorsum generally shiny, abundantly to densely punctate............... pedisequus

\section{Onthophagus mokwamensis sp. $\mathrm{n}$.}

Figs 9-10, 72-76, 204

\section{Material examined}

Holotype male only (RMNH), from West New Guinea: [Arfak Range:] Mokwam Birdahead [Bird's Head], 27.vii. 2007, [G.] Withaar.

\section{Identification}

The very close forebody punctation and matt appearance of the elytra distinguish this species from the two other group members. Clypeal apex with upright, slightly tapering, shortly bidentate lobe, as in $O$. pedisequus (note that lobe may be longer in unknown major males). Elytral interstriae finely asperate-punctate on largely microreticulate background; numerous punctures on sides and apical declivity with recurved bristles. Protibia long, distally curved inward, with retro-dentate external edge and spiniform terminal spur. Head and pronotal surface, clypeal apex aside, without pronounced protrusions. Female unknown. Small, body length ca $7 \mathrm{~mm}$.

\section{Description (holotype, male)}

Body length ca $7 \mathrm{~mm}$. Habitus generally deplanateelongate, slender. Colour generally uniformly black, matt, due to punctation and microreticulation. Pilosity generally whitish to pale yellow, very short, bristle-like; apparently glabrous surfaces locally have micro-stubbles in fine punctures. Punctation on some parts very dense, punctures usually matt, mostly isodiametric, on forebody many punctures subocellate.

Head black, generally matt, shiny between punctures; entire head surface densely to crowdedly punctate. Clypeal border very widely rounded from subrectangular genal tip to upright apicomedian lobe, its tip finely bidentate-emarginate; lateral border of clypeus immarginate; clypeogenal transition continuous, clypeogenal suture indistinct; border from genal tip to occipital side concave. Clypeofrontal surface without any elevation, central part very slightly convex; head surface virtually glabrous. Vertex, posterior delimitation aside, without any elevation. Eye foramina narrow, ca 9 facet rows across widest 


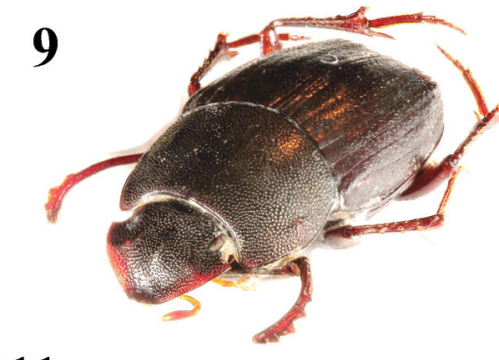

11
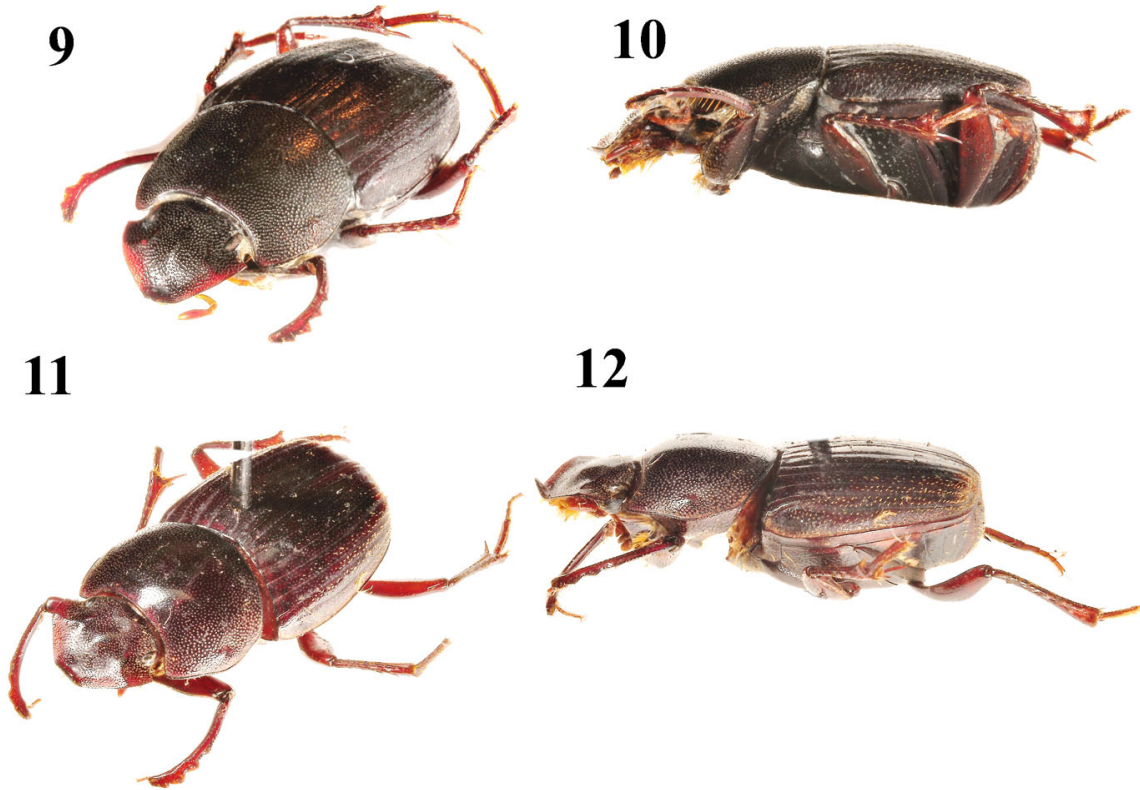

12
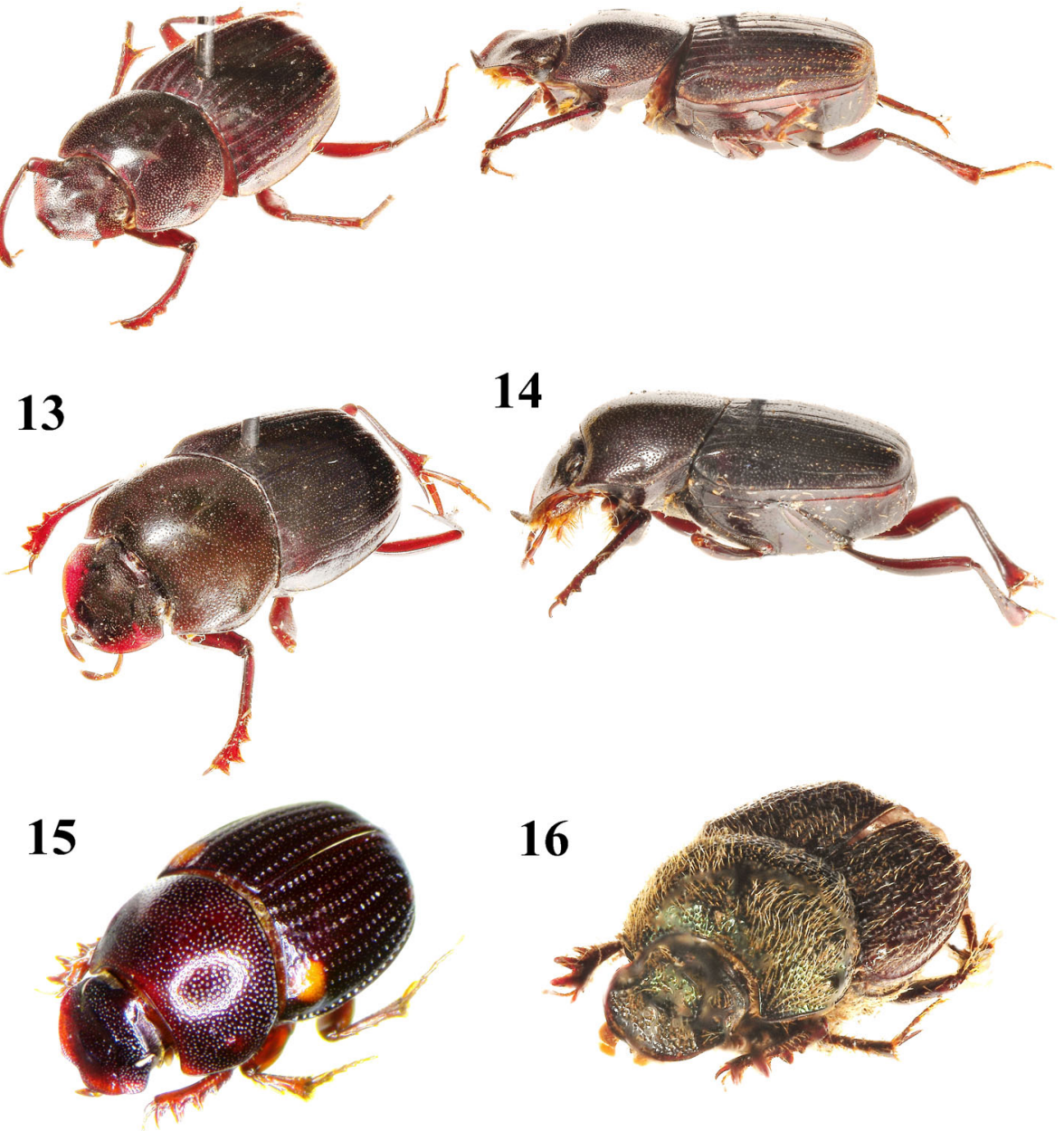

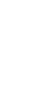
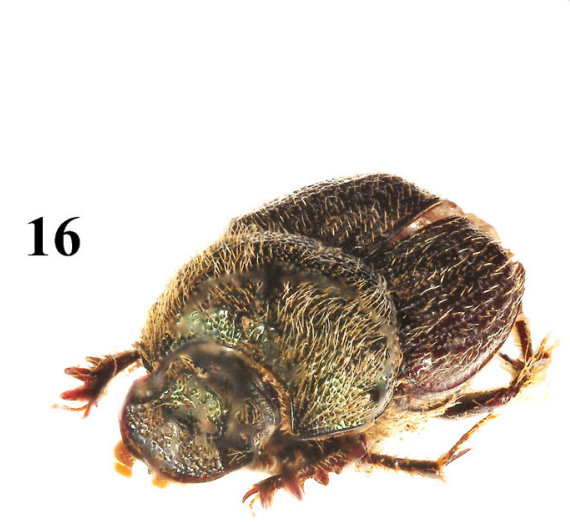

Figs 9-16. Habitus oblique and lateral views of Onthophagus (males), with approximate length. 9-10, O. mokwamensis, holotype $7 \mathrm{~mm}$; 11-12, pedisequus, paratype $9 \mathrm{~mm}$; 13-14, parapedisequus, paratype $9 \mathrm{~mm}$; 15 , tarasovi, paratype $4 \mathrm{~mm}$; 16, papurugosus, holotype $5.5 \mathrm{~mm}$.

point. Ratio interocular distance/maximum (transverse, single) eye width ca 9.

Pronotum evenly, moderately convex (disc without midline impression), anterior declivity gradual, slight; anterior and lateral borders finely, distinctly marginate; anterior section of lateral border virtually straight in full-face view, widely rounded in dorsal view, anterolateral angle rounded; posterior sec- 
tion of lateral border widely rounded, posterolateral angle fully rounded off to widely rounded, immarginate (but serially punctate) base. Entire pronotal surface with dense to crowded subocellate punctation, denser and punctures larger on lateral declivity, virtually glabrous. Colour of pronotum entirely black, generally matt, but shiny between punctation.

Elytra elongate, black, almost entirely matt (microreticulate), disc slightly shiny; apex brownish; base shallowly concave in dorsal view, apex of elytra unmodified, scutellum indistinct. Elytron with 8 distinct, straight to slightly curved striae, largely subparallel, narrow; stria 7 slightly ending at humeral umbone; strial punctures fine, widely separated (mostly 5-10 puncture diameters), slightly crenulating interstrial edges. Interstrial surfaces on disc virtually flat, all with abundant, very fine, scattered, asperate punctation, many punctures with micro-stubble, lateral and apical declivities with longer, mostly recurved bristles. Epipleuron matt (microreticulate), flat, glabrous.

Antennal club dark-brown, scapus slender, unmodified. Mentum shallowly emarginate in front. Propectoral sides black, microreticulate, with simple coxal-marginal line; anterior surface impunctate, slightly concave; proepisternal surface crowdedly punctate. Mesosternum finely punctate(-setose). Anterior lobe of metasternum hardly convex behind mesosternum, with superficial midline impression caudad, over deplanate disc; metasternal surface black, flanks matt (microreticulate), vaguely shiny on anterior lobe and disc, most of surface densely to crowdedly punctate, with micro-stubbles. Abdominal ventrites black (sides and anal margin yellowbrown), matt (strongly microreticulate), with fine, superficial, (partly) bristle-bearing punctures. Pygidium brown, evenly, distinctly convex; surface matt, with numerous short bristles in very fine superficial punctures; base with transverse ridge.

Protibia shining brown, slender, proximally straight, distally curved inward, with $3+1$ short external denticles (some separated by minute serration); proximal serration minute, consisting of ca 10 small denticles; the 4 larger denticles with angular tip shifted proximad, (perpendicular) length shorter than width at base; apex produced, rounded, with very short spiniform terminal spur among very short bristles; protibial underside with low longitudinal crest; protarsus inserted away from apex, at level of angular tip of apico-external denticle. Profemur brown-black, slender, with shining underside, densely punctate (punctures multi-sized), many punctures with very short bristle. Meso- and metafemora like profemur, more slender, punctation less dense. Meso- and mesotibiae shining brown, straight, very slender, dilated on apex to transverse (in axial view narrow, bent) subelliptic crest, which is fringed with short fossorial spines; external side with 4-5 very slight, spine-bearing fossorial protrusions. Tarsi slender, with fine sickle-shaped claws; mesoand metatarsomeres 1 slender, straight, longer than $2-5$ combined. Terminal spurs on meso- and metatibiae elongate-acuminate. Approximate length proportions metatibial terminal spur $/ /$ metatarsomeres 1-5: $11 / / 16 / 4 / 3 / 3 / 4$

Parameres plump, with downward distal tip, Fig. 204.

Measurements in $\mathrm{mm}$ (dorsal view). Maximum width of head 2.4. Median length of pronotum 2.3, maximum width 3.6. Sutural length of elytra 3.5, maximum width combined 4.0 .

\section{Variation and sexual dimorphism \\ Only male holotype known.}

\section{Distribution \\ West New Guinea: Doberai Peninsula.}

\section{Etymology}

Named after the type locality, in the Arfak Mountains, on the Doberai Peninsula (= Vogelkop) in West New Guinea.

\section{The Onthophagus quadripustulatus group}

\section{Group characters}

These are all small species, those known from New Guinea having distinctly coloured elytra - entirely yellow to rufous brown, or symmetrically patterned with distinct black and yellow or (rufous) brown markings. Head usually with pair of more or less connected, slight, blunt vertexal protrusions (forming a low transverse saddle) or a simple transverse ridge; pronotum convex, unmodified, and clypeal apex simply bisinuate to slightly bidentate. Habitus elongate, not deplanate-oval. Head without pronounced marginal protrusions. Eyes very small, narrow. Anterior section of lateral pronotal border evenly rounded in dorsal view. Pygidial base with transverse ridge. Male protibia may be elongate, slender, curved inward distally, and apex may be penicillate - not so in the new species described hereafter. Dorsum glabrous or with very short setae. Body length up to $6 \mathrm{~mm}$. Group established by Matthews (1972).

\section{Comments}

This is considered a taxonomically difficult, heterogeneous group, with representatives in Australia, New Guinea, and the Moluccas (Storey \& Weir 1990, Huijbregts \& Krikken 2012). Undescribed 
species were mentioned, but nobody tackled the group as a whole and described them. Matthews (1972) already implied the questionable synonymy and diversity around $O$. quadripustulatus Fabricius, 1775 (he saw the types of Fabricius). We also noticed some heterogeneity among the males with modified protibiae at hand, but describe only one new New Guinea outsider with peculiarly punctate elytral striae - if characters like the shape of the protibiae are considered decisive in grouping these species, it might not belong near quadripustulatus and its relatives after all. The key just serves to distinguish the new species from some similar taxa in New Guinea.

\section{Included Papuasian species}

O. tarasovi sp. n. - Papua New Guinea

O. quadripustulatus Fabricius, 1775 - Papua New Guinea, Australia, Moluccas

O. flavomaculatus Gillet, 1930 - Papua New Guinea

\section{Key to species (males)}

1. Discal striae of elytra with distinct geminate punctation. Elytron with limited yelloworange patches only (including larger one on base of interstriae 6-8, humeral area), most of surface black-brown, shining. Protibia unmodified. Dorsum without long setae

- Elytral striae all with simple punctation. Elytron with different colouration, unicolour black-brown, or with more extensive yellow or rufous pattern ..............

2. Protibia broad, apex unmodified ......... ......................flavomaculatus

- Protibia slender, curved, with apex penicillate and retro-dentate................ ............... quadripustulatus complex

\section{Onthophagus tarasovi sp. $\mathrm{n}$.}

Figs 15, 77-81, 205

\section{Material examined}

Holotype male (CMNC) from Papua New Guinea: Brown River, $30 \mathrm{mi}$ N Port Moresby, 15-16.vii. 1974, S. Peck. Paratypes in Appendix 1.

\section{Identification}

The strial punctation of the elytra is the primary feature in this species, the discal punctation consisting of distinct contiguous pairs, on either side of the stria strongly crenulating the adjacent interstriae. Pronotum covered with closely set subocellate punctation. Elytra with limited symmetric colour pattern, largely shining black, with well defined yellow-orange humeral patch. Dorsum lacking long setae. Male protibia unmodified, broad, apicoexternal denticle oblique to tibial axis, apex without hair-tuft and without particular protrusions; mesoand metatibiae strongly dilated distad. Head of male with both transverse clypeofrontal and interocular elevation (frons not bituberculate). Eye foramina remarkably narrow. Small, body relatively compact, length $3.5-4.5 \mathrm{~mm}$.

\section{Description (holotype, male)}

Body relatively compact, length ca $4 \mathrm{~mm}$. Habitus convex. Colour largely brown-black, shining between numerous punctures, elytra with some (symmetric) yellow to brown markings; underside largely black-brown, legs lighter brown. Dorsum quasiglabrous, punctures with micro-stubbles; underside with numerous pale yellow setae; punctation generally fine, distinct, size and density varying according to body part.

Head black-brown. Clypeal border widely, evenly rounded to narrowly reflexed, broadly bisinuate apex; clypeofrontal surface evenly, densely, distinctly punctate throughout (finer on clypeus, larger and subocellate on frons, and more crowded); clypeogenal transition slightly indented at border; clypeogenal suture vague; clypeofrontal transition with arcuate ridge. Genal border evenly rounded in front, straight to occipital attachment. Frontal elevation (between anterior part of eyes) transverse, length about half interocular distance, on either end less raised than medially. Eye foramina very narrow, with ca 6 facet rows across widest point. Ratio interocular distance/maximum (transverse, single) eye width ca 18.

Pronotum black, shiny; surface moderately, evenly convex (lacking midline impression); anterior declivity gradual, unmodified; surface densely, evenly (subocellate-)punctate throughout, intervening micropunctation hardly distinct, sparse; anterior and lateral borders finely marginate; anterior section of lateral border straight (full-face view), anterolateral angle shortly rounded, rectangular; posterior section of lateral border also straight (full-face view), posterolateral angle rounded off; pronotal sides and basal border widely rounded in dorsal view.

Elytra shining black, yellow-brown patch on base of interstriae 6-8 (humeral umbone), small patch on apical umbone, and narrow yellow-brown apical margin; scutellum indistinct, shape of base and apex unmodified; epipleuron finely rugulatepunctate, brown-black. Elytra broad, with 8 straight to slightly curved, fine striae; stria 7 very slightly curved in front, ending at humeral umbone; strial punctures very distinct, geminate on disc, mostly separated by ca 4 puncture diameters, strongly crenulating interstriae; punctures in stria 8 (along epipleural ridge) simply isodiametric, large, filled with 
whitish matter. Interstrial surfaces slightly convex, with sparse micropunctation.

Antennal club grey-brown, scapus unmodified. Mentum shallowly emarginate in front. Postocular area of propectus slightly concave, posteriorly delimited by simple coxal-marginal ridge; propectoral sides abundantly punctate-setose. Metasternum shiny, anterior lobe very slightly prow-shaped in front; metasternal lobe and disc with slight midline impression, abundantly, finely punctate; metasternal flanks with numerous larger (subocellate) punctures. Abdominal ventrites moderately shiny, each with more or less distinct row of fine, mostly seta-bearing punctures. Pygidium shiny black, apex lighter brown; base ridged; surface evenly, slightly convex, crowded with (subocellate) punctation.

Legs short, generally shiny medium-brown. Protibia robust, with $3+1$ larger external denticles (distal 3 larger, acuminate), hardly separated by serration; proximal serration consisting of ca 4 minor denticles; apico-external denticle long, oblique to tibial axis; apico-internal angle unmodified (no hairbrush), terminal spur small, elongate-acuminate, slightly curved; protibial underside with low longitudinal crest; protarsus slender. Profemur robust, underside shiny, abundantly punctate-setose. Mesoand metafemoral undersides shiny, with numerous fine punctures, mainly with short setae. Meso- and metatibiae relatively robust, strongly dilated distad to transversely subelliptic crest, which is fringed with short fossorial spines below, and some long spines above; externally with ca 3 slight, spinebearing fossorial protrusions. Meso- and metatarsi generally very slender, with very fine claws; mesoand metatarsomeres 1 long, straight, unmodified, shorter than 2-5 combined. Terminal spurs on mesoand metatibiae elongate-acuminate. Approximate length proportions terminal spur//metatarsomeres 1-5: 9//9/5/3/2/5.

Parameres with tips slightly convergent (fullface view), broad, tapering-curved downward (lateral view), Fig. 205.

Measurements in mm (dorsal view). Maximum width of head 1.35. Median length of pronotum 1.35 , maximum width 2.10 . Sutural length of elytra 2.15 , maximum width combined 2.35 .

\section{Variation and sexual dimorphism}

A small series is known, with little variation. Female very similar to male. Slight differences in size, body length usually around $4 \mathrm{~mm}$.

\section{Distribution}

Papua New Guinea: SE region.

\section{Etymology}

Dedicated to our ever helpful colleague, Onthophagus specialist Sergey Tarasov, currently at the Natural History Museum (Oslo, Norway).

\section{The Onthophagus tauroides group}

\section{Group characters}

Major males in this group have a pair of long, slender, curved horns between the posterior end of their eyes, in the way of the West Palaearctic O. taurus Schreber, 1759 (actually, a species introduced to Australia and other regions). Contrary to O. taurus the horns of the known group members are quite robust, usually more broadly complanate; in major males they are directed laterad (behind and beyond the eyes), evenly arcuate upward, tapering, not distinctly interconnected at base (no connecting transverse elevation, horns without accessory lobes or denticles on inner edge). Eye foramina broadly elliptic. Any protrusions on female vertex very slight. Male clypeofrontal ridge usually more or less effaced (distinct in O. opacotaurus sp. n.); clypeogenal ridge distinct, slightly protruding at border, clypeal border extending straight or weakly curved (convex) to reflexed, bisinuatetruncate clypeal apex; genal border widely rounded. Pronotum usually depressed behind horns, anteromedian surface distinctly declivous, slightly protruding, usually convex (gibbous, topped or not by vague, blunt transverse ridge; lacking plica, never distinctly bifid); anterolateral angles of pronotum distinct, adjacent anterior section of lateral border slightly concave or sinuate. Pronotal surface smooth or punctate, neither granulate, nor (punctate-)rugulate. Pygidium slightly convex, base with transverse ridge. Dorsum brown to black, at most with very slight metallic lustre, usually glabrous (lacking long setae). Females usually with pair of low vertexal protrusions or mere transverse ridge. Body length usually 10-14 mm.

\section{Comments}

A closely related group with similar horns, but having them distinctly interconnected at base, is clustered around Onthophagus catenatus Lansberge, 1883 , and will be dealt with in a forthcoming paper (Krikken \& Huijbregts in prep.). Do not rely on alternatives 83/104 in Balthasar's key (1969), as $O$. costifer Gillet, 1930 is undoubtedly a close relative of tauroides and two new species proposed below - the type of costifer is here re-described. Note the subtle effect of the course of the coxal-marginal ridge (on the lateral surface of the propectus) on the outline of the anterolateral part of the pronotum, significant in distinguishing the species (couplet 3 in the key below). 


\section{Included Papuasian species}

O. tauroides Gillet, 1930 - Papua New Guinea

O. opacotaurus sp. n. - Papua New Guinea

O. costifer Gillet, 1930 - West New Guinea, Papua New Guinea

O. pseudocostifer sp. n. - Papua New Guinea

\section{Key to species (males)}

1. Pronotal sides (dorsal view) rounded between anterior and posterior section of lateral border. Forebody more or less shining, else pronotum distinctly, abundantly to densely punctate. Clypeofrontal ridge more or less effaced ...................... 2

- Pronotal sides (dorsal view) distinctly angular between anterior and posterior section of lateral border. Forebody and elytra distinctly matt, any primary punctation sparser and weaker, on pronotum limited to lateral declivities. Clypeofrontal ridge fine but distinct................ opacotaurus

2. Pronotal disc and lateral declivities distinctly, evenly punctate, punctation usually dense ........................... 3

- Dorsum, including pronotum, largely shiny, at most sparsely micropunctate. Anterolateral angle of pronotum acute...tauroides

3. Elytral interstriae almost smooth, at most with inconspicuous micropunctation, striae deep, with sharp edge on either side. Anterolateral edge of pronotum slightly sinuate (Fig. 95), coxal-marginal ridge on underside joining and expanding edge to (sub)obtuse anterolateral angle ........ costifer

- Elytral interstriae with fine but very distinct punctation, discal striae fine. Anterolateral edge of pronotum slightly concave (Fig. 96), coxal-marginal ridge on underside simply joining edge to more acute anterolateral angle ................ pseudocostifer

\section{Onthophagus tauroides Gillet, 1930}

Figs 17-18, 82-88, 206

\section{Material examined}

All listed in Appendix 1.

\section{Identification}

Never generally matt, pronotum largely shining, with indistinct micropunctation only. Anterolateral angle of pronotum (full-face view) acute, lateral border behind angle slightly concave; transition from anterior to posterior section of lateral pronotal border rounded (not angular). Elytral striae distinct, nar- row; interstriae shiny, and indistinctly, sparsely micropunctate. Clypeofrontal ridge of male obsolescent. Parameres slender compared to relatives, more gradually curved downward (lateral view), tapering tips divergent (full-face view). General colour usually dark brown to black, occasionally lighter and slightly bronzy. Body length usually $9.5-12.5 \mathrm{~mm}$.

\section{Distribution}

Papua New Guinea: N region; SE region: Kokoda Trail.

\section{Onthophagus opacotaurus sp. $\mathbf{n}$.}

Figs 19-20, 89-94, 207

\section{Material examined}

Holotype male (CMNC) from Papua New Guinea: Iora Creek, $23 \mathrm{~km}$ S Kokoda, Kokoda Trail, $1900 \mathrm{~m}$, Templeton Cross, 6-8.viii.1976, O. Kukal, dung trap, upper montane rainforest. Paratype in Appendix 1.

\section{Identification}

The generally matt dorsal surface, the distinct clypeofrontal ridge, and the angular transition separating the anterior and posterior section of the lateral border of the pronotum, should sufficiently distinguish $O$. opacotaurus males from the three other species listed here. Pronotal disc micropunctate only, primary punctation distinct and dense mainly on lateral declivities. Anterolateral angle of pronotum (full-face view) rectangular. Elytral striae fine, interstriae at most sparsely micropunctate. Female with pair of slight conical vertexal protrusions. General colour probably usually dark brown. Body length ca $12 \mathrm{~mm}$.

\section{Description (holotype, male)}

Body length ca $12 \mathrm{~mm}$. Habitus convex, robust. Colour of dorsal side dark brown, ventral parts medium brown, largely matt (microreticulate), legs and certain other parts shiny. Dorsal side and pygidium virtually glabrous (apart from any inconspicuous micro-stubbles); ventral side and legs with numerous long, pale brown setae. Most dorsal parts lacking more distinct punctation, having inconspicuous, sparse, evenly scattered micropunctation only.

Clypeal border marginate, sides evenly, very widely rounded to sinuate-truncate, reflexed, shortly lobiform apex; clypeal surface somewhat shiny, superficially rugulate-punctate; clypeogenal transition at border continuous, suture finely ridged to widely arcuate, distinct clypeofrontal ridge. Genal surface superficially rugulate-punctate as on clypeus, genal border evenly, widely rounded. Frons between poste- 

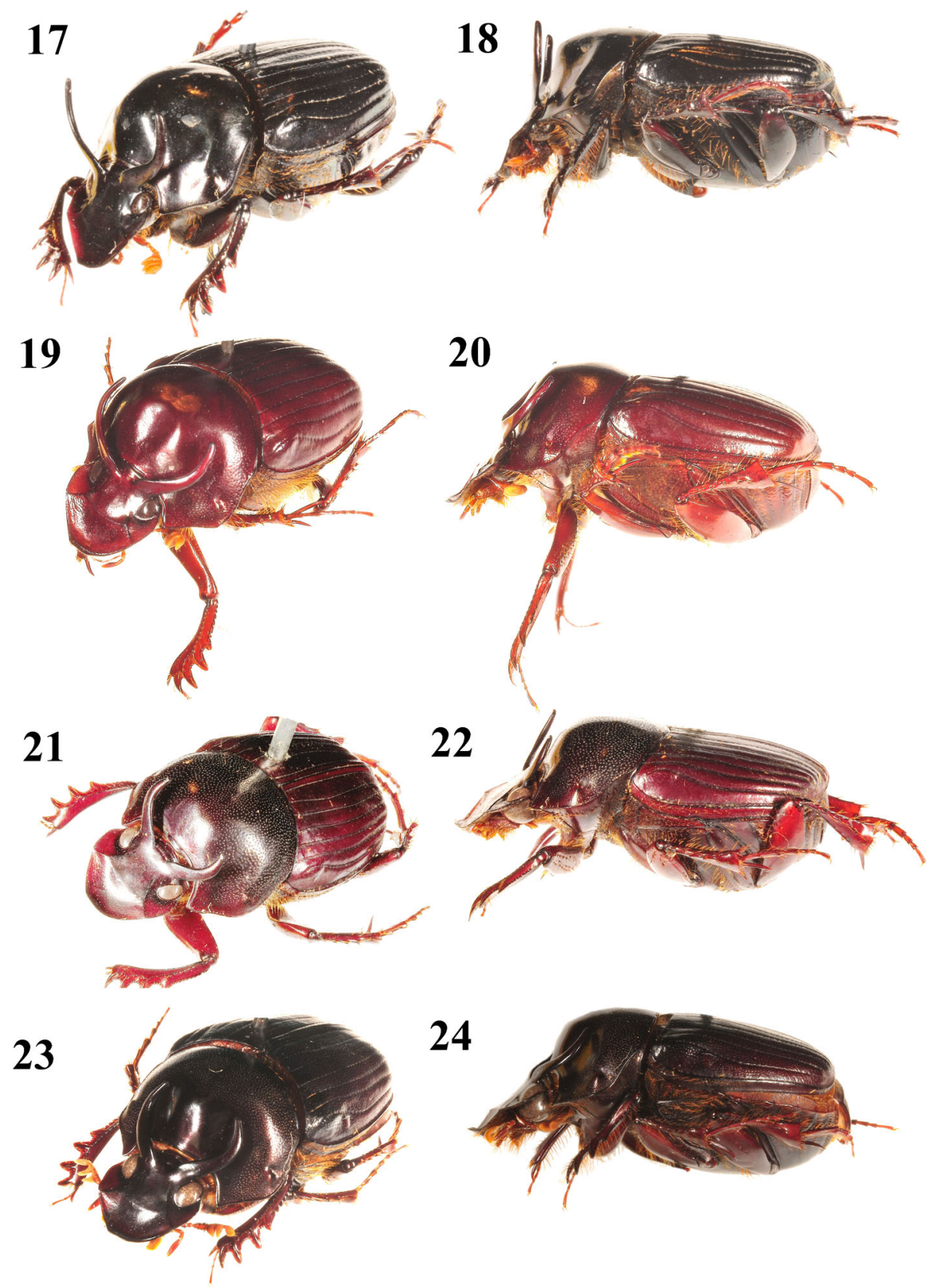

Figs 17-24. Habitus oblique and lateral views of Onthophagus (males), with approximate length. 17-18, O. tauroides, E Pt Moresby $12 \mathrm{~mm}$; 19-20, opacotaurus, holotype $12 \mathrm{~mm}$; 21-22, costifer, lectotype $12 \mathrm{~mm}$; 23-24, pseudocostifer, holotype $13.5 \mathrm{~mm}$.

rior end of eyes with pair of long, transversely complanate, basally broad horns, strongly directed laterad (behind eyes), evenly curving upward to tapering tip; interocular surface matt, micropunctate. Eye foramina large, broadly elliptic, with ca 23 facet rows across widest point. Ratio interocular distance/maximum (transverse, single) eye width ca 3.7 .

Pronotum generally strongly convex, disc deplanate (lacking midline impression); anteromedian surface abruptly declivous from antediscal blunt rim, 
medially slightly depressed; sides, behind horns of head, shallowly impressed, concavity sloping down to anterolateral corner; anterior and lateral borders of pronotum marginate; anterior 0.4 of lateral border, from obtuse angle to anterolateral angle, very slightly dilated by coxal-marginal ridge; anterolateral angle distinct, rectangular; posterior section of lateral border distinctly sinuate, posterolateral angle distinct, rounded off to base; base finely marginate only along obtuse median angle. Medial parts of pronotal surface matt, micropunctate, lateral declivities abundantly to densely annulate-punctate.

Elytra dark brown, entirely matt, only humeral umbone shining, finely punctate; scutellum indistinct, base and apex unmodified; epipleuron punctate-setose in front, slightly shiny. Elytra broad, with 8 straight to slightly curved, narrow but distinct striae; stria 7 distinctly sinuate in front, extending over humeral umbone, stria 8 relatively coarse; strial punctures fine, on disc mostly separated by $4-$ 8 puncture diameters, slightly crenulating interstrial edges. Interstrial surfaces very slightly convex, with inconspicuous micropunctation, slightly more pronounced on lateral declivity.

Antennal club light-brown, scapus unmodified. Mentum shallowly emarginate in front. Propectoral sides with coxal-marginal ridge reaching lateral border (as just visible from above), most of surface abundantly (hemi)punctate-setose. Anterior lobe of metasternum slightly convex, abundantly punctatesetose; metasternal disc micropunctate only, with very slight midline impression; flanks and adjacent parts sericeous, densely to crowdedly annulatepunctate-setose. Abdominal ventrites sericeous, all laterally with annulate-punctate-setose row of punctures along base. Pygidium very slightly convex, brown, sericeous, with abundant fine punctation, without distinct setae; borders marginate, base with transverse ridge.

Legs generally shining brown. Protibia with $3+$ 1 larger external denticles (distal 3 larger, acuminate) separated by fine serration; proximal serration consisting of 6-7 smaller denticles; apico-external denticle oblique to tibial axis; apical edge with long, tapering, distally down-curved terminal spur; protibial underside with low longitudinal crest; protarsus unmodified. Profemur robust, underside with numerous larger seta-bearing punctures. Meso- and metafemoral undersides with very few larger setabearing punctures. Meso- and metatibia robust, dilated distad to transversely subelliptic creat, which is fringed with fine fossorial species and setae; external side with ca 5 sets of slight, spine-bearing fossorial protrusions. Tarsi generally slender, with welldeveloped sickle-shaped claws; meso- and metatarsomeres 1 elongate, straight, unmodified. Terminal spurs on meso- and metatibiae elongate, tapering. Approximate length proportions metatibial terminal spur//metatarsomeres 1-5: 15//16/6/4/3/6.

Parameres with downward tip (lateral view), relatively slender, apex rounded (full-face view), Fig. 207.

Measurements in mm (dorsal view). Maximum width of head 3.4. Median length of pronotum 3.9, maximum width 5.9. Sutural length of elytra 5.2, maximum width combined 6.6.

\section{Variation and sexual dimorphism}

Single known female has pair of short conical vertexal protrusions, transversely rugulate clypeus and genae, more pronounced (but still fine) frontal punctation, and a shortly rounded (non-angular) delimitation between the anterior and posterior sections of the lateral pronotal border. Pronotal surface generally slightly convex, punctate area extending from lateral declivities to anterior side. Body length, as male, ca $12 \mathrm{~mm}$.

\section{Distribution}

Papua New Guinea: SE region: Kokoda Trail.

\section{Etymology}

Name expresses similarity to O. taurus and predominantly matt appearance.

\section{Onthophagus costifer Gillet, 1930}

Figs 21-22, 95, 97-102, 208

\section{Material examined}

Lectotype male (IRSNB), designated hereafter: [Indonesia: West New Guinea]: Mamberamo River: Pionierbivak, xii.1920, W.C. van Heurn. New Guinea, 1 paralectotype female (IRSNB). More material listed in Appendix 1.

\section{Comments}

The two syntypes of Onthophagus costifer in the IRSNB were re-examined after the arrival of more costifer-like material, which was different in at least the shape of the anterolateral angle of the pronotum and the pronunciation of the elytral striation and punctation. A lectotype is designated for costifer to consolidate the separation from this close relative (described hereafter as $O$. pseudocostifer sp. n.), and to specify the type locality. Gillet (1930) mentioned that his $O$. costifer came from New Guinea without further details. Not so: the male IRSNB syntype, here designated lectotype, has the following detailed original label data:

[label 1] "N. Guinea Exped./Mamberamo Riv. \ W.C. v. Heurn Dez. \1920. Pionierbivak" [all lines 
printed]; [label 2] "type [vertical, on left side, written in red ink] \Onthoph. $\sigma^{7} \backslash$ costifer m. [2 horizontal lines written in black ink] \J.J.E. Gillet det. [printed]" (handwriting of Gillet); plus four more subsequently added curatorial labels, plus our lectotype label. Female paralectotype with [label 1] "Neu$\backslash$ Guinea” [printed], and a label identical to label 2 on the lectotype pin, except for the $\sigma^{7}$ symbol being replaced by o; three more curatorial labels added to this female, plus our paralectotype label. Lectotype re-described hereafter.

Note that the species may be widespread, apparently occurring as far East as Wau in Papua New Guinea. Other relatives were seen from the $\mathrm{Mt} \mathrm{Ha-}$ gen area, but these may be minors of a different species (more material required).

\section{Identification}

Pronotal disc and lateral declivities strongly, mostly densely punctate. Anterolateral angle of pronotum (Fig. 95, full-face view) slightly obtuse, lateral border in front narrowly expanded by forward curve of coxal-marginal ridge (on propectoral surface); transition from anterior to posterior section of lateral pronotal border rounded (not angular). Elytral striae deep, with distinct edge, interstriae sparsely micropunctate. Pronotum more or less shiny in front and between punctation, remainder of dorsal surface more matt. Clypeofrontal ridge of male obsolescent. Female vertex with vague transverse ridge. General colour brown to black. Body length usually 9.5-12 mm.

\section{Description (lectotype, male)}

Body length ca $12 \mathrm{~mm}$. Habitus convex, robust. Colour black-brown, some parts matt (microreticulate), others shiny. Dorsal side and pygidium virtually glabrous (apart from any inconspicuous microstubbles); ventral side and legs with numerous long, pale brownish setae. Pronotum with distinct punctuation; many parts with inconspicuous, sparse micropunctation.

Clypeal border marginate, sides evenly, very widely rounded to truncate, reflexed, shortly lobiform apex; clypeal surface shiny, abundantly, evenly, minutely punctate; clypeogenal transition at border virtually continuous, suture finely ridged onto frons; clypeofrontal ridge obsolescent. Genal surface and frons virtually matt, sparsely micropunctate; genal border evenly, widely rounded. Frons between posterior end of eyes with pair of long, transversely complanate, basally broad horns, strongly directed laterad (behind eyes), evenly curving upward to tapering tip. Eye foramina large, broadly elliptic, with ca 25 facet rows across widest point. Ratio interocu- lar distance/maximum (transverse, single) eye width ca 3.

Pronotum generally strongly convex, disc slightly convex (lacking midline impression); anteromedian surface gradually, moderately declivous from discal centre, anterolateral declivities behind horns of head very shallowly impressed; anterior and lateral borders of pronotum marginate; anterior section of lateral border slightly sinuate (full-face view); anterolateral angle slightly obtuse; posterior section of lateral border slightly concave, posterolateral angle rounded off to base; base virtually immarginate, medially rounded, finely marginate. Most of anterior pronotal surface shining, anteriorly with abundant fine punctation only; most of disc and lateral declivities densely, evenly subannulate-punctate, many punctures filled with flat, pale substance; interpunctural surface shiny.

Elytra dark brown, entirely matt (sericeous); scutellum indistinct, shape of base and apex unmodified; epipleuron sericeous, punctate-setose in front. Elytra broad, with 8 straight to slightly curved, very distinct striae (sides with edge); stria 7 distinctly sinuate in front, extending over more shiny humeral umbone; strial punctures distinct, mostly separated by $4-6$ puncture diameters, distinctly crenulating well-defined interstrial edges. Interstrial surfaces very slightly convex on disc, all with indistinct, sparse micropunctation only.

Antennal clubs missing; scapus unmodified. Mentum shallowly emarginate in front. Propectoral sides with coxal-marginal ridge widely curving forward, onto lateral border; surface abundantly (hemi)punctate-setose. Anterior lobe of metasternum slightly convex, with numerous seta-bearing punctures in front; disc shiny, sparsely micropunctate; metasternal flanks sericeous, abundantly annulate-punctatesetose. Abdominal ventrites all sericeous, laterally with annulate-punctate-setose row of punctures. Pygidium very slightly convex, brownish black, matt, any punctation indistinct; borders marginate, base with transverse ridge.

Legs generally shining brown. Protibia with $3+$ 1 larger external denticles (distal 3 larger, acuminate) separated by fine serration; proximal serration consisting of 7-9 smaller denticles; apico-external denticle oblique to tibial axis; apical edge with long, acuminate, curved terminal spur; protibial underside with low longitudinal crest; protarsus unmodified. Profemur robust, underside with numerous seta-bearing punctures. Meso- and metafemoral undersides with very few seta-bearing punctures. Meso- and metatibia robust, dilated distad to transversely subelliptic crest, which is fringed with fossorial spines and setae; external side with ca 6 sets of spine-bearing fossorial protrusions. Tarsi gener- 
ally slender, with well-developed sickle-shaped claws; meso- and metatarsomeres 1 elongate, straight, unmodified. Terminal spurs on meso- and metatibiae elongate-acuminate. Approximate length proportions metatibial terminal spur//metatarsomeres $1-5$ : 12//14/6/4/3/6.

Parameres with downward tip (lateral view), outline in full-face view broad, with tapering-divergent tip (Jayapura male, Fig. 208).

Measurements in mm (dorsal view). Maximum width of head 3.6. Median length of pronotum 4.2, maximum width 6.1. Sutural length of elytra 6.2, maximum width combined 7.4.

\section{Variation and sexual dimorphism}

Small paralectotype female (ca $9.5 \mathrm{~mm}$ long) has low transverse vertexal ridge and evenly, slightly convex, entirely strongly punctate pronotum; clypeus very vaguely rugulate-punctate, clypeofrontal ridge distinct. A pair from the vicinity of Wau (Papua New Guinea) is tentatively assigned to this species; the possibly minor male has slightly different parameres, but is certainly different from $O$. pseudocostifer.

\section{Distribution}

West New Guinea: NE region. Papua New Guinea: SE region.

\section{Onthophagus pseudocostifer sp. n.}

Figs 22-23, 96, 103-108, 209

\section{Material examined}

Holotype male (CMNC) from Papua New Guinea: Iora Creek, $17 \mathrm{~km} \mathrm{~S} \mathrm{Kokoda,} \mathrm{Kokoda} \mathrm{Trail,} 1400 \mathrm{~m}$, 3-6.viii.1976, O. Kukal, carrion, montane rainforest. Paratypes in Appendix 1.

\section{Identification}

Pronotal disc and lateral declivities strongly, densely punctate. Anterolateral angle of pronotum (full-face view) acute, lateral border shortly behind angle shallowly concave (Fig. 96, not sinuate in any way, as in the previous species); transition from anterior to posterior section of lateral pronotal border rounded (not angular). Elytral striae fine; interstriae sericeous, finely but distinctly, abundantly punctate. Pronotum in larger males more or less shiny in front and between punctation, remainder of dorsal surface more matt. Clypeofrontal ridge of male obsolescent. General colour usually dark brown to black. Body length usually $10-13.5 \mathrm{~mm}$.

\section{Description (holotype, male)}

Body length ca $13.5 \mathrm{~mm}$. Habitus convex, robust. Colour black-brown, some parts matt (microreticu- late), others shiny. Dorsal side and pygidium virtually glabrous (apart from any inconspicuous microstubbles); ventral side and legs with numerous long, pale brownish setae. Pronotum and elytral interstriae with distinct punctation, many parts with inconspicuous, sparse micropunctation.

Clypeal border marginate, sides evenly, very widely rounded to bisinuate, reflexed, shortly lobiform apex; clypeal surface shiny, laterally very superficially punctate; clypeogenal transition at border virtually continuous, suture finely ridged onto frons; clypeofrontal ridge effaced. Genal surface superificially, finely punctate, border evenly, widely rounded. Frons between posterior end of eyes with pair of long, transversely complanate, basally broad horns, strongly directed laterad (behind eyes), evenly curving upward to tapering tip; interocular surface micropunctate. Eye foramina large, broadly elliptic, with ca 30 facet rows across widest point. Ratio interocular distance/maximum (transverse, single) eye width ca 2.7.

Pronotum generally strongly convex, disc slightly convex (lacking midline impression); anteromedian surface gradually, steeply declivous from discal centre, anterolateral declivities behind horns of head shallowly impressed; anterior and lateral borders of pronotum marginate; anterior section of lateral border slightly concave; anterolateral angle distinct, virtually acute; posterior section of lateral border slightly concave, posterolateral angle rounded off to base; base virtually immarginate, medially with rounded, very obtuse, slightly marginate median angle. Most of anterior pronotal surface shining, micropunctate only; most of disc and lateral declivities densely, evenly subannulate-punctate, many punctures filled with flat, pale substance; interpunctural surface shiny.

Elytra black-brown, entirely matt (sericeous); scutellum indistinct, shape of base and apex unmodified; epipleuron sericeous, punctate-setose in front. Elytra broad, with 8 straight to slightly curved, narrow, distinct striae; stria 7 distinctly sinuate in front, extending over humeral umbone; strial punctures fine but distinct, mostly separated by 4-6 puncture diameters, distinctly crenulating interstrial edges. Interstrial surfaces very slightly convex on disc, all with abundant, fine but distinct stubble-bearing punctation.

Antennal club light-brown, scapus unmodified. Mentum shallowly emarginate in front. Propectoral sides with coxal-marginal ridge virtually straight, reaching lateral border, surface abundantly (hemi)punctate-setose. Anterior lobe of metasternum slightly convex, abundantly punctate-setose in front; disc shiny, sparsely, evenly micrropunctate; metasternal flanks sericeous, abundantly annulate-punctate- 
setose. Abdominal ventrites all shiny, laterally with annulate-punctate-setose row of punctures. Pygidium very slightly convex, brownish black, matt, with abundant, almost effaced, minute punctation; apical part shiny, more distinctly, abundantly, finely punctate; borders marginate, base with transverse ridge.

Legs generally shining dark brown to almost black. Protibia with $3+1$ larger external denticles (distal 3 larger, acuminate) separated by fine serration; proximal serration consisting of 6-7 smaller denticles; apico-external denticle oblique to tibial axis; apical edge with long, acuminate, curved terminal spur; protibial underside with low longitudinal crest; protarsus unmodified. Profemur robust, underside with several seta-bearing punctures. Meso- and metafemoral undersides with very few seta-bearing punctures. Meso- and metatibia robust, dilated distad to transversely subelliptic crest, which is fringed with fossorial spines and setae; external side with ca 6 sets of spine-bearing fossorial protrusions. Tarsi generally slender, with welldeveloped sickle-shaped claws; meso- and metatarsomeres 1 elongate, straight, unmodified. Terminal spurs on meso- and metatibiae elongate-acuminate. Approximate length proportions metatibial terminal spur//metatarsomeres 1-5: 16//18/7/5/4/7.

Parameres with downward tip (lateral view), outline in full-face view broad, tips broad, taperingdivergent (full-face view), Fig. 209.

Measurements in mm (dorsal view). Maximum width of head 3.9. Median length of pronotum 4.3, maximum width 6.7. Sutural length of elytra 6.2, maximum width combined 7.4.

\section{Variation and sexual dimorphism}

Females with transversely rugulate clypeal surface, short, shallowly bisinuate clypeal margin, and distinct clypeofrontal ridge; vertex with low transverse ridge. Female pronotum evenly, slightly convex, strongly punctate throughout. Small males (down to ca $10 \mathrm{~mm}$ long) with reduced vertexal protrusions and more distinct clypeofrontal ridge, may superficially look like females.

\section{Distribution}

Papua New Guinea: SE region: Kokoda Trail.

\section{Etymology}

Name refers to potential mix-up with the lookalike O. costifer.

\section{The Onthophagus coprimorphus group}

\section{Group characters}

The high, pointed (sub)deltoid plates on either side of a distinct median pronotal depression may be the easiest recognizable attribute of this group - note that the plates vary in shape (proportions) according to species, and that there may be intraspecific polymorphism (known females have less developed paramedian projections, but are basically similar to males). Clypeal apex widely rounded to slightly truncate. Eyes large. Clypeofrontal ridge distinct, angle with clypeogenal suture or ridge distinct, but usually obtuse. Pygidial base with transverse ridge. Dorsum glabrous or with very short setae. Colour more or less uniformly black (some parts may be brown). Medium-sized, body length usually $8-12 \mathrm{~mm}$.

\section{Comments}

The head protrusions (particularly those between the eyes) vary, in such a way that the Moluccan species mentioned below does not key out near $O$. coprimorphus in Balthasar's key (1969) at all: it lacks the interocular protrusions. Here we give a key to all four known species (syntypes of $O$. coprimorphus seen in IRSNB, SDEI). Further differences between the species, parameral shape aside, include: details of frontal and pronotal punctation as well as elytral microsculpture, development of (additional) projections along pronotal midline, dorsal outline of lateral borders of pronotum, margination of pronotal base, body size, etc.

\section{Included Papuasian and Moluccan species}

O. coprimorphoides Huijbregts \& Krikken, 2012 Moluccas

O. coprimorphus Gillet, 1930 - West New Guinea

O. ioranus sp. n. - Papua New Guinea

O. ubaidillahi sp. n. - West New Guinea

\section{Key to species (males)}

1. Frons with pair of tubercles between eyes, usually connected by transverse saddle. Pronotal paramedian plates broad at base (in profile). Anterolateral surface of pronotum punctate. Parameres simply curved (in profile). New Guinea ................. 2

- Interocular protrusions absent, vertex with low, long, transverse ridge. Pronotal paramedian plates narrow, strongly tapering (in profile). Median depression of pronotum shallow, envenly concave, basomedian surface lacking projection. Anterolateral surface of pronotum impunctate. Parameres humped, tips downward under hump (in profile). Moluccas............coprimorphoides 
2. Pronotal depression evenly concave, basomedially lacking upright projection ........ 3

- Pronotal depression with longitudinal costa ending in third upright basomedian plate, more or less similar to paramedian projections ..................... ubaidillahi

3. Pronotum with anterior section of lateral border sinuate, lateral and basal surface (around paramedian projections) distinctly, (almost) densely punctate. Elytral interstriae slightly matt (sericeous), very finely, evenly, abundantly punctate. Clypeofrontal ridge distinctly arcuate (parallel to anterior clypeal border). Clypeogenal transition at border distinctly interrupted. Frons finely punctate. Parameral tips only slightly divergent, narrow, not dilated (upper side view). Small, slender................... ioranus

- Pronotum with anterior section of lateral border evenly rounded, pronotal surface smooth, shining. Elytral surface also shining, with numerous scattered interstrial micropunctures. Clypeofrontal ridge less strongly arcuate than anterior border of clypeus, angle with clypeogenal ridge very obtuse. Clypeogenal transition at border at most vaguely interrupted. Frons rugulate(-punctate). Parameral tips strongly divergent and spatuliform (upper side view). Broad, plump .............. coprimorphus

\section{Onthophagus ioranus sp. $\mathrm{n}$.}

Figs 109-113, 120, 210

\section{Material examined}

Holotype male only (CMNC), from Papua New Guinea: Iora Creek, $17 \mathrm{~km} \mathrm{~S}$ Kokoda, Kokoda Trail, 1400 m, 3-6.viii.1976, O. Kukal, carrion, montane rainforest.

\section{Identification}

Pronotal depression evenly concave, basomedially lacking upright projection (unlike O. ubaidillah); paramedian plates flanking depression broad at base (in profile). Pronotum with anterior section of lateral border sinuate, lateral and basal surface (around paramedian projections) distinctly, (almost) densely punctate. Elytral interstriae slightly matt (sericeous), very finely, evenly, abundantly punctate. Clypeofrontal ridge distinctly arcuate (parallel to anterior clypeal border). Clypeogenal transition at border distinctly interrupted. Frons finely punctate. Frons with pair of tubercles between eyes, usually connected by transverse saddle. Anterolateral surface of pronotum punctate. Parameres simply curved, not humped (in profile); parameral tips only slightly divergent, narrow, not dilated (upper side view). Small, slender, body length ca $10.5 \mathrm{~mm}$.

\section{Description (holotype, male)}

Body length ca $10.5 \mathrm{~mm}$. Habitus distinctly convexraised, pronotal armature dominant. Colour generally black, legs dark brown, forebody more or less shining, elytra slightly matt (interstriae sericeous), dorsum virtually glabrous; underside with long palebrown setae.

Clypeal border with sides evenly, widely rounded to very slightly, narrowly reflexed, submarginate, fully rounded apex; clypeal surface entirely transversely rugulate-punctate; clypeogenal transition slightly interrupted at border (genal surface slightly elevated at transition), clypeogenal transition with vague suture to distinctly arcuate clypeofrontal ridge. Genal border rounded, lateral tip fully rounded, genal surface very densely, finely punctate; frontal surface with abundantly finely punctate, punctures arranged in superficial rugulation, sparser and finer between eyes and on interocular protrusions; protrusions placed close to eyes, three-sided, not connected by raised saddle. Vertex hardly raised. Eye foramina very broadly elliptic, with ca 30 facet rows across widest point. Ratio interocular distance/maximum (transverse, single) eye width ca 2.5.

Pronotum generally raised, convex, with broad, median longitudinal concavity over most of discal area, its surface almost smooth, sparsely micropunctate; concavity lined on either side with long, erect, tapering projection, its base broad in lateral view; lateral declivities slightly convex; most of pronotal surface outside protrusions and concavity (lateral and basal surface) evenly, abundantly to almost densely punctate, punctures all fine but distinct, ocellate; borders, including base, distinctly marginate; anterior section of lateral border virtually straight (fullface view), sinuate in dorsal view; anterolateral angle distinct, rectangular, shortly rounded; posterior section of lateral border sinuate, posterolateral angle very obtuse, virtually rounded off; pronotal basal border evenly rounded.

Elytra black, slightly matt; scutellum indistinct; shape of base and apex unmodified; apicosutural angle distinct; epipleuron slightly convex, with brownish setae. Elytra moderately broad, with 8 straight to slightly curved, narrow, distinct striae; stria 7 almost straight in front, ending at humeral umbone; strial punctures simple, distinct, mostly separated on disc by 4-7 puncture diameters, slightly crenulating interstrial edges. Interstrial surfaces very slightly con- 
vex, all interstriae with evenly scattered, sparse, fine punctation.

Antennal club yellowish, scapus unmodified. Mentum shallowly emarginate in front. Postocular area of propectus shallowly concave, posteriorly delimited by simple coxal-marginal ridge. Proepisternal surface with numerous seta-bearing (subannulate) hemipunctures. Anterior lobe of metasternum unmodified (evenly convex), with annulate seta-bearing punctures, disc smooth, with shallow midline impression; metasternal flanks matt, with numerous seta-bearing annulate punctures. Abdominal ventrites matt, with fine seta-bearing annulate punctures along base. Pygidium slightly convex, black, matt, glabrous, with evenly scattered, abundant, fine punctation; base ridged.

Protibia with $3+1$ robust external denticles, some separated by fine serration (2-3 small denticles); proximal serration consisting of ca 6 small denticles; apico-external denticle oblique to tibial axis; terminal spur long, acuminate, distally curved; protibial underside with slight longitudinal crest; protarsus slender, unmodified. Femora robust, undersides with numerous seta-bearing annulate (hemi)punctures, meso- and metafemora also with micropunctation. Meso- and metatibiae dilated distad to transversely subelliptic crest, which is fringed with long fossorial spines; externally with ca 3 slight, spine-bearing fossorial protrusions. Meso- and metatarsi generally robust, with sickleshaped claws; meso- and metatarsomeres 1 long, straight, unmodified. Terminal spurs on meso- and metatibiae elongate-tapering, metatibial spur broad, tip slightly curved, slightly blunted. Approximate length proportions terminal spur//metatarsomeres 1-5: 13//15/6/4/3/6.

Parameres simple, curved downward (rounded, in lateral view), Fig. 210.

Measurements in $\mathrm{mm}$ (dorsal view). Maximum width of head 3.3. Median length of pronotum 3.8, maximum width 5.4. Sutural length of elytra 4.7, maximum width combined 5.9.

\section{Variation and sexual dimorphism}

Only male holotype available.

\section{Distribution}

Papua New Guinea: SE region: Kokoda Trail.

\section{Etymology}

Named after the type locality of this species; to be treated as masculine noun.

\section{Onthophagus ubaidillahi sp. $\mathrm{n}$.}

Figs 35-36, 114-118, 121, 211

\section{Material examined}

Holotype male only (MBBJ), from Indonesia: Irian Jaya: Freeport Concession, 11.iii.1997, R. Ubaidillah, Dpt. 5-2 97.206, dry lowland forest, $4^{\circ} 26^{\prime} 21^{\prime \prime} \mathrm{S}-136^{\circ} 52^{\prime} 59^{\prime \prime} \mathrm{E}, 300 \mathrm{ft}$, dung pitfall trap.

\section{Identification}

The decisive feature of $O$. ubaidillahi is the pronotal depression having a longitudinal costa ending in a third upright (basomedian) plate, more or less similar to the paramedian projections flanking the depression about halfway pronotal length. Frons with pair of tubercles between eyes, connected by transverse saddle. Pronotal paramedian plates broad at base (in profile). Anterolateral surface of pronotum punctate. Parameres simply curved, not humped (in profile). Body length ca $11 \mathrm{~mm}$.

\section{Description (holotype, male)}

Body length ca $11 \mathrm{~mm}$. Habitus distinctly convexraised, pronotal armature dominant. Colour generally black, legs black with tinge of brown, dorsum and most other parts shining; dorsum (apart from microstubbles) glabrous, underside with long palebrown setae.

Clypeal border with sides evenly, widely rounded to very slightly, narrowly reflexed, submarginate, fully rounded apex; clypeal surface entirely transversely rugulate-punctate; clypeogenal transition hardly interrupted at border (genal surface slightly elevated at transition), clypeogenal transition with straight ridge to very weakly curved clypeofrontal ridge. Genal border widely, evenly rounded, genal surface very densely, finely rugulate punctate; frontal surface with crowdedly, transversely rugulate-punctate; tips of interocular protrusions slightly away from eyes, connected by crest, ridge from tip running to posterior side of eyes. Vertex behind crest not raised, smooth, matt. Eye foramina very broadly elliptic, with 35-40 facet rows across widest point. Ratio interocular distance/maximum (transverse, single) eye width ca 2.

Pronotum generally raised, with broad, median concavity over most of discal area, its surface virtually smooth; concavity lined on either side with long, erect, tapering projection, its base broad in lateral view; bottom of concavity with median costa, ending posteriorly in basomedian longitudinal projection similar to those bordering the concavity; lateral declivities very slightly convex, evenly, abundantly punctate, punctures all fine but distinct, changing to micropunctation toward projections; surface be- 

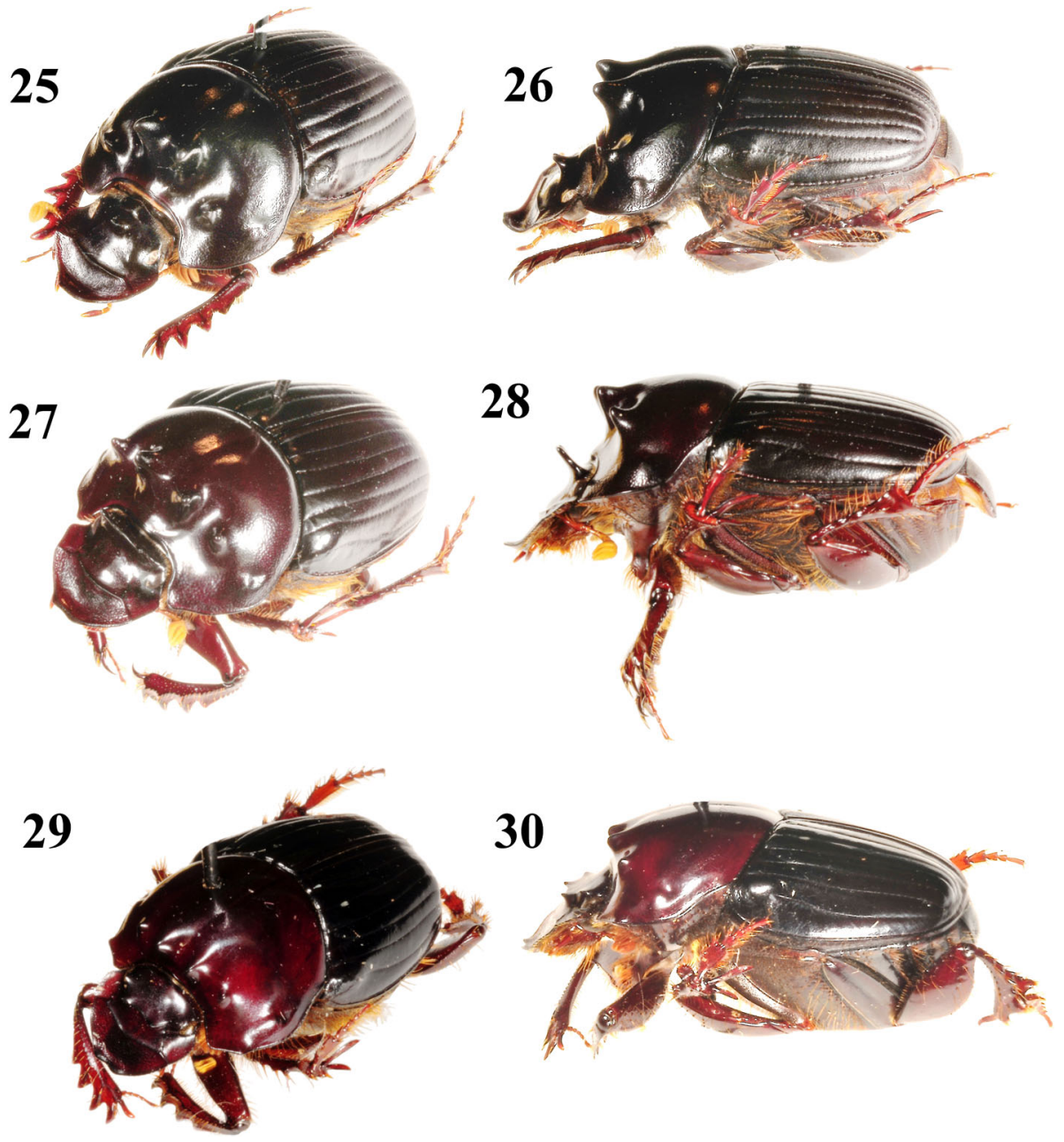

Figs 25-30. Habitus oblique and lateral views of Onthophagus (male holotypes), with approximate length. 25-26, O. alaindrumonti, holotype $12.5 \mathrm{~mm}$; 27-28, andrewsmithi, holotype $12.5 \mathrm{~mm}$; 29-30, labdacus, holotype $11 \mathrm{~mm}$.

tween basomedian and paramedian projections shallowly concave; anterior and lateral borders distinctly marginate; anterior section of lateral border virtually straight (full-face view), widely rounded in dorsal view; anterolateral angle distinct, rectangular, shortly rounded; posterior section of lateral border sinuate, posterolateral angle very obtuse, virtually rounded off; pronotal basal border evenly rounded.

Elytra black, shining; scutellum indistinct; shape of base and apex unmodified; apicosutural angle distinct; epipleuron slightly convex, with row of brown setae. Elytra broad, with 8 straight to slightly curved, narrow, distinct striae; stria 7 almost straight in front, ending at humeral umbone; strial punctures simple, distinct, mostly separated on disc by $4-6$ puncture diameters, slightly crenulating interstrial edges. Interstrial surfaces very slightly convex, at most with indistinct micropunctation.

Antennal club yellowish, scapus unmodified. Mentum shallowly emarginate in front. Postocular area of propectus shallowly concave, posteriorly delimited by simple coxal-marginal ridge. Proepisternal surface with numerous annulate seta-bearing punctures. Anterior lobe of metasternum unmodified (evenly convex), with annulate seta-bearing punctures, disc smooth, with shallow midline impression; metasternal flanks shining, with numerous seta-bearing annulate punctures. Abdominal ventrites slightly matt, with deep seta-bearing annulate punctures along base. Pygidium slightly convex, 
31
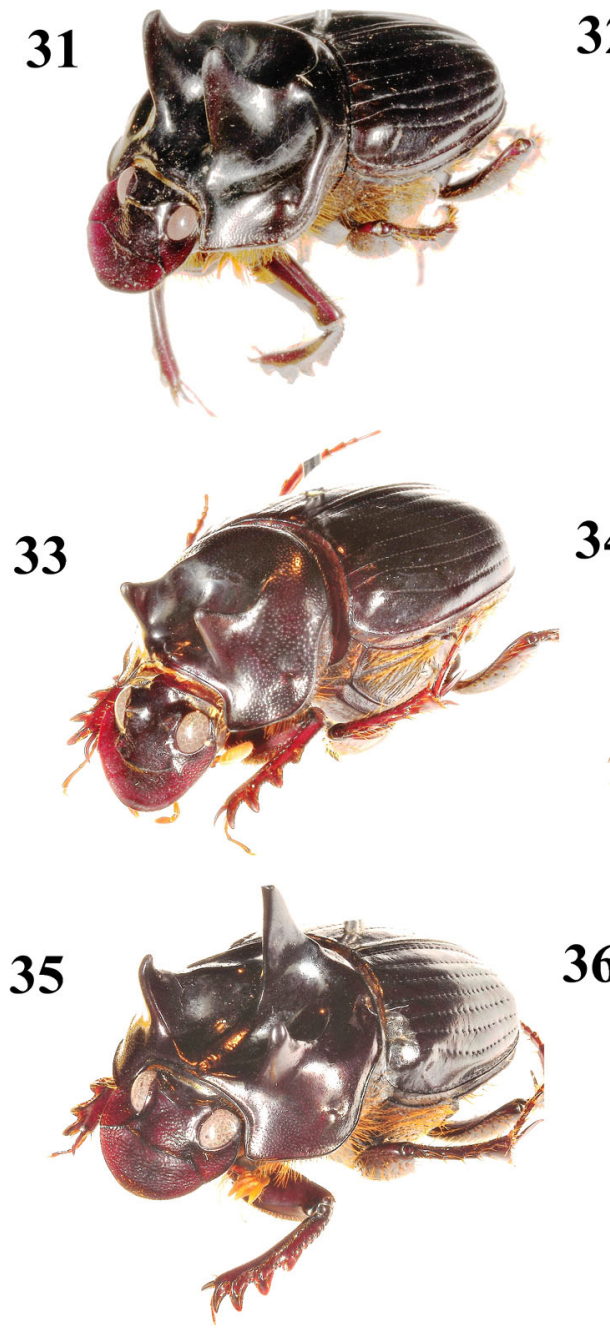

32

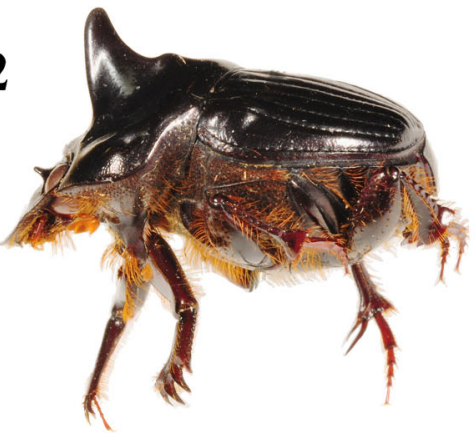

34
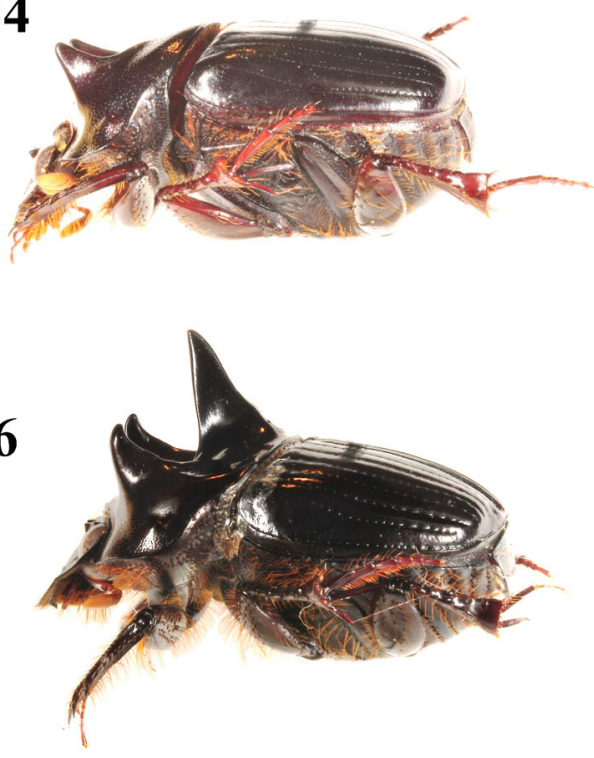

Figs 31-36. Habitus oblique and lateral views of Onthophagus (males), with approximate length. 31-32, O. coprimorphus, syntype Prauwenbivak $12 \mathrm{~mm}$; 33-34, ioranus, holotype $10.5 \mathrm{~mm}$; 35-36, ubaidillahi, holotype $11 \mathrm{~mm}$.

black, matt, glabrous, with evenly scattered, abundant, fine punctuation (larger punctures annulate); base ridged.

Protibia with $3+1$ robust external denticles, some separated by fine serration (1-3 small denticles); proximal serration consisting of ca 6 small denticles; apico-external denticle oblique to tibial axis; terminal spur long, acuminate, curved; protibial underside with slight longitudinal crest; protarsus slender, unmodified. Femora robust, undersides with numerous seta-bearing annulate punctures, meso- and metafemora also with finer punctation. Meso- and metatibiae dilated distad to transversely subelliptic crest, which is fringed with long fossorial spines; externally with ca 3 slight, spinebearing fossorial protrusions. Meso- and metatarsi generally robust, with sickle-shaped claws; mesoand metatarsomeres 1 long, straight, unmodified. Terminal spurs on meso- and metatibiae elongatetapering, metatibial spur broad, tip slightly curved, blunted. Approximate length proportions terminal spur//metatarsomeres 1-5: 15//15/6/4/3/5.

Parameres simple, curved downward (rounded, in lateral view), Fig. 211.

Measurements in $\mathrm{mm}$ (dorsal view). Maximum width of head 4.1. Median length of pronotum 4.8, maximum width 7.0. Sutural length of elytra 5.1, maximum width combined 7.0. 


\section{Variation and sexual dimorphism}

Only male holotype available.

\section{Distribution}

West New Guinea: SC region.

\section{Etymology}

Dedicated to our colleague Rosichon Ubaidillah, from MBBJ, who collected this remarkable species in southwestern New Guinea, along with other interesting scarabs.

\section{The Onthophagus declivis group}

\section{Group characters}

The males in this group are characterized primarily by the sharply defined, shiny, broad, perfectly deplanate pronotal disc, tapering caudad, in the New Guinea species having a generally pyriform outline with a long backward projection. Frontovertex with (usually interocular) transverse elevation or pair of protrusions. Clypeofrontal ridge of male at most slightly arcuate, simple (clypeofrontal transition of female in one species, O. tarsius, peculiarly multiridged, Fig. 145). Eye foramina of the two New Guinea species very large, outline almost circular (separated by $2.5-3$ single eye widths). Large, body length usually $12-14 \mathrm{~mm}$.

\section{Comments}

This group around O. declivis Harold, 1869 was established by Matthews (1972), who included five Australian species - one, with a body length of $18 \mathrm{~mm}$, is apterous. The eye foramina of the Australian species are very small compared with our two reported from New Guinea. The Australians are apparently associated with dung. The hitherto known Papuasian representative (a single male) came from Yapen Island (West New Guinea), and agrees with the Papua New Guinea specimen here illustrated (picture of Arrow's male holotype in BMNH seen).

\section{Included Papuasian species}

O. francoisgenieri sp. n. - Papua New Guinea

O. tarsius Arrow, 1941 - West New Guinea, Papua New Guinea

\section{Key to species (males)}

1. Postfrons with transverse ridge ending in tubercle near eye, lacking long horns. Pronotal border evenly rounded in front (dorsal view) ......................tarsius

- Postfrons with pair of long arcuate horns, which are evenly curved backward, behind eyes, tapering, usually extending over lateral declivities of pronotum. Pronotal border at some distance behind anterolateral angle with flap-like expansion (dorsal view)..... ..................... francoisgenieri

\section{Onthophagus francoisgenieri sp. $\mathbf{n}$.}

Figs 37-38, 136-143, 212

\section{Material examined}

Holotype male (CMNC) from Papua New Guinea: Madang: Baitabag (8 km NW Madang), $100 \mathrm{~m}$, 30.i.2000, $6^{\circ} 08^{\prime} 19^{\prime \prime} \mathrm{S}-145^{\circ} 46^{\prime} 34^{\prime \prime} \mathrm{E}$, R.S. Anderson, rainforest litter, RSA2000-027. Paratypes in Appendix 1 .

\section{Identification}

The pair of very long, evenly arcuate postfrontal horns gives the identity of major males of this declivis group member immediately away, and so does the angular expansion of the lateral pronotal margin. The flat pronotal disc of $O$. francoisgenieri males has an outline slightly different from tarsius (cf. illustrations). The female of $O$. francoisgenieri does not have the peculiarly multi-ridged clypeofrontal transition of the tarsius female - the head has a simple, almost straight ridge, and the postfrontal horns are very short (as in minor males!). Posterolateral section of pronotal border strongly sinuate. Body length $10.5-13.5 \mathrm{~mm}$.

\section{Description (holotype, male)}

Body length ca $13.5 \mathrm{~mm}$. Habitus robust, horns on head and pronotal plane dominant. Colour generally black, dorsum more or less shining, virtually glabrous; underside and legs with long light-brown setae.

Clypeal border evenly, widely rounded, slightly reflexed and submarginate, apex fully rounded; clypeal surface entirely transversely rugulate-punctate; clypeogenal transition very slightly interrupted at border (genal margin slightly elevated at transition), clypeogenal transition with ridge continuing in almost straight clypeofrontal ridge; fine, straight clypeogenal ridge splitting off onto frons. Genal border fully rounded, no distinct lateral tip, genal surface rugulate-punctate; frontal surface densely punctate, punctures somewhat transverse, sparser and finer between eyes; horns based close to posterior part of eyes, very long, complanate, broad at base, slightly tapering, evenly arcuate to rounded tip; horns almost contiguous at base (but not connected by ridge). Eye foramina almost circular, with 40-45 facet rows across widest point. Ratio interocular distance/maximum (transverse, single) eye width ca 2.8 . 

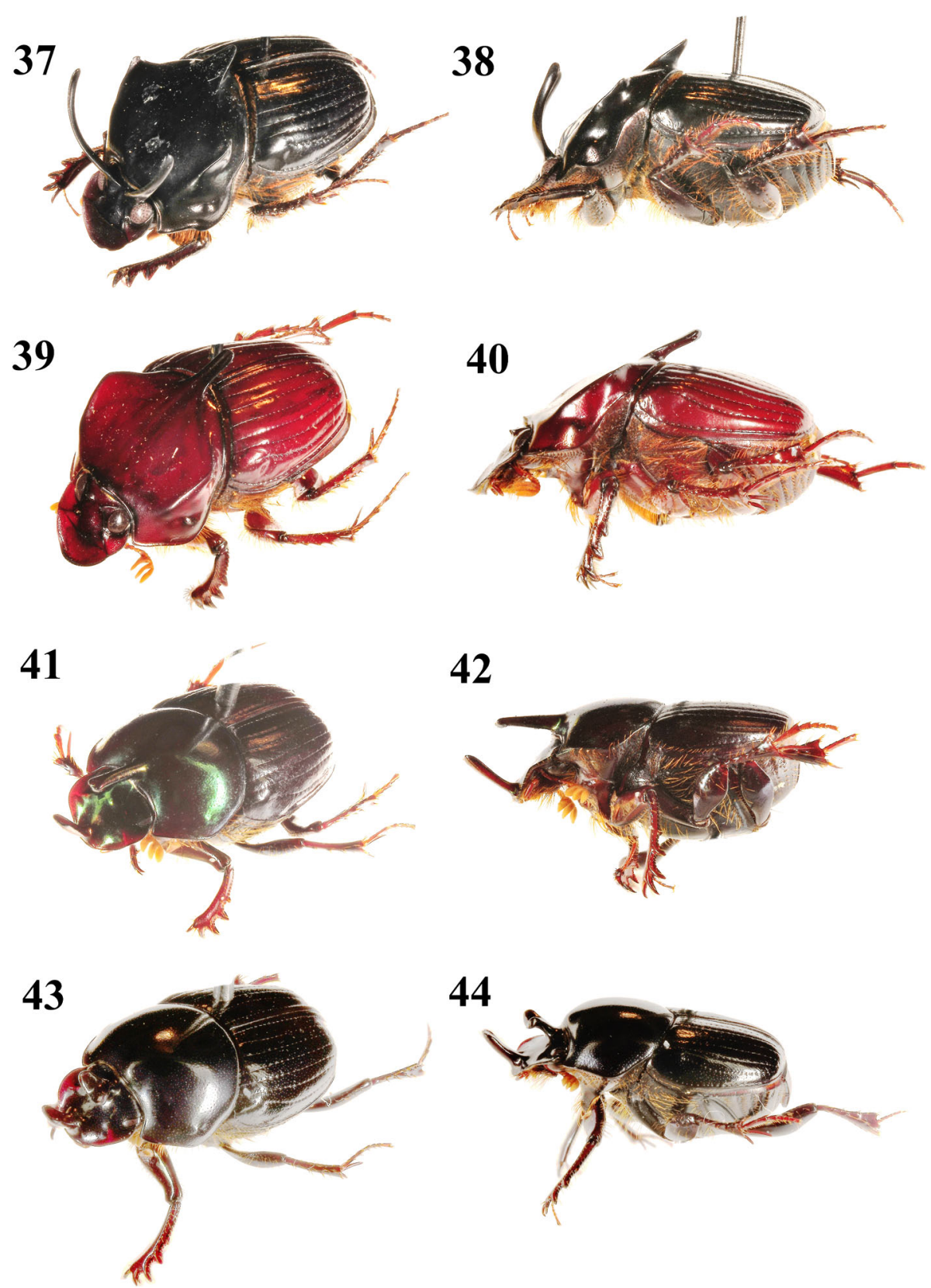

Figs 37-44. Habitus oblique and lateral views of Onthophagus (males), with approximate length. 37-38, O. francoisgenieri, holotype $13.5 \mathrm{~mm}$; 39-40, tarsius, Baiyer R $14 \mathrm{~mm}$; 41-42, platalea, Timika $7.5 \mathrm{~mm}$; 43-44, yifer, holotype $7 \mathrm{~mm}$.

Pronotum generally raised, with extensive perfectly flat disc, sloping up from apex to posterior spike, its surface almost smooth, very sparsely micropunctate, with vague microreticulation; posterior edges of discal plane sharply defined, steeply de- clivous, with (rounded) posterolateral angle and posteromedian, tapering projection (a flat spike with a rounded apex); midline of discal plane very shallowly impressed; lateral pronotal declivities convex; most of pronotal surface outside discal plane abundantly 

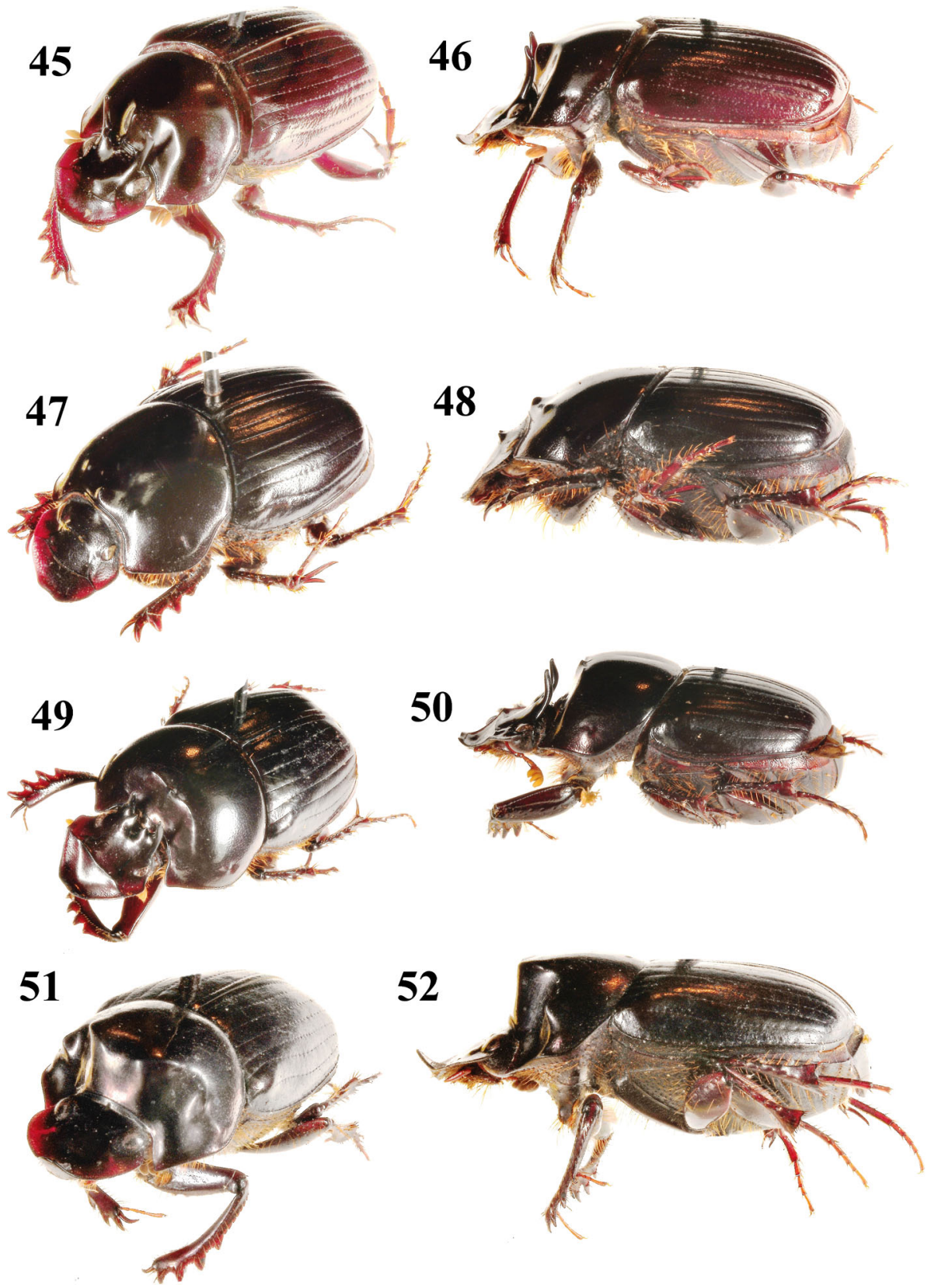

Figs 45-52. Habitus oblique and lateral views of Onthophagus (male holotypes), with approximate length. 45-46, O. hagenmontis, $11.5 \mathrm{~mm}$; 47-48, peotoxus, $9.5 \mathrm{~mm}$; 49-50, papuplicatus, $12.5 \mathrm{~mm}$; 51-52, sylvipapuanus, $9 \mathrm{~mm}$.

to densely punctate, punctures all fine but distinct; anterior and lateral borders distinctly marginate; anterior section of lateral border virtually straight (fullface and dorsal views); anterolateral angle distinct, subrectangular, shortly rounded; posterior section of lateral border strongly sinuate from angular expan- sion at ca 0.3 from anterolateral angle; posterolateral angle very obtuse, rounded off; pronotal basal border very slightly evenly rounded to slight basomedian angle (beneath posterior projection); foveolar area on lateral declivity slightly bulbous. 
Elytra black, shiny; scutellum indistinct, shape of base and apex unmodified; apicosutural angle distinct; epipleuron with row of light-brown setae in front. Elytra broad, with 8 straight to slightly curved, narrow, distinct striae; stria 7 widely, evenly curving to base of humeral umbone; strial punctures simple, distinct, mostly separated on disc by $5-8$ puncture diameters, slightly crenulating interstrial edges. Surface of interstriae slightly convex, all with scattered, sparse micropunctation.

Antennal club yellowish, scapus unmodified. Mentum shallowly emarginate in front. Postocular area of propectus shallowly concave, posteriorly delimited by sinuate coxal-marginal ridge; propectoral sides with numerous distinct seta-bearing (subannulate) hemipunctures. Anterior lobe of metasternum unmodified (slightly convex with very slight midline ridge in front), with (subannulate) seta-bearing punctures, disc more smooth, with shallow midline impression; metasternal flanks sericeous, with numerous seta-bearing (subannulate) punctures. Abdominal ventrites sericeous, each with row of distinct seta-bearing annulate punctures along base. Pygidium slightly convex, black, matt, virtually glabrous, with unevenly scattered, abundant to dense punctation; base with transverse ridge, marginate apex micropunctate.

Legs shiny black, robust. Protibia with $3+1$ strong external denticles, separated by some serration (2-3 small denticles); proximal serration consisting of ca 7 small denticles; apico-external denticle oblique to tibial axis; terminal spur long, acuminate, curved; protibial underside with slight longitudinal crest; protarsus unmodified. Femoral undersides with numerous seta-bearing subannulate (hemi)punctures and with some micropunctation. Meso- and metatibiae dilated distad to transversely subelliptic crest, which is fringed with short fossorial spines below, with longer spines and setae above; externally with ca 5 sets of slight, spinebearing fossorial protrusions. Meso- and metatarsi generally robust, with sickle-shaped claws; mesoand metatarsomeres 1 long, straight, unmodified. Terminal spurs on meso- and metatibiae elongatetapering, Approximate length proportions terminal spur//metatarsomeres 1-5: 16//16/7/4/3/5.

Parameres simple, curved downward in lateral view (Fig. 212), divergent, tip spatuliform in full-face view.

Measurements in $\mathrm{mm}$ (dorsal view). Maximum width of head 4.3. Median length of pronotum 5.8 (apical-basal borders), maximum width 8.0. Sutural length of elytra 4.9, maximum width combined 8.1.

\section{Variation and sexual dimorphism}

Female has pair of short, triangular, upright postfrontal horns connected by slight ridge (evenly concave in axial view). Clypeofrontal ridge virtually straight, unmodified, remainder of head very similar to male. Pronotum behind anterior edge with robust, short, triangular median denticle, posteriorly drawn out to ridge, gradually effaced shortly behind denticle; surface on either side of this ridge shallowly concave, external border of concavity rounded from anteromedian denticle. Lateral margin of pronotum not angularly expanded, posterior section of lateral border strongly sinuate. Elytra, ventral side, and legs similar to male.

Variation in size (body length $10.5-13.5 \mathrm{~mm}$ ) and colour (black to brown), horns in minor males (down to $11 \mathrm{~mm}$ long) much shorter, and lateral and posterior projection on pronotal crests shorter.

\section{Distribution \\ Papua New Guinea: N region.}

\section{Etymology}

Dedicated to our colleague François Génier (CMNC), in recognition of facilitating the study of Ottawa-based material of New Guinea Onthophagus.

\section{The Onthophagus labdacus group}

\section{Group characters}

These are rather large, black or brown species with, in both sexes, a set of four distinct, angular or subconical protrusions on (the median pair topping) their anterior pronotal declivity, placed in a virtually transverse line (in dorsal view). Clypeal apex slightly lobate-reflexed, bisinuate-bidentate. Clypeofrontal transition with slight ridge, not simply reaching clypeogenal borders. Eye foramina small. Anterolateral angle of pronotum shortly rounded. Pygidial base with transverse ridge. Dorsum glabrous or with very short setae. Body size usually 11$13 \mathrm{~mm}$.

\section{Comments}

Onthophagus labdacus Balthasar, 1969 (holotype seen in NMPC) seems a close relative of the two new species, and they all may have something to do with some of the larger Australian species with four antediscal pronotal tubercles in Matthews (1972) treated as a group around O. conspicuus Macleay, 1864.

Protrusions on head may be deceptively polymorphic. 
Included Papuasian species

O. alaindrumonti sp. n. - Papua New Guinea

O. andrewsmithi sp. n. - Papua New Guinea

O. labdacus Balthasar, 1969 - West New Guinea

\section{Key to species (males)}

1. Dorsum (including elytra) shining. Head in both sexes with four protrusions on trapezoid ridge (one on either side close to eyes, one pair in front of eyes, more approximated, Fig. 135). Anterior section of lateral pronotal margin with projecting angle. Paramedian protrusions of pronotum separated by anteriorly gradually declivous depression...................... labdacus

- Dorsum (at least elytra) more or less sericeous, matt. Head with different elevation(s). Anterior section of lateral pronotal margin rounded or sinuate, lacking projecting angle. Paramedian protrusions of pronotum set jointly on more abruptly declivous anteromedian protrusion ......... 2

2. Anterior section of lateral pronotal border evenly rounded. Elytra strongly matt, stria 8 coarsely punctate over entire length. Male frontal horn high, narrow, more or less conical ................. alaindrumonti

- Anterior section of lateral pronotal border slightly sinuate. Elytra less matt, stria 8 finer, some distinct punctures in front only. Male frontal elevation varying from transverse ridge, laterally protruding on either side, to pair of high, upright conical tubercles .................... andrewsmithi

\section{Onthophagus alaindrumonti sp. n.}

Figs 25-26, 122-127, 213

\section{Material examined}

Holotype male only (CMNC), from Papua New Guinea: Iora Creek, 17 km S Kokoda, Kokoda Trail, 1400 m, 3-6.viii.1976, O. Kukal, carrion, montane rainforest.

\section{Identification}

In this group the primary features of $O$. alaindrumont $i$ are the anterolateral outline of the pronotum, the shape of the male frontal horn, and the elytral interstrial microsculpture. Anterior section of lateral pronotal border evenly rounded (not sinuate), anterolateral angle shortly rounded. Elytra strongly matt, juxtepipleural stria coarsely punctate over entire length. Male frontal horn high, narrow, more or less conical. Paramedian protrusions of pronotum set jointly on more abruptly declivous anteromedian protrusion. Body length ca $12.5 \mathrm{~mm}$.

\section{Description (holotype, male)}

Body length ca $12.5 \mathrm{~mm}$. Habitus high, convex, with four transversely arranged pronotal protrusions. Colour generally black, forebody and legs shining, elytra and much of ventral side matt (microreticulate). Ventral side with numerous long, brownish setae, dorsum (inconspicuous micro-stubbles aside) glabrous.

Clypeal border laterally virtually straight, ending at broadly lobate, reflexed apex, its tip slightly bisinuate; most of clypeofrontal surface with numerous micropunctures, sides of clypeus and genae shallowly (rugulate-)punctate. Clypeogenal transition continuous, slightly rounded at border, clypeogenal ridge straight, ending at transverse, slightly arcuate clypeofrontal ridge. Genal border curved, lateral tip rounded (not angular). Frons medially between eyes with erect horn, its base subconical, tip transverse (rectangular in axial view). Eye foramina narrow (elongate-elliptic), with ca 15 facet rows across widest point. Ratio interocular distance/maximum (transverse, single) eye width 8-9.

Pronotum generally strongly convex (disc with distinct midline impression), anteromedian declivity steep, topped by pair of subconical protrusions on either side; lateral protrusions also subconical, separated from paramedians by concavity; anterior and lateral pronotal borders marginate, anterior section of lateral border (dorsal view) slightly sinuate in front to shortly rounded anterolateral angle, adjacent surface slightly depressed; posterior section of lateral border slightly sinuate, posterolateral angle rounded off; basal border finely marginate, vaguely angular medially. Pronotal surface shining on disc (laterally subsericeous), disc scattered with indistinct micropunctation, lateral declivities (rugulate-)punctate.

Elytra black, distinctly matt; shape of base and apex unmodified, scutellum indistinct; epipleuron with numerous coarse seta-bearing punctures. Elytra broad, with 8 straight to slightly curved, narrow, largely subparallel, well-defined striae; stria 7 evenly curved to near shining humeral umbone; juxtepipleural stria (8) coarse, with deep punctures; punctures of striae 1-7 mostly separated by (2-)-4-6 diameters, slightly crenulating interstrial edges; striae $3+4$ and $5+6$ distinctly joined on anteapical elytral declivity. Interstriae slightly convex, all with abundant, scattered micropunctation.

Antennal club yellow; scapus unmodified. Mentum shallowly emarginate in front. Propectoral sides with simple (slightly arcuate, ridged) coxal-marginal line; surface abundantly (hemi)annulate-punctate, many punctures with long seta. Anterior lobe of 
metasternum slightly convex, punctate-setose in front, with superficial midline impression extending caudad; median parts of metasternum shining, with scattered micropunctation, flanks matt, with abundant, seta-bearing annulate punctation. Abdominal ventrites matt, laterally all with one or two transverse rows of annulate, seta-bearing punctures along base. Pygidium black, surface evenly slightly convex, abundantly, evenly, finely subannulate-punctate, setae short; pygidial base with transverse ridge.

Protibia with $3+1$ larger external denticles (distal 3 more distinctly acuminate), separated by some fine serration; proximal serration consisting of 4 small denticles; apico-external denticle oblique to tibial axis, apico-internal angle with long, curved, acuminate spur; protibial underside with low longitudinal crest; protarsus unmodified. Profemur robust, shiny, underside with numerous seta-bearing (hemi)punctures. Meso- and metafemoral undersides shiny, with few seta-bearing (hemi)punctures. Meso- and metatibiae robust, strongly dilated distad to transversely subelliptic crest, which is fringed with fine fossorial spines and setae; external side with 3-4 sets of spine-bearing fossorial protrusions. Tarsi generally slender, with fine, sickle-shaped claws; meso- and metatarsomeres 1 robust, long, straight, unmodified. Terminal spurs on meso- and metatibiae long, tapering. Approximate length proportions of metatibial terminal spur//metatarsomeres 1 5: 14//16/6/4/3/5.

Parameres tapering to downward spatuliform tip, Fig. 213.

Measurements in mm (dorsal view). Maximum width of head 3.7. Median length of pronotum, maximum 4.5, width 7.0. Sutural length of elytra 5.3, maximum width combined 7.2.

\section{Variation and sexual dimorphism \\ Only male holotype available.}

\section{Distribution}

Papua New Guinea: SE Region: Kokoda Trail.

\section{Etymology}

Dedicated to our Belgian colleague Alain Drumont, in recognition of his assistance with accessing $\mathrm{On}$ thophagus material in the IRSNB.

\section{Onthophagus andrewsmithi sp. n.}

Figs 27-28, 128-133, 214

\section{Material examined}

Holotype male (CMNC) from Papua New Guinea: Iora Creek, 17 km S Kokoda, Kokoda Trail, 1900 m,
Templeton Cross, 3-6.viii.1976, O. Kukal, dung trap, upper montane rainforest. Paratypes in Appendix 1 .

\section{Identification}

Within this group the primary features of $O$. andrewsmithi are the anterolateral outline of the pronotum, the shape of the frontovertexal elevation, and the elytral interstrial microsculpture. Anterior section of lateral pronotal border slightly concave-sinuate (not evenly rounded), anterolateral angle shortly rounded. Elytra less matt than in $O$. drumonti, juxtasutural stria finer, some distinct punctures in front only. Male vertex with polymorphic elevation: a pair of protrusions, connected by variably high intervening lamina, or with high tubercles only. Paramedian protrusions of pronotum set jointly on more abruptly declivous anteromedian protrusion. Body length usually $11-12.5 \mathrm{~mm}$.

\section{Description (holotype, male)}

Body length ca $12.5 \mathrm{~mm}$. Habitus high, convex, with four transversely arranged pronotal protrusions. Colour generally black to dark-brown, forebody and legs shining; elytra slightly shiny, much of ventral side matt (microreticulate). Ventral side with numerous long, brownish setae, dorsum (inconspicuous micro-stubbles aside) glabrous.

Clypeal border laterally virtually straight, ending at broadly lobate, reflexed apex, its tip slightly bisinuate; most of clypeofrontal surface with numerous micropunctures, sides of clypeus and genae shallowly (rugulate-)punctate. Clypeogenal transition continuous, slightly rounded at border, clypeogenal ridge straight, ending at transverse, slightly arcuate clypeofrontal ridge. Genal border straight in front, lateral tip rounded off (subangular). Frons between posterior part of eyes with robust transverse lamina, its lateral sides with short upward point, intervening crest slightly undulate. Eye foramina narrow (elongate-elliptic), with ca 15 facet rows across widest point. Ratio interocular distance/maximum (transverse, single) eye width 8-9.

Pronotum generally strongly convex (disc with superficial midline impression), anteromedian declivity steep, topped by pair of subconical protrusions on either side; lateral protrusions more angular, separated from paramedians by concavity; anterior and lateral pronotal borders marginate, anterior section of lateral border (dorsal view) evenly rounded to shortly rounded anterolateral angle, adjacent surface slightly depressed; posterior section of lateral border slightly sinuate, posterolateral angle rounded off; basal border finely marginate, vaguely angular medially. Pronotal surface shining on disc (laterally sub- 
sericeous), disc scattered with indistinct micropunctation, lateral declivities (rugulate-)punctate.

Elytra black, only slightly shiny (sericeous); shape of base and apex unmodified, scutellum indistinct; epipleuron with numerous coarse seta-bearing punctures. Elytra broad, with 8 straight to slightly curved, narrow, largely subparallel, well-defined striae; stria 7 evenly curved to near shining humeral umbone; juxtepipleural stria (8), with deep punctures in front; punctures of striae 1-7 fine, mostly separated by (2-)4-6 diameters, very slightly crenulating interstrial edges; striae $3+4$ and $5+6$ indistinctly joined on anteapical elytral declivity. Interstriae slightly convex, on disc with abundant, scattered micropunctation, punctation on lateral interstriae stronger and more abundant.

Antennal club yellow; scapus unmodified. Mentum shallowly emarginate in front. Propectoral sides with simple (straight, ridged) coxal-marginal line, not reaching border; surface abundantly (hemi)annulate-punctate, many punctures with long seta. Anterior lobe of metasternum slightly convex, punctate-setose in front, with superficial midline impression extending caudad; median parts of metasternum shining, with scattered micropunctation, flanks matt, with abundant, seta-bearing annulate punctation. Abdominal ventrites matt, laterally all with one or two transverse rows of annulate, seta-bearing punctures along base. Pygidium black, surface evenly slightly convex, abundantly, evenly, finely punctate, setae short; pygidial base with transverse ridge.

Protibia with $3+1$ larger external denticles (distal 3 more distinctly acuminate), separated by some fine serration; proximal serration consisting of 45 small denticles; apico-external denticle oblique to tibial axis, apico-internal angle with long, curved, acuminate spur; protibial underside with low longitudinal crest; protarsus unmodified. Profemur robust, shiny, underside with numerous seta-bearing (hemi)punctures. Meso- and metafemoral undersides shiny, with few seta-bearing (hemi)punctures. Meso- and metatibiae robust, strongly dilated distad to transversely subelliptic crest, which is fringed with fine fossorial spines and setae; external side with 3-4 sets of spine-bearing fossorial protrusions. Tarsi generally slender, with fine, sickle-shaped claws; meso- and metatarsomeres 1 robust, long, straight, unmodified. Terminal spurs on meso- and metatibiae long, tapering. Approximate length proportions of metatibial terminal spur//metatarsomeres $1-$ 5: $16 / / 17 / 8 / 4 / 3 / 5$.

Parameres tapering to downward spatuliform tip, Fig. 214.

Measurements in mm (dorsal view). Maximum width of head 3.9. Median length of pronotum, maximum 4.2, width 7.4. Sutural length of elytra 5.6, maximum width combined 7.3.

\section{Variation and sexual dimorphism}

The pronotum of the female is similar in shape to that of the male, but usually the protrusions and concavities are less pronounced. Ornamentation of frontovertex strongly polymorphic. The female frons has a low, transverse ridge between the eyes. The ridge on the male head, apparently connecting a pair of paraocular protrusions, is positioned on the vertex, and may be so low as to leave only the conical lateral protrusions. Body length 11-12.5 mm.

\section{Distribution \\ Papua New Guinea: SE region: Kokoda Trail.}

\section{Etymology}

Dedicated to our colleague Andrew Smith in Ottawa (CMNC), in recognition of his support to our ongoing study of New Guinea Onthophagus.

\section{The Onthophagus platalea group}

\section{Group characters}

Clypeus of males with high, upright spatuliform projection on or just behind apex. Head broad, clypeogenal border evenly rounded from apex to occipital sides. Male frons may have additional protrusion. Pronotum generally convex, in male of one species with long forward prong or spike. Eye foramina narrow. Male lacking clypeofrontal ridge. At least head and pronotum very shining, with (variably strong) metallic lustre (species in eliptaminus group, above, pigmented, with mattifying microsculpture). Parameres humped (lateral view), tips on underside spatuliform, set close to parameral base. Females have shallowly emarginate clypeal apex, clypeofrontal ridge, and low interocular protrusion(s). Pygidium with basal ridge. Body length usually $6-8 \mathrm{~mm}$.

\section{Comments}

The new species described below appears a relative of Onthophagus platalea Arrow, 1941 (pictures of BMNH male holotype seen), which strongly agrees in general structure. The shining integument, the high projection on the male clypeal apex, and the full-face outline of the head seem to be the most characteristic features. There is a strong sexual dimorphism.

\section{Included Papuasian species}

O. platalea Arrow, 1941 - West New Guinea

O. yifer sp. n. - West New Guinea 


\section{Key to species (males)}

1. Frons posteriorly with robust Y-shaped stalk. Pronotum evenly convex. Elytral interstriae smooth, finely, distinctly punctate ........................... yifer

- Frons lacking long, complex protrusions. Pronotum with long, slender forward prong. Elytral interstriae superficially scabrous, indistinctly punctate.... O. platalea

\section{Onthophagus yifer sp. n.}

Figs 43-44, 146-152, 215

\section{Material examined}

Holotype male (MBBJ) from Indonesia: Irian Jaya: Timika, Freeport Concession, Mach 912, 1997, Rosichon Ubaidillah, 97.204, heath forest mossy, $4^{\circ} 16^{\prime} 99^{\prime \prime} \mathrm{S}-137^{\circ} 00^{\prime} 86^{\prime \prime} \mathrm{E}, 1950 \mathrm{ft}$, dung pans trap (DPT. 9). Paratypes in Appendix 1.

\section{Identification}

Major males of this species characterized by the two distinct medial projections on the head, one just behind the clypeal apex, the other between the eyes. The latter projection is Y-shaped in axial view, its top looking like a saddle when viewed from above. Clypeofrontal transition in male not marked in any way. O. yifer is virtually shining black, with forebody metallic lustre in some individuals. Pronotum strongly, nearly evenly convex, finely, sparsely punctate. Elytral striae and their punctation fine but distinct; interstriae smooth, shining, sparsely, finely punctate. Parameres humped, tip recurved to parameral base (lateral view), as small, relatively broad plate (full-face view). Body length usually 6-7 $\mathrm{mm}$.

\section{Description (holotype, male)}

Body length ca $7 \mathrm{~mm}$. Habitus distinctly convex, head armature dominant. Colour generally black, shining, without distinct weak metallic lustre. Dorsum virtually glabrous; underside with long palebrown setae.

Clypeal border with sides and apex evenly, widely rounded; clypeus has just behind apex robust, upright, spatuliform projection; clypeogenal transition continuous at border, with vague suture. Genal border widely rounded, lacking distinct lateral tip; interocular surface medially with high, robust, (in axial view) Y-shaped, upright projection; apex in dorsal view saddle-like. Most of head surface with sparse micropunctation. Eye foramina narrowly elliptic, with ca 9 facet rows across widest point. Ratio interocular distance/maximum (transverse, single) eye width ca 11 .
Pronotum generally convex, slightly steeper in front, with vague impression on either side; anterior section of lateral border virtually straight (full-face view); anterolateral angle distinct, rectangular; posterior section of lateral border also virtually straight, posterolateral angle rounded to finely marginate base; pronotal basal border widely rounded, lateral borders widely rounded in dorsal view. Entire pronotal surface finely, sparsely punctate, interspersed with sparse micropunctation.

Elytra moderately broad, with base and apex unmodified, scutellum indistinct; apicosutural angle distinct; epipleuron with row of pale-brown setae. Elytra with 8 straight to slightly curved, narrow, distinct striae; stria 7 slightly curved in front, ending at humeral umbone; strial punctures simple, distinct, mostly separated on disc by 5-7 puncture diameters, slightly crenulating interstrial sides. Interstrial surfaces very slightly convex, all interstriae with evenly scattered, sparse, fine punctation.

Antennal club yellowish, scapus unmodified. Mentum shallowly emarginate in front. Postocular area of propectus shallowly concave, posteriorly delimited by simple coxal-marginal ridge. Propectoral sides with numerous seta-bearing punctures. Anterior lobe of metasternum unmodified (evenly convex), with seta-bearing annulate punctures, disc smooth, with numerous fine punctures, and with shallow midline impression; metasternal flanks with numerous seta-bearing annulate punctures. Abdominal ventrites laterally each with row of fine setabearing annulate punctures. Pygidium with very vague median ridge, apical half distinctly convex, black, slightly shiny, glabrous, with abundant, evenly scattered punctation; base ridged. Most ventral parts shiny, some (locally) with vague microreticulation.

Protibia with $3+(1)$ external denticles, some separated by fine serration (3-4 small denticles); proximal serration consisting of ca 8 small denticles; apico-external denticle oblique to tibial axis (proximal denticle almost immersed in serration); terminal spur long, acuminate, curved; protibial underside with slight longitudinal crest; protarsus slender, unmodified. Femora robust, undersides with several seta-bearing punctures and very sparse micropunctation. Meso- and metatibiae dilated distad to transverse crest, which is fringed with fossorial spines below (shape of apex subelliptic on mesotibia; sinuate on metatibia), externally with ca 3 slight, spinebearing fossorial protrusions. Meso- and metatarsi slender, with sickle-shaped claws; meso- and metatarsomeres 1 long, straight, unmodified. Terminal spurs on meso- and metatibiae elongate. Approximate length proportions terminal spur//metatarsomeres $1-5$ : $x / / 18 / 6 / 4 / 3 / 5$ (tips of spurs broken off). 
Parameres humped, fine subtriangular tips (fullface view) strongly curved downward, set close to parameral base (lateral view), Fig. 215.

Measurements in mm (dorsal view). Maximum width of head 2.1. Median length of pronotum 2.7, maximum width 3.6. Sutural length of elytra 2.8, maximum width combined 3.8.

\section{Variation and sexual dimorphism}

What is assumed to be a female of this species (body length ca $6.5 \mathrm{~mm}$ ) has a clypeofrontal and an interocular ridge; its clypeal border is shallowly bisinuate, the margin lacking the high protrusion of the males. Another female, with a strongly metallic forebody, has a pair of interocular swellings instead of a full ridge, but then it may belong to a different species, possibly $O$. platalea. Forms looking like $O$. platalea, which lacks the Y-shaped frontal projection and has a forward pronotal projection, occur in the same region as yifer. They must be closely related, but, judged from the material at hand, appear two different species; the option of $O$. yifer being a morph of platalea is rejected.

\section{Distribution}

West New Guinea: SC region.

\section{Etymology}

Name refers to the species carrying a Y-shaped horn on its frons.

\section{The Onthophagus asper group}

\section{Group characters}

Small, predominantly black-brown species, which may have a metallic lustre. Dorsum and pygidium strongly punctate(-rugulate) or asperate(-punctate), and very distinctly setose. Anterior border of clypeus bisinuate-bidentate. Eye foramina narrow. Pronotum at most slightly bigibbose on anterior declivity. Pygidial base ridged. Protibia unmodified. Small species, body length usually $2.5-5.5 \mathrm{~mm}$.

\section{Comments}

Group of species proposed by Matthews (1972), created around $O$. asper Macleay, 1864 for three Australian species; $O$. ocelliger Harold, 1877 has been recorded from both Australia and New Guinea (Gillet 1930; material from Australia seen), and we add here a fourth member to the group, from North of the Owen Stanley Range in Papua New Guinea. There is one other group of Onthophagus in New Guinea with a very hairy appearance, with a single New Guinea representative, O. hirtuosus Gillet, 1930 (more relatives in the Oriental Region); this species differs from the asper group members in its pygidial base lacking a transverse ridge, and in other characters - for instance, the shape of the vertexal protrusions (cf. Krikken \& Huijbregts 2011).

\section{Included Papuasian species}

O. ocelliger Harold, 1877 - Papua New Guinea, Australia

O. papurugosus sp. n. - Papua New Guinea

\section{Key to species (male)}

1. Elytral interstriae all virtually equally convex, coarsely punctate, striae fine, indistinct (almost crowded out by interstrial punctures). Clypeal border shallowly bisinuate in front. Head with complete clypeofrontal and transverse interocular ridges. Pronotum very coarsely punctate, bigibbose in front. Elytra lacking any markings. Apparently larger, body length ca $5.5 \mathrm{~mm} . . .$. . ..........................papurugosus

- Odd-numbered elytral interstriae more convex than others, interstriae asperate(-punctate), striae broad, distinct. Clypeus more deeply emarginate in front. Head with short clypeofrontal ridge and pair of slight interocular protrusions. Pronotum distinctly, crowdedly punctate, shape evenly rounded in front. Elytra with small symmetric orange-yellow markings. Smaller, body length $3-4.5 \mathrm{~mm} . . . \ldots \ldots \ldots$. ocelliger

\section{Onthophagus papurugosus sp. $\mathrm{n}$.}

Figs 16, 153-157, 216

\section{Material examined}

Holotype male only (AMNH), from NE Papua New Guinea: Oro Bay, 20 mi S Buna, xi.1943-ii.1944, J. Helfer.

\section{Identification}

The overall heavily punctate-setose appearance, the pair of slight antediscal protrusions on the pronotum, and the equal convexity of the elytral interstriae are primary features of $O$. papurugosus, compared to its closest relative on New Guinea, O. ocelliger. Unicoloured blackish, with distinct metallic lustre, lacking symmetric markings (contrary to ocelliger); setae pale-yellow, abundant and mostly very long. Clypeal border anteriorly shallowly bisinuate. Frons with transverse interocular ridge, clypeofrontal transition with weakly arcuate ridge; clypeogenal transition indistinct, i.e. ridge or suture apparently absent. Clypeogenal border in outline virtually continuous 
from genae to bisinuate apical border, margin narrowly reflexed. Body length ca $5.5 \mathrm{~mm}$, ocelliger being distinctly smaller.

\section{Description (holotype, male)}

Body length ca $5.5 \mathrm{~mm}$. Habitus convex-compact. Colour generally black, looking matt, but shiny between coarse microsculpture, locally with metallic lustre. Dorsum with very abundant, long, paleyellow setae, underside also with numerous paleyellow setae; punctation on dorsal side generally crowded, coarse, more or less rugulate.

Clypeus and frons with numerous erect setae. Clypeal border widely, evenly rounded, to broadly bisinuate apex, margin narrowly reflexed; clypeal surface crowdedly, distinctly punctate throughout; clypeogenal ridge fine, straight; clypeofrontal transition with very slightly arcuate ridge. Genal border with short, rounded lateral tip, continuous to clypeal border, posteriorly straight to occipital attachment. Frontal ridge (between eyes) transverse, slightly sinuate, length roughly half interocular distance; punctation behind ridge finer, less dense. Eye foramina narrow, with ca 6 facet rows across widest point. Ratio interocular distance/maximum (transverse, single) eye width ca 10.

Pronotum strongly convex, slightly bigibbose in front of disc, and with slight, ill defined basomedian impression; anterior declivity steep; surface entirely, crowdedly punctate-setose, many setae recurved, very long (many time the puncture diameters); anterior and lateral borders finely marginate; anterior section of lateral border straight (full-face view), anterolateral angle shortly rounded, subrectangular; posterior section of lateral border sinate (full-face view), posterolateral angle rounded off; pronotal sides and basal border widely rounded in dorsal view.

Elytra broad; scutellum indistinct, shape of base and apex unmodified; epipleuron finely punctatesetose; elytron with 8 straight to slightly curved, fine striae, more or less crowded out (i.e. indistinct) by coarse punctation, humeral umbone ill defined; strial punctures very fine, separated by several puncture diameters, hardly crenulating interstriae. Interstrial surfaces all slightly convex, crowded with coarse punctures (more or less rugulate-punctate) bearing long setae.

Antennal club dark-brown, scapus unmodified. Mentum shallowly emarginate in front. Postocular area of propectus posteriorly delimited by slight, simple coxal-marginal ridge. Propectoral sides abundantly punctate-setose. Metasternum shiny, anterior lobe very slightly convex in front; metasternal lobe and disc with slight midline impression, abundantly, finely punctate-setose; metasternal flanks crowdedly punctate-setose. Abdominal ventrites moderately shiny, punctate-setose. Pygidium black, matt, generally crowdedly, finely punctate-setose, setae subappressed; base marginate; surface evenly, slightly convex.

Legs generally shiny black-brown. Protibia robust, with $3+1$ larger external denticles (distal 3 larger, acuminate), each separated by some serration; proximal serration consisting of ca 7 small denticles; apico-external denticle long, oblique to tibial axis; apico-internal edge with short spine (without hair-brush), terminal spur distinct, elongateacuminate, curved; protibial underside with low longitudinal crest; protarsus slender. Femoral undersides shiny, with numerous (partly seta-bearing) punctures. Meso- and metatibiae strongly dilated distad to transversely subelliptic crest, which is fringed with short fossorial spines below, and some long spines and setae above; externally with ca 3 slight, spine-bearing fossorial protrusions. Mesoand metatarsi generally slender, with fine, sickleshaped claws; meso- and metatarsomeres 1 long, straight, unmodified. Terminal spurs on mesoand metatibiae elongate-acuminate. Approximate length proportions terminal spur//metatarsomeres 1-5: $11 / / 10 / 4 / 3 / 2 / 4$

Parameres with tips slightly dilated-rounded (fullface view), curved downward, Fig. 216.

Measurements in $\mathrm{mm}$ (dorsal view). Maximum width of head 1.75. Median length of pronotum 2.35 , maximum width 3.05 . Sutural length of elytra 2.10, maximum width combined 3.60.

\section{Variation and sexual dimorphism}

Only male holotype available.

\section{Distribution \\ Papua New Guinea: SE region: N coastal side.}

\section{Etymology}

Name is a contraction derived from the geographic origin and the rugose dorsum of this species.

\section{Ungrouped Onthophagus species}

\section{Introductory comment}

The following species cannot simply be placed in a defined operational group with other Papuasian Onthophagus; comments on their possible position are given where applicable. The paragraphs headed Identification start with primary distinguishing attributes, which mostly concern cephalic and pronotal structure, i.e. their outline and ornamentation (see also operational key to groups and species above). In 
combination with the illustrations there should be no doubt as to the identity of these ungrouped species, hereafter listed in alphabetical order.

\section{Included Papuasian species}

O. hagenmontis sp. n. - Papua New Guinea

O. ioramaculatus sp. n. - Papua New Guinea

O. papuater sp. n. - Papua New Guinea

O. papuplicatus sp. n. - West New Guinea, Papua New Guinea

O. peotoxus sp. n. - West New Guinea

O. sylvipapuanus sp. n. - West New Guinea, Papua New Guinea

O. toxopeus sp. n. - West New Guinea

\section{Onthophagus ioramaculatus sp. $\mathrm{n}$.}

Figs 57-58, 164-172, 217

\section{Material examined}

Holotype male (CMNC) from Papua New Guinea: Iora Creek, $23 \mathrm{~km}$ S Kokoda, Kokoda Trail, 1900 m, Templeton Cross, 6-8.viii.1976, O. Kukal, dung trap, upper mountain rainforest. Paratypes in Appendix 1 .

\section{Identification}

Characters rendering O. ioramaculatus unique in the Papuasian context include the shape of the horns on the head of major males, the strongly punctate elytral striae (some being conspicuously contiguous on the apical elytral declivity), and the basic colour pattern. Head of male with pair of vertexal horns, which are remarkably, abruptly bent inward in major males, base of horns set away from eye foramina; other individuals with more simple horns, long in major females. Pronotum with dense ocellate punctation, virtually glabrous. Basal border of pronotum with distinct, obtuse median angle. Head with bisinuate apex; clypeofrontal ridge absent. Elytral striae broad, well defined, with distinct roundish punctures, juxtepipleural stria consisting of row of very large punctures from humerus to near elytral apex. Elytral interstriae matt, with sparse micropunctation only, glabrous. Base and apex of elytra with distinct yellow parts, pygidium as well as meso- and metafemora largely yellow, most other parts brown (or lighter, pigmentation may be reduced), locally with metallic lustre. Male protibia with apico-internal angle. Body length usually 5-6 $\mathrm{mm}$.

\section{Description (holotype, male)}

Body length ca $6 \mathrm{~mm}$. Habitus convex. Colour largely brown-black, matt, with metallic lustre, some parts yellow. Dorsum quasi-glabrous, punctures with micro-stubbles, underside with numerous pale-yellow setae; punctation very different according to body part.

Head black-brown. Clypeal border widely, evenly rounded to narrowly reflexed, bisinuate apex; lateral clypeal surface and genae abundantly, finely, shallowly punctate, punctation more or less effaced on discal clypeofrontal surface; clypeogenal transition virtually continuous at border; clypeogenal suture distinct, curving onto frons, continuing on either side as slight elevation to base of vertexal protrusions; clypeofrontal transition without any elevation. Genal border with lateral tip rounded. Vertex with pair of fine horns away from eyes, basal part dilated, upright; tip abruptly bent inward (apices of horns approximated), straight, slender, with outside knee and gradual inside curve (axial view). Eye foramina narrow, with ca 7 facet rows across widest point. Ratio interocular distance/maximum (transverse, single) eye width ca 10.

Pronotum black with vague metallic lustre, matt, moderately, evenly convex (disc slightly deplanate, lacking distinct midline impression); anterior side transversely steeply declivous, not particularly modified, punctures on declivity smaller and sparser than elsewhere on pronotum; most of pronotal surface densely, evenly annulate-punctate, punctures large, (sub)isodiametric; anterior and lateral borders finely marginate, base very finely marginate; anterior section of lateral border virtually straight (full-face view), anterolateral angle very shortly rounded, virtually rectangular; posterior section of lateral border nearly straight (full-face view), posterolaterally rounded to base; basal border with very obtuse but distinct median angle (in dorsal view).

Elytra black-brown, yellow-brown patch on base of interstriae 2-4 and 6-7 (humeral umbone), apex of most interstriae convex and also yellow; scutellum indistinct, shape of base unmodified; epipleuron virtually smooth, brown. Elytra broad, with 8 straight to slightly curved, broad, well-defined, shiny striae; stria 7 evenly, very slightly curved in front, ending at humeral umbone, striae 3-4 and 5-6 contiguous on apical declivity; strial punctures very distinct, mostly separated by $2-4$ puncture diameters, slightly crenulating interstriae; punctures in stria 8 large, filled with whitish matter, extending posteriorly to near elytral apex. Interstrial surfaces matt (microreticulate), slightly convex on disc, with sparse micropunctation; interstria 8 strongly convex.

Antennal club light-brown, scapus unmodified. Mentum shallowly emarginate in front. Postocular area of propectus posteriorly delimited by simple coxal-marginal ridge. Propectoral sides brown, virtually glabrous. Metasternum shining, disc finely, abundantly punctate; anterior lobe very slightly bulbous in front; intercoxal lobe and disc with slight 
midline impression; metasternal flanks with finer (seta-bearing) punctures, and with four very large deep ones along anterior margin. Abdominal ventrite 1 moderately shiny, 2-6 matt, these with more or less distinct row of fine, mostly seta-bearing punctures. Pygidium brown, matt (microreticulate), apex (margin) shining; base ridged; surface generally flat, with sparse, very fine, seta-bearing (ocellate) punctation.

Legs generally shiny brown, meso- and metafemora largely yellow. Protibia robust, with $3+1$ larger external denticles (distal 3 larger, acuminate), separated by some serration; proximal serration consisting of 6 small denticles; apico-external denticle long, oblique to tibial axis; apico-internal angle slightly produced, terminal spur small, elongateacuminate (worn off in holotype); protibial underside with low longitudinal crest; protarsus slender. Profemur robust, underside shiny, finely, abundantly punctate-setose. Meso- and metafemoral undersides shiny, with numerous micropunctures, glabrous. Meso- and metatibiae robust, strongly dilated distad to transversely subelliptic crest, which is fringed with short fossorial spines below, and some long spines and setae above; externally with 3 slight, spinebearing fossorial protrusions. Meso- and metatarsi generally very slender, with fine sickle-shaped claws; meso- and metatarsomeres 1 long, straight, unmodified, almost as long as $2-5$ combined. Terminal spurs on meso- and metatibiae elongate-acuminate (tip of long mesotibial spur rounded). Approximate length proportions terminal spur//metatarsomeres 1-5: $11 / / 14 / 5 / 4 / 2 / 4$.

Parameres with tips dilated-rounded (full-face view), curved downward (lateral view), Fig. 217.

Measurements in mm (dorsal view). Maximum width of head 1.9. Median length of pronotum 1.9, maximum width 3.2. Sutural length of elytra 3.0, maximum width combined 3.6.

\section{Variation and sexual dimorphism}

Variation considerable, partly related to body size: major males with pair of abruptly bent horns on the head, as in holotype, females and minor males with simply upright horns or tubercles, which may even be obsolescent in the smallest individuals. Basic colour pattern constant, but degree of pigmentation varies. Body length 4-6 mm.

\section{Distribution}

Papua New Guinea: SE region: Kokoda Trail.

\section{Etymology}

Name is a contraction referring to type locality and patterned colouration of this species.

\section{Onthophagus papuplicatus sp. $\mathbf{n}$.}

Figs 49-50, 189-195, 221

\section{Material examined}

Holotype male (CMNC) from Papua New Guinea: Kokoda Trail, 30-34 mi E Port Moresby, 2200 ft, 16-17.vii.1974, S. Peck. Paratypes in Appendix 1.

\section{Identification}

Males are, in the Papuasian context, easily recognizable by the combination of a transverse ridge (plica) topping the anterior pronotal declivity, the vertexal horns being characteristically transversely expanded inward and connected at base, and the transverse clypeofrontal ridge virtually extending to the clypeogenal borders. Female vertex with transverse ridge, not reaching eye foramina. O. papuplicatus may be related to certain other Onthophagus with such a sharp, transverse, medially pointed pronotal ridge, two Moluccan species with this feature being included in a group around the $O$. malasiacus Gillet, 1927 (Huijbregts \& Krikken 2012); these, however, have simple, short vertexal horns. Elytra subsericeous, i.e. not fully shining. Body length usually $10-12.5 \mathrm{~mm}$.

\section{Description (holotype, male)}

Body length ca $12.5 \mathrm{~mm}$. Habitus convex, plump. Colour generally black, more or less shiny (part of surface more or less microreticulate, sericeous); legs shining black-brown. Dorsum and pygidium virtually glabrous, punctation generally abundant, fine, many parts micropunctate; ventral side and legs with seta-bearing punctures, most setae long yellowbrown.

Clypeal border laterally finely marginate, straight to slightly sinuate, slightly reflexed, marginate apex; clypeal surface laterally finely punctate, medially almost smooth, micropunctate; clypeogenal ridge continuous into transverse clypeofrontal, virtually rectilinear ridge. Genal border straight in front, sinuate to posterior side of eye; genal and frontal surface largely micropunctate. Entire head shining. Vertex with pair of long, medially slightly connected, upright, transverse, tapering horns, their tips slightly curved inward, their base internally with broad plate topped by (angular) denticle. Eye foramina elliptic, with ca 15 facet rows across widest point. Ratio interocular distance/maximum (transverse, single) eye width ca 8.

Pronotum generally strongly convex, disc somewhat deplanate (with vague midline impression); anterior declivity abrupt, topped by transverse plica (medially slightly protuberant). Pronotal surface shining, disc abundantly, evenly, very finely punctate, lateral declivities more distinctly punctate; an- 
terior declivity sparsely micropunctate. Anterior and lateral borders of pronotum marginate; anterior section of lateral border very slightly concave, almost straight (full-face view), anterolateral angle shortly rounded, subrectangular; posterior section of lateral border slightly sinuate, posterolateral angle rounded off; pronotal basal border evenly, widely rounded, very finely marginate.

Elytra black, disc shiny, vaguely sericeous; humeral area more shining; scutellum indistinct; shape of base and apex unmodified; epipleuron punctatesetose. Elytra broad, with 8 straight to slightly curved, narrow, fine striae; stria 7 evenly, very slightly curved in front, ending at humeral umbone; strial punctures minute, mostly indistinct, widely separated. Interstrial surfaces slightly convex, interstriae indistinctly micropunctate, punctures more pronounced on lateral declivity, elytral surface glabrous throughout.

Antennal club yellow, scapus unmodified. Mentum shallowly emarginate in front. Propectoral sides with simple, curved coxal-marginal ridge (not reaching border); surface matt, sericeous, densely (annulate-)punctate-setose. Anterior lobe of metasternum unmodified (very slightly convex), disc shiny, micropunctate, midline impression effaced caudad; metasternal flanks matt, sericeous, abundantly, finely punctate-setose. Abdominal ventrites slightly shiny, laterally with basal row of fine setabearing punctures; abdominal sides and anal ventrite brown. Pygidium black, slightly, evenly convex; base with transverse ridge; surface densely, finely, shallowly punctate, matt.

Protibia with $3+1$ larger external denticles (distal 3 longer, acuminate), hardly separated by fine serration; proximal serration consisting of 56 smaller denticles; apico-external denticle oblique to tibial axis; apico-internal angle with elongateacuminate, distally curved spur; protibial underside with low longitudinal crest; protarsus unmodified. Profemur robust, underside smooth, with micropunctation and several small punctures, bearing long setae. Meso- and metafemoral undersides smooth, with micropunctation and few small punctures, bearing long setae. Meso- and metatibiae robust, dilated distad to transversely subelliptic crest, which is fringed with fine fossorial spines and setae; external side with 4-5 sets of slight, spinebearing fossorial protrusions. Tarsi generally slender, with fine, sickle-shaped claws; meso- and metatarsomeres 1 robust, long, straight, unmodified. Terminal spurs on meso- and metatibiae elongateacuminate. Approximate length proportions terminal spur//metatarsomeres 1-5: 12//15/6/4/3/5.

Parameres tapering to downward, slender tip, Fig. 221.
Measurements in $\mathrm{mm}$ (dorsal view). Maximum width of head 4.0. Median length of pronotum 4.4, maximum width 7.1. Sutural length of elytra 5.2, maximum width combined 7.2.

\section{Variation and sexual dimorphism}

Sexual dimorphism mainly obvious in the shape of the head, the pair of elaborate male vertexal protrusions in females being replaced by a simple transverse ridge (crest shallowly concave in axial view, laterally not reaching eye foramina), and a transversely rugulate clypeus. Variation in development of male vertexal protrusions also obvious, but rather in size (like length of upward horns) than in basic shape. Differences in other characters apparently slight and individual. There are slight differences between the specimens from West New Guinea and Papua New Guinea, for instance in the anterolateral outline and the punctation of the pronotum, but more material is needed for an adequate taxonomic assessment. Body length $9-12.5 \mathrm{~mm}$.

\section{Distribution}

Papua New Guinea: SE region, incl. Kokoda Trail; West New Guinea: SC region.

\section{Etymology}

Name is a contraction referring to geographic origin and fold topping anterior pronotal declivity of this species.

\section{Onthophagus toxopeus sp. n.}

Figs 53-54, 183-188, 223

\section{Material examined}

Holotype male only (RMNH), from [Indonesia: West New Guinea:] Netherlands-Indian-American New Guinea Expedition: Mist Camp, 1800 m, 19.i.1939, L.J. Toxopeus, op rottend aas [on rotting carrion].

\section{Identification}

Combination of primary features of this species includes: a strongly, broadly protruding anterior pronotal declivity, clypeus with an upright apicomedian lobe (subtriangular, tip rounded), and a vertexal pair of interconnected horns; elytra distinctly more elongate than usual in most congeners. Clypeogenal and clypeofrontal ridges absent. For detailed shape of pronotum, see pictures. Body length ca $10.5 \mathrm{~mm}$.

\section{Description (holotype, male)}

Body length ca $10.5 \mathrm{~mm}$. Habitus convex-compact. Colour generally dark-brown, much of dorsum, and 

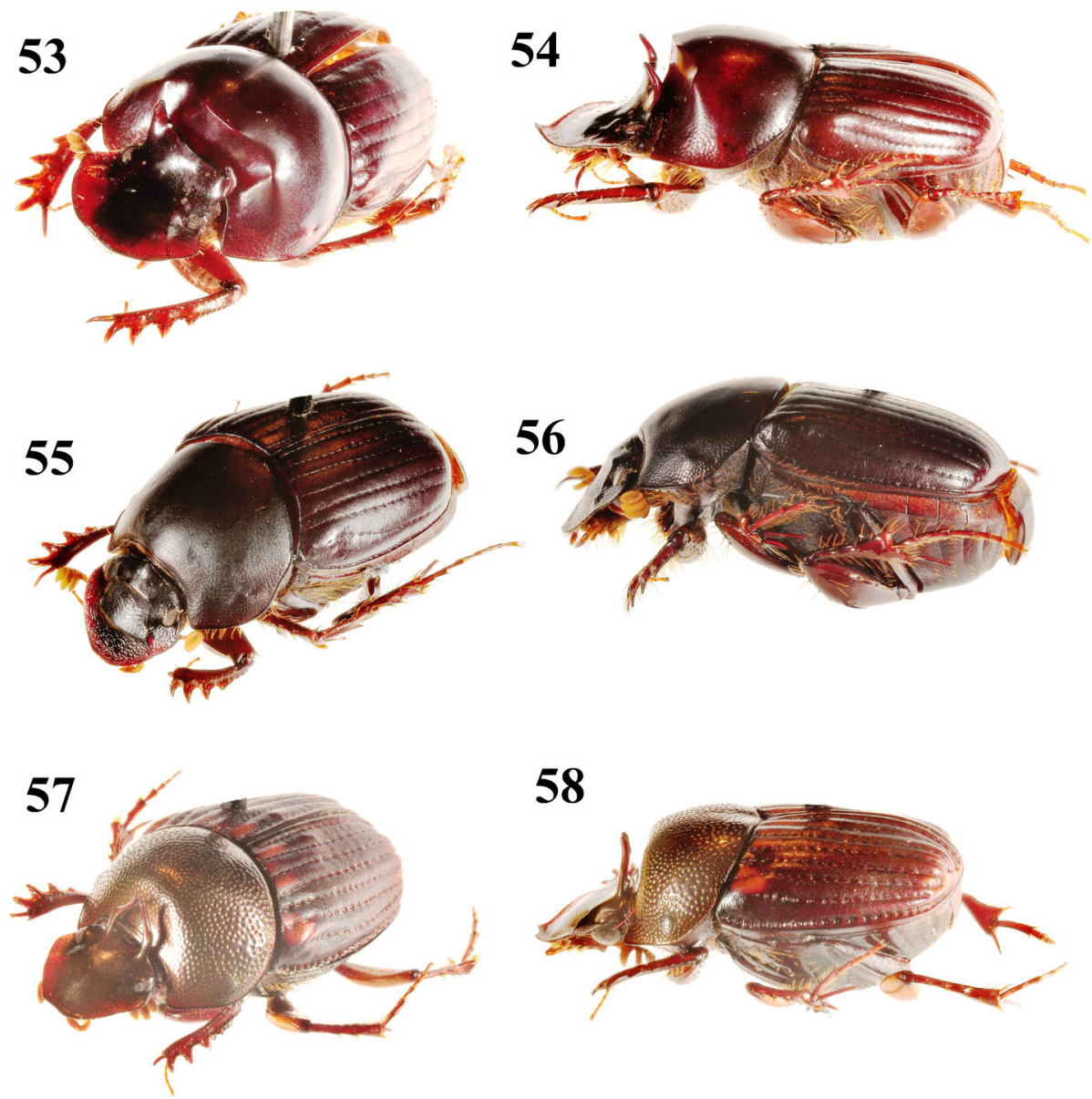

58

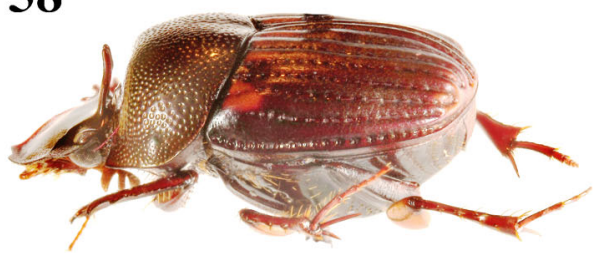

Figs 53-58. Habitus oblique and lateral views of Onthophagus (male holotypes), with approximate length. 53-54, O. toxopeus, $10.5 \mathrm{~mm}$; 55-56, papuater, $7 \mathrm{~mm}$; 57-58, ioramaculatus, $6 \mathrm{~mm}$.

certain ventral parts matt (more or less microreticulate, sericeous). Dorsum glabrous, ventral side and legs with numerous long yellow-brown setae.

Clypeogenal border widely, evenly rounded to reflexed, subtriangular anteromedian lobe, its tip rounded; clypeogenal suture fine, vaguely running onto frons, almost effaced; clypeofrontal transition lacking any elevation. Vertex with pair of virtually upright paraocular horns connected by high, (in dorsal view) slightly sinuate, transverse lamina (slightly convex in front). Genal border rounded, immarginate, transition to clypeus at border very slightly interrupted. Head shining, disc with sparse, scattered micropunctures, punctation more distinct and abundant on margins of clypeus and gena. Eye foramina elliptic, with ca 13 facet rows across widest point. Ratio interocular distance/maximum (transverse, single) eye width ca 6 .
Pronotum almost black, matt, generally strongly convex, disc very slightly convex, lacking midline impression; anteromedian protrusion very broad, with very steep declivity from antediscal rim (medially abrupt, very slightly sinuate in dorsal view, laterally effaced to slight, blunt protrusion); surface behind vertexal horns shallowly concave. Almost entire pronotal disc sparsely micropunctate, lateral declivities abundantly, distinctly punctate; posterolateral border with row of annulate punctures. All pronotal borders finely marginate, base medially with very obtuse angle; lateral border widely, evenly rounded (dorsal view), almost straight (full-face view), anterolateral angle shortly rounded, rectangular; posterolateral section of lateral border almost straight (full-face view), posterolateral angle vague, rounded off.

Elytra dark-brown, matt, humeral umbone distinctly shining; scutellum indistinct, shape of ely- 

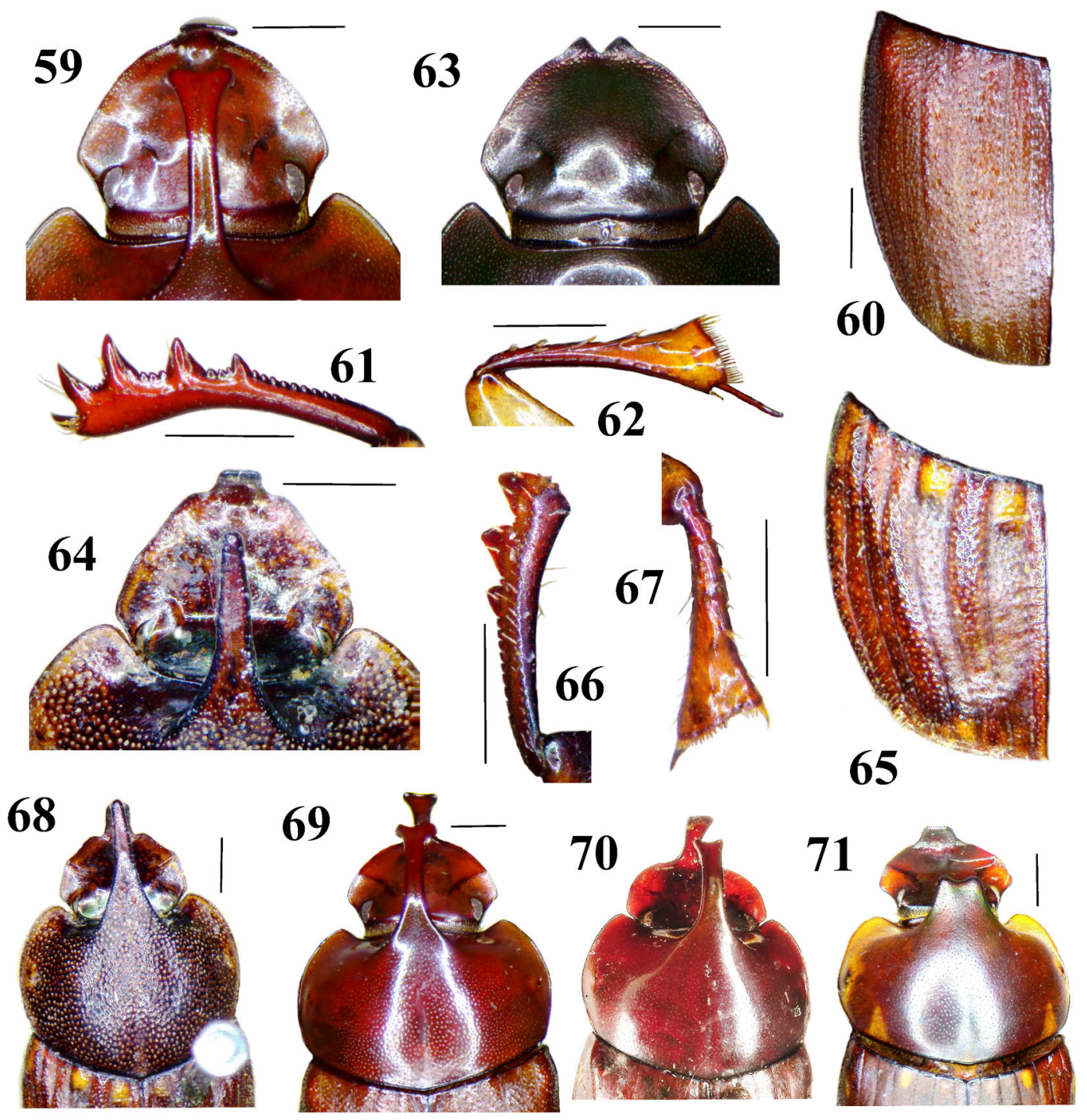

Figs 59-71. Onthophagus species, body parts. 59-63, 69, O. kokoiorus, male holotype, female paratype Mt Hagen (63); 64-68, solomonensis, male holotype; 70, eliptaminus, male paratype Eliptamin; 71, signifer male Finschhafen. Contours of head full-face view $(59,63,64)$, forebody dorsal view $(68-71)$, left elytron dorsal view $(60,65)$, protibia upper side $(61,66)$, metatibia underside $(62,67)$. Scale lines equal $1 \mathrm{~mm}$.

tral base and apex unmodified. epipleuron punctatesetose in front. Elytra broad, with 8 straight to slightly curved, narrow, distinct striae; stria 7 evenly, slightly curved in front, ending at humeral umbone; strial punctures distinct, fine, mostly separated by 48 puncture diameters, slightly crenulating interstrial edges. Interstrial surfaces slightly convex, all with inconspicuous, scattered micropunctation.

Antennal club yellow-brown; scapus unmodified. Mentum shallowly emarginate in front. Propectoral sides with fine, short, distally straight coxal- marginal ridge (not reaching border), surface abundantly (hemi)punctate-setose (puncture size varies). Anterior lobe of metasternum evenly, slightly convex, abundantly punctate-setose, disc shining, with midline impression almost effaced; metasternal flanks matt, abundantly annulate-punctate-setose. Abdominal ventrites matt, dark-brown, laterally each with basal row of annulate seta-bearing punctures. Pygidium brown, matt, finely, abundantly punctate, surface evenly slightly convex; base with transverse ridge. 

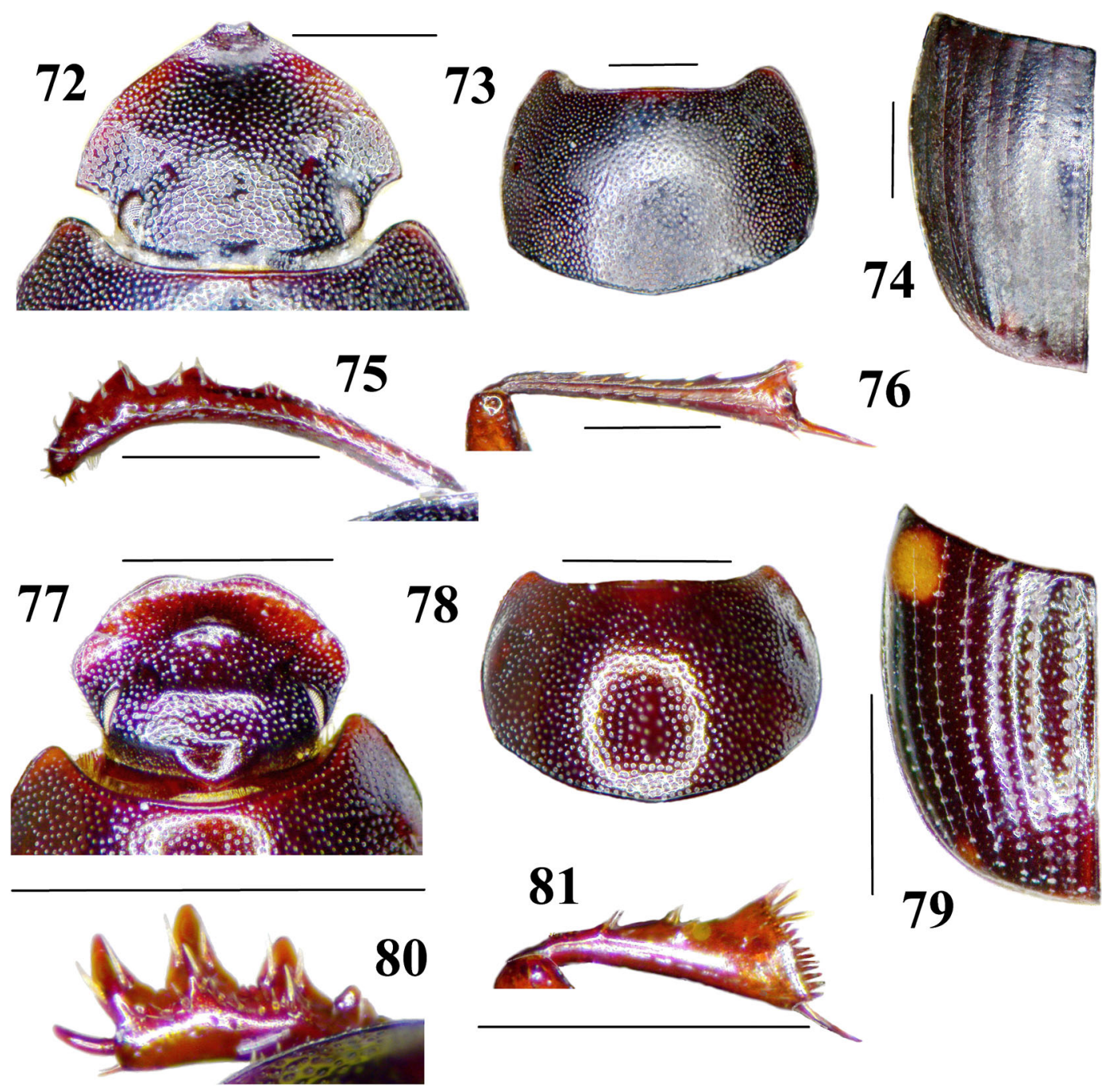

Figs 72-81. Onthophagus species, body parts. 72-76, O. mokwamensis, male holotype; 77-81, tarasovi, male holotype. - Contours of (male), head full-face view $(72,77)$, pronotum dorsal view $(73,78)$, left elytron dorsal view $(74,79)$, protibia upper side $(75,80)$, metatibia upper $(76)$, underside $(81)$. Scale lines equal $1 \mathrm{~mm}$.

Legs generally shining medium-brown. Protibia with $3+1$ large external denticles (distal 3 larger, more or less acuminate), separated by some serration; proximal serration consisting of $6-8$ small denticles; apico-external denticle oblique to tibial axis; protibial apex shortly angular, with elongateacuminate, distally curved spur; protibial underside with low longitudinal crest; protarsus unmodified. Profemoral underside with numerous setabearing (hemi-)punctures and inconspicuous micropunctation; meso- and meta femoral underside with very few seta-bearing punctures and inconspicuous micropunctation. Meso- and metatibia ro- bust, dilated distad to transversely subelliptic crest, which is fringed with fine fossorial spines and setae; external side of tibiae with 3-4 sets of slight, spine-bearing fossorial protrusions. Tarsi generally slender, with fine sickle-shaped claws; meso- and metatarsomeres 1 slender, long, straight, unmodified. Terminal spurs on meso- and metatibiae long, tapering. Approximate length proportions terminal spur//metatarsomeres 1-5: 11//13/4/3/2/5.

Parameres tapering to slightly divergent, somewhat spatuliform tip, Fig. 223.

Measurements in $\mathrm{mm}$ (dorsal view). Maximum width of head 3.3. Median length of pronotum 3.5, 

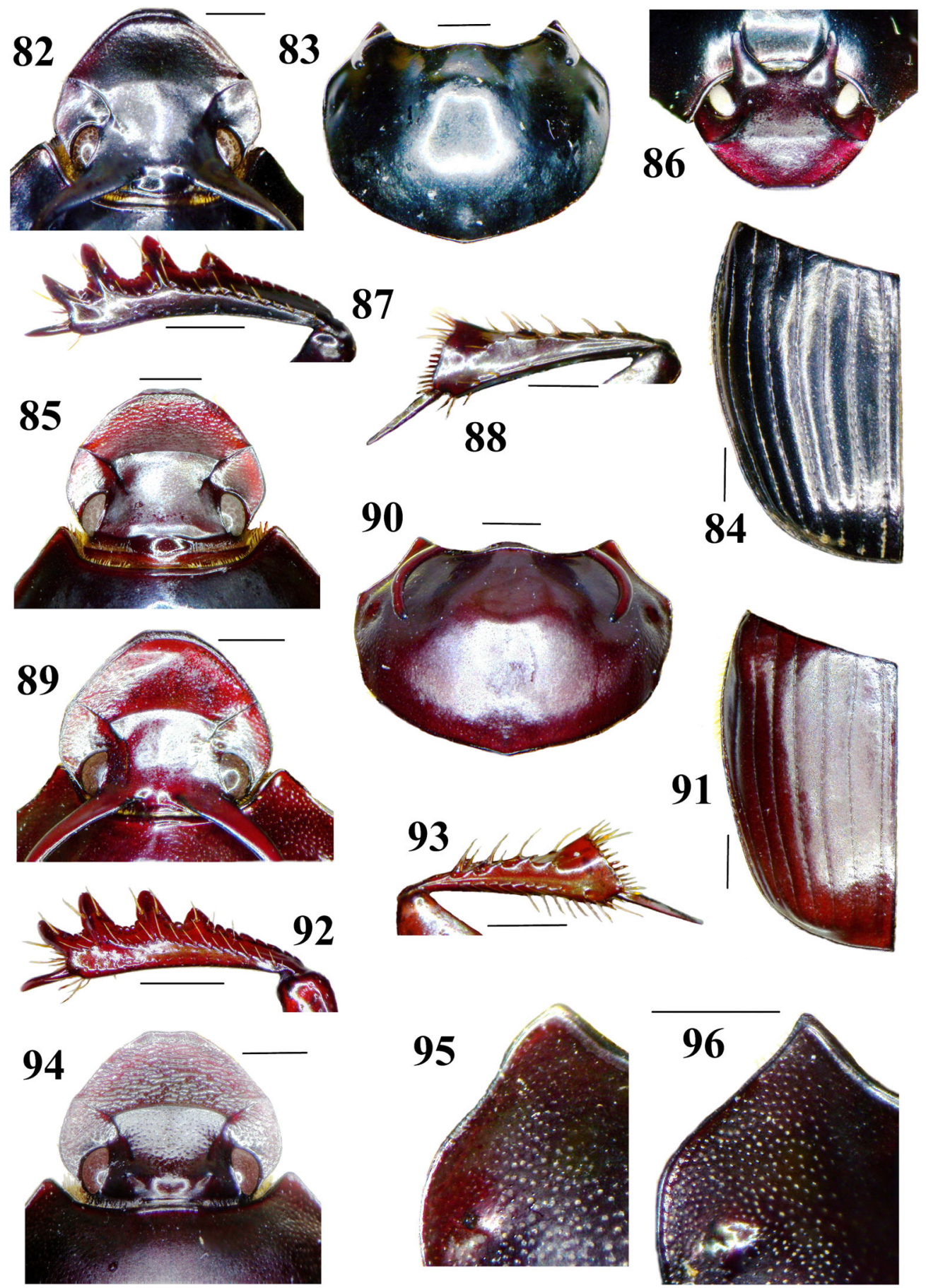

Figs 82-96. Onthophagus species, body parts. 82-88, O. tauroides, major male E Pt Moresby; 82-84, 87-88, female Ofi Creek (85), minor male E Pt Moresby (86); 89-94, opacotaurus, male holotype, female paratype (94); 95, costifer lectotype; 96, pseudocostifer holotype. - Contours of head full-face view $(82,85,89,94)$, frontal (86), pronotum dorsal view $(83,90)$, left elytron dorsal view $(84,91)$, protibia upper side $(87,92)$, metatibia underside $(88,93)$, anterolateral pronotal corners full-face $(95,96)$. Scale lines equal $1 \mathrm{~mm}$. 

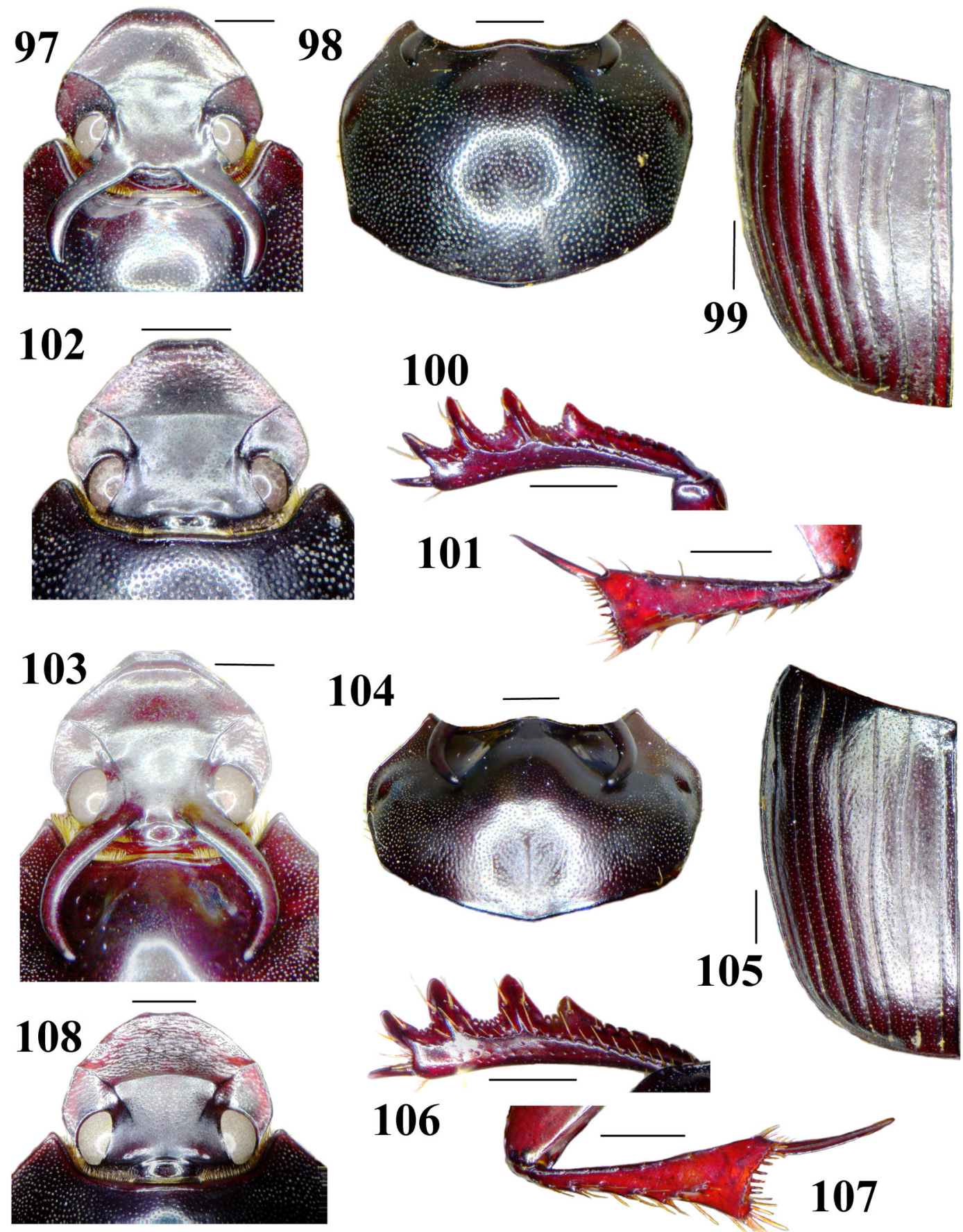

Figs 97-108. Onthophagus species, body parts. 97-102, O. costifer, male lectotype, female paralectotype (102); 103-108, pseudocostifer, male holotype, female paratype Iora Creek (108). - Contours of head full-face view (97, $102,103,108)$, pronotum dorsal view $(98,104)$, left elytron dorsal view $(99,105)$, protibia upper side $(100,106)$, metatibia underside $(101,107)$. Scale lines equal $1 \mathrm{~mm}$. 

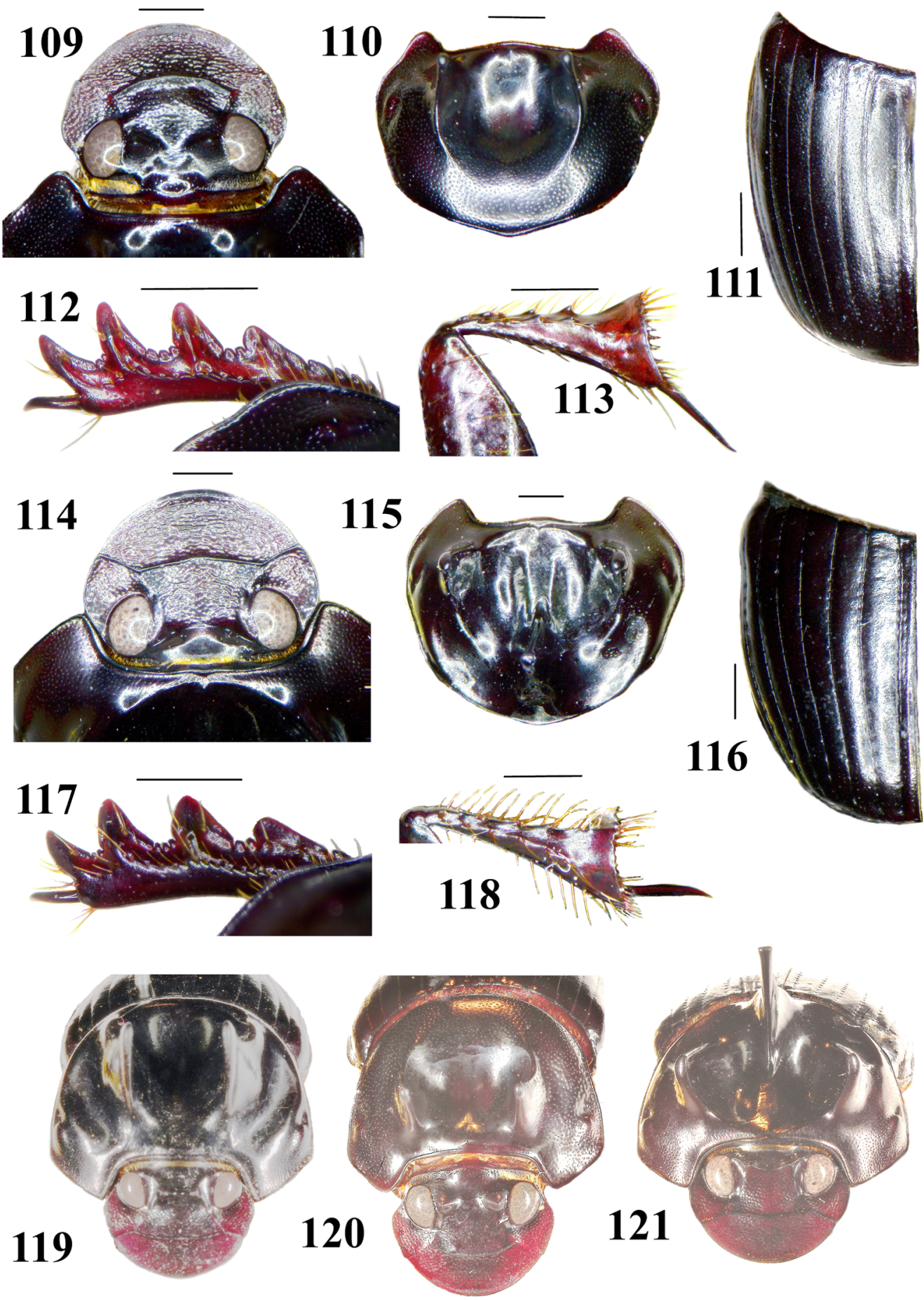

Figs 109-121. Onthophagus species, body parts. 109-113, 120, O. ioranus, male holotype; 114-118, 121, ubaidillahi, male holotype; 119, coprimorphus, male syntype Prauwenbivak. - Contours of head full-face view (109, $114)$, pronotum dorsal view $(110,115)$, left elytron dorsal view $(111,116)$, protibia upper side $(112,117)$, metatibia underside $(113,118)$, forebody dorsofrontal $(119-121)$. Scale lines equal $1 \mathrm{~mm}$. 

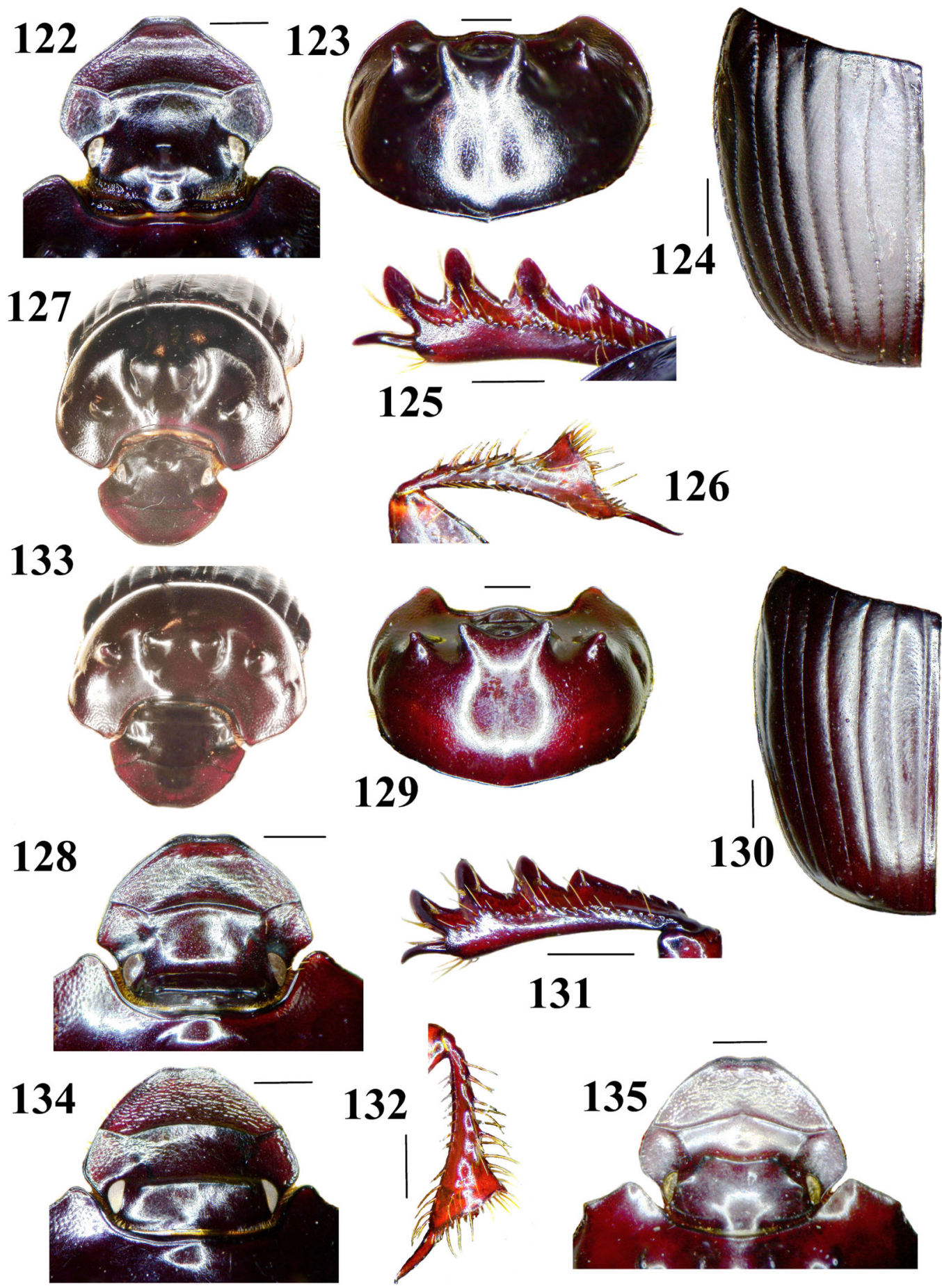

Figs 122-135. Onthophagus species, body parts. 122-127, O. alaindrumonti, male holotype; 128-134, andrewsmithi, male holotype, female paratype Iora Creek (134); 135 labdacus male holotype. - Contours of head full-face view $(122,128,134,135)$, pronotum dorsal view $(123,129)$, left elytron dorsal view $(124,130)$, protibia upper side $(125,131)$, metatibia underside $(126,132)$, forebody frontal $(127,133)$. Scale lines equal $1 \mathrm{~mm}$. 

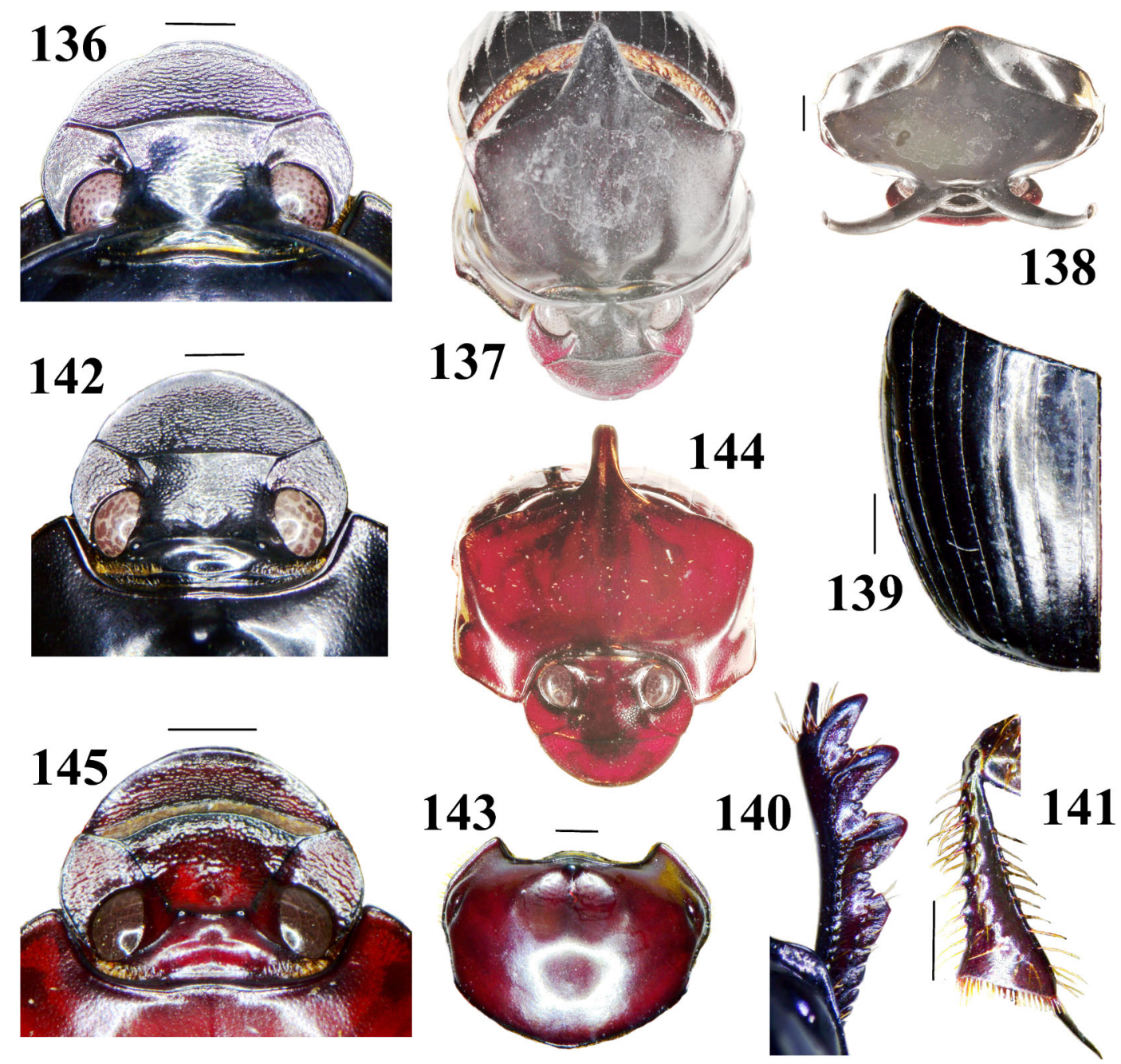

Figs 136-145. Onthophagus species, body parts. 136-143, O. francoisgenieri, male holotype, female paratype Baitabag (142, 143); 144-145, tarsius male Baiyer River (144), female Baiyer River (145). - Contours of head full-face view $(137,142,145)$, forebody dorsofrontal $(137,144)$, dorsocaudal (138), dorsal (143), left elytron dorsal view (139), protibia upper side (140), metatibia underside (141). Scale lines equal $1 \mathrm{~mm}$.

maximum width 5.6. Sutural length of elytra 4.6, maximum width combined 5.6.

\section{Variation and sexual dimorphism}

Only the male holotype, apparently major, is available.

\section{Distribution}

West New Guinea: C mountain region: N side.

\section{Etymology}

Name taken from the collector's name (at the time a renown specialist in Southeast Asian lycaenid butterflies); unmodified masculine noun (meaning: archer).

Onthophagus peotoxus sp. n.

Figs 47-48, 178-182, 219

\section{Material examined}

Holotype male only (RMNH), from [Indonesia: West New Guinea:] Netherlands-Indian-American New Guinea Expedition: Araucaria Camp, 800 m, iii.1939, L.J. Toxopeus. 

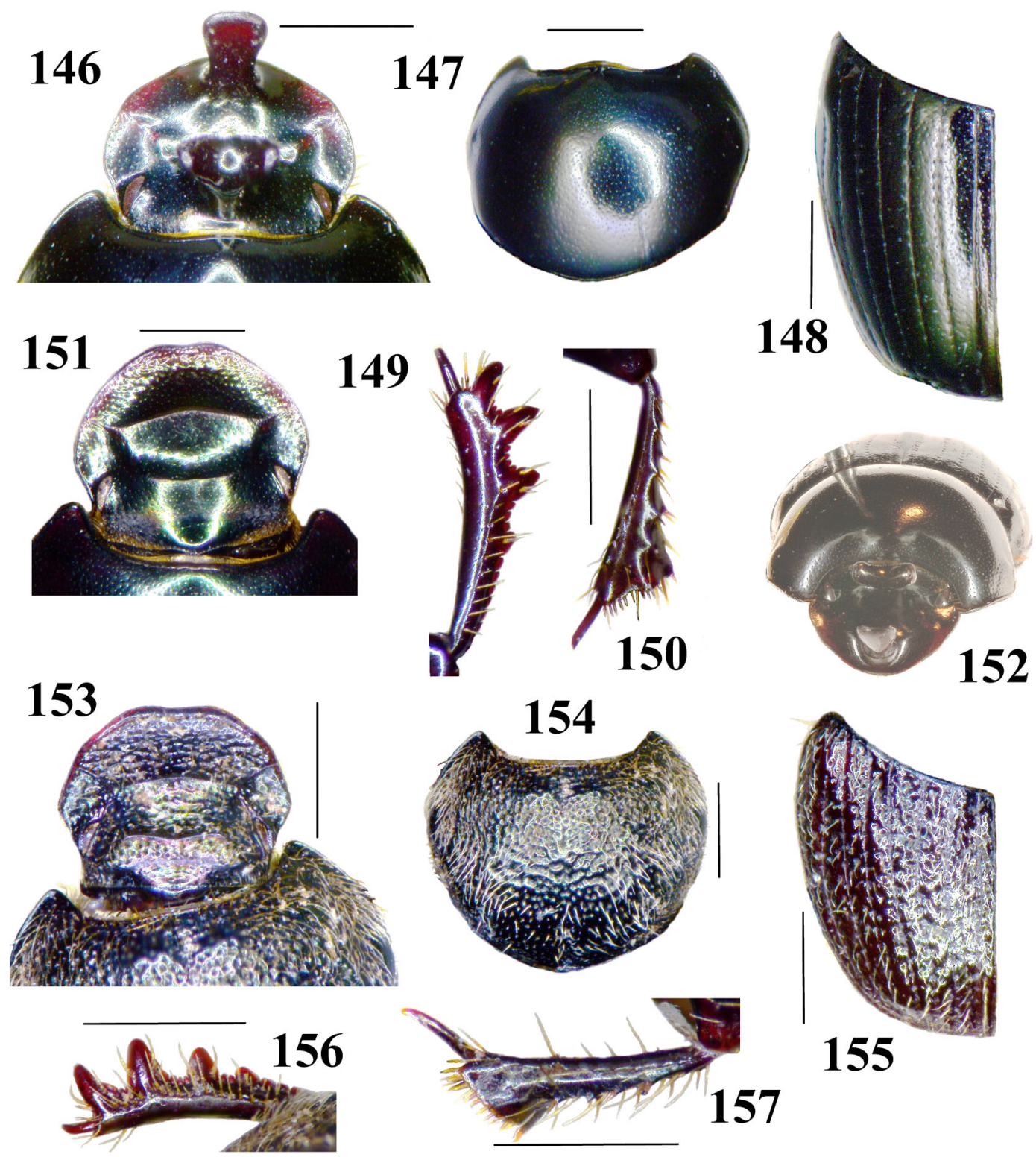

Figs 146-157. Onthophagus species, body parts. 146-152, O. yifer, male holotype, female paratype Timika (151); 153-157, papurugosus, male holotype. - Contours of head full-face view $(146,151,153)$, pronotum dorsal view $(147,154)$, left elytron dorsal view $(148,155)$, protibia upper side $(149,156)$, metatibia underside $(150,157)$, forebody frontal (152). Scale lines equal $1 \mathrm{~mm}$.

\section{Identification}

This Onthophagus has a characteristic set of forebody protrusions, including a short, transverse interocular ridge, laterally on either side delimited by a small cone, and a set of three low cones around the slightly depressed anterior declivity of the pronotum. Whether $O$. peotoxus is based on a major male remains to be seen, but we do not see direct connections with other Papuasian congeners, except perhaps $O$. papuater, described hereafter. Habitus deplanate, dorsum very shining black. Anterior margin of clypeus bisinuate. Tibiae robust. Body length ca $9.5 \mathrm{~mm}$. 

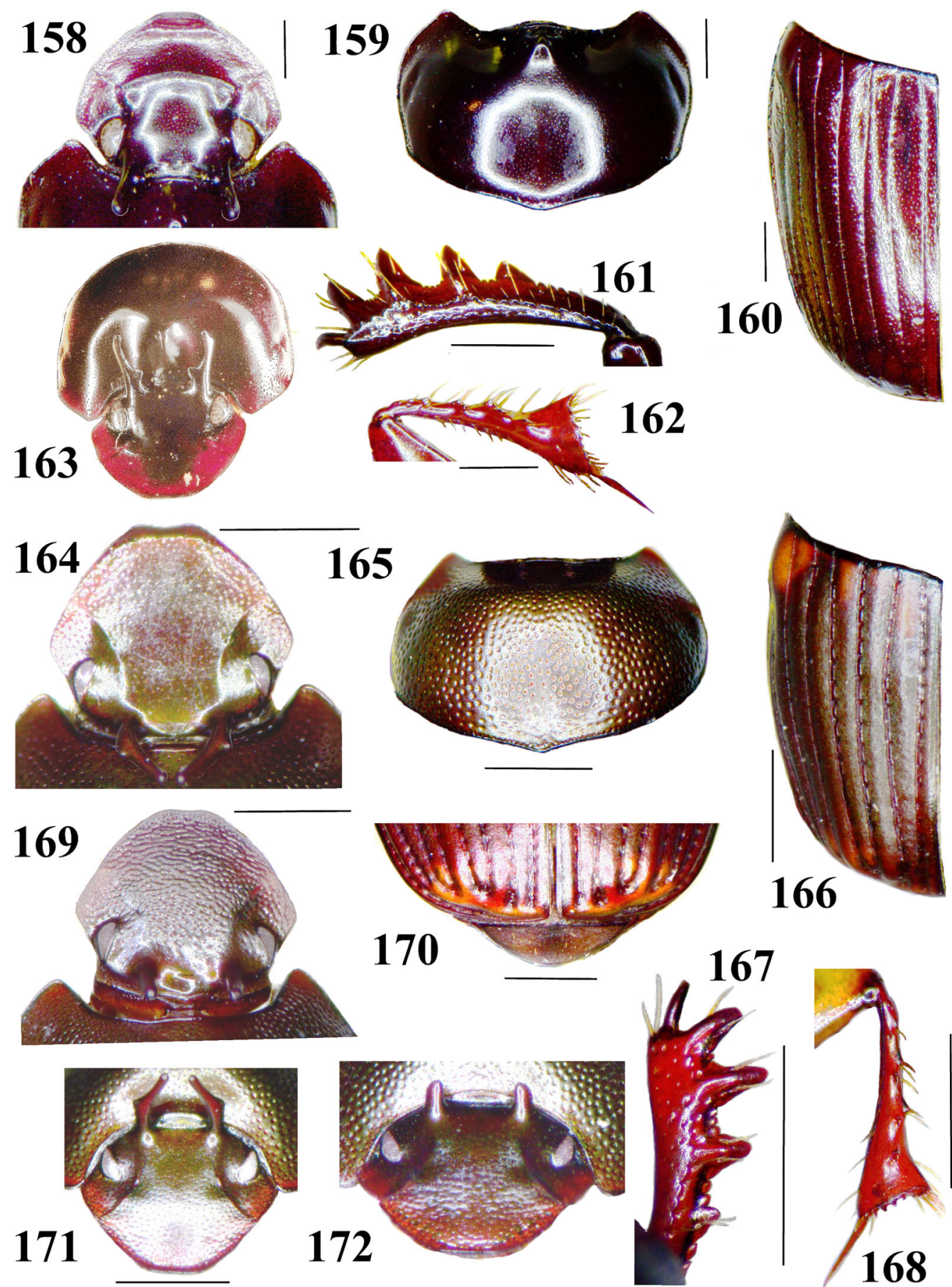

Figs 158-172. Onthophagus species, body parts. 158-163, O. hagenmontis, male holotype; 164-172, ioramaculatus male holotype, female paratype E Kagi (169); male paratypes major (171), minor (172). - Contours of head fullface view $(158,164,169)$, pronotum dorsal view $(159,165)$, left elytron dorsal view $(160,166)$, protibia upper side $(161,167)$, metatibia underside $(162,168)$, elytral tip dorsocaudal $(170)$, head frontal $(171,172)$. Scale lines equal $1 \mathrm{~mm}$. 

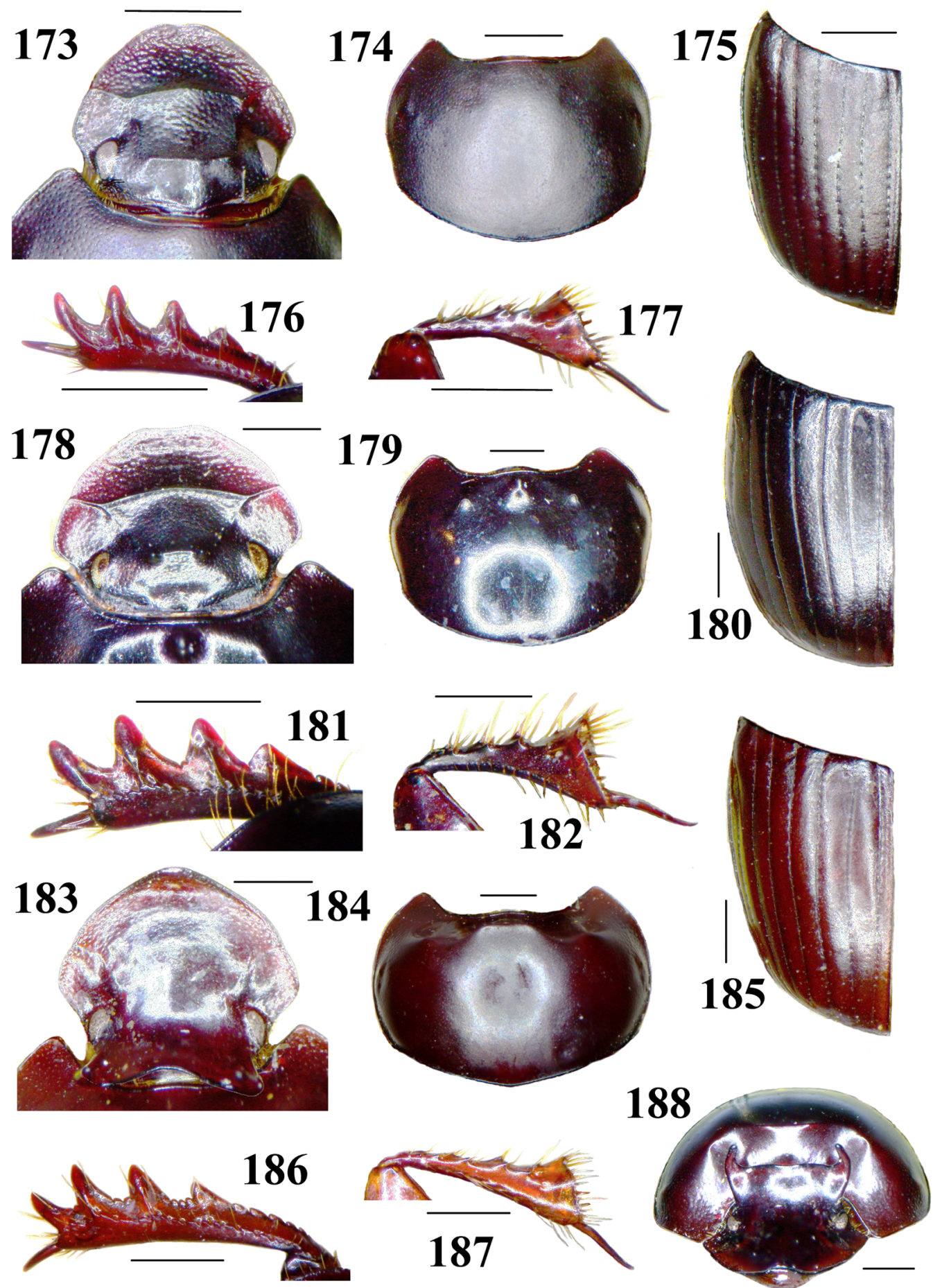

Figs 173-188. Onthophagus species, body parts, male holotypes. 173-177, O. papuater; 178-182, peotoxus; 183188 , toxopeus. - Contours of head full-face view $(173,178,183)$, pronotum dorsal view $(174,179,184)$, left elytron dorsal view $(175,180,185)$, protibia upper side $(176,181,186)$, metatibia underside $(177,182,187)$, forebody frontal (188). Scale lines equal $1 \mathrm{~mm}$. 

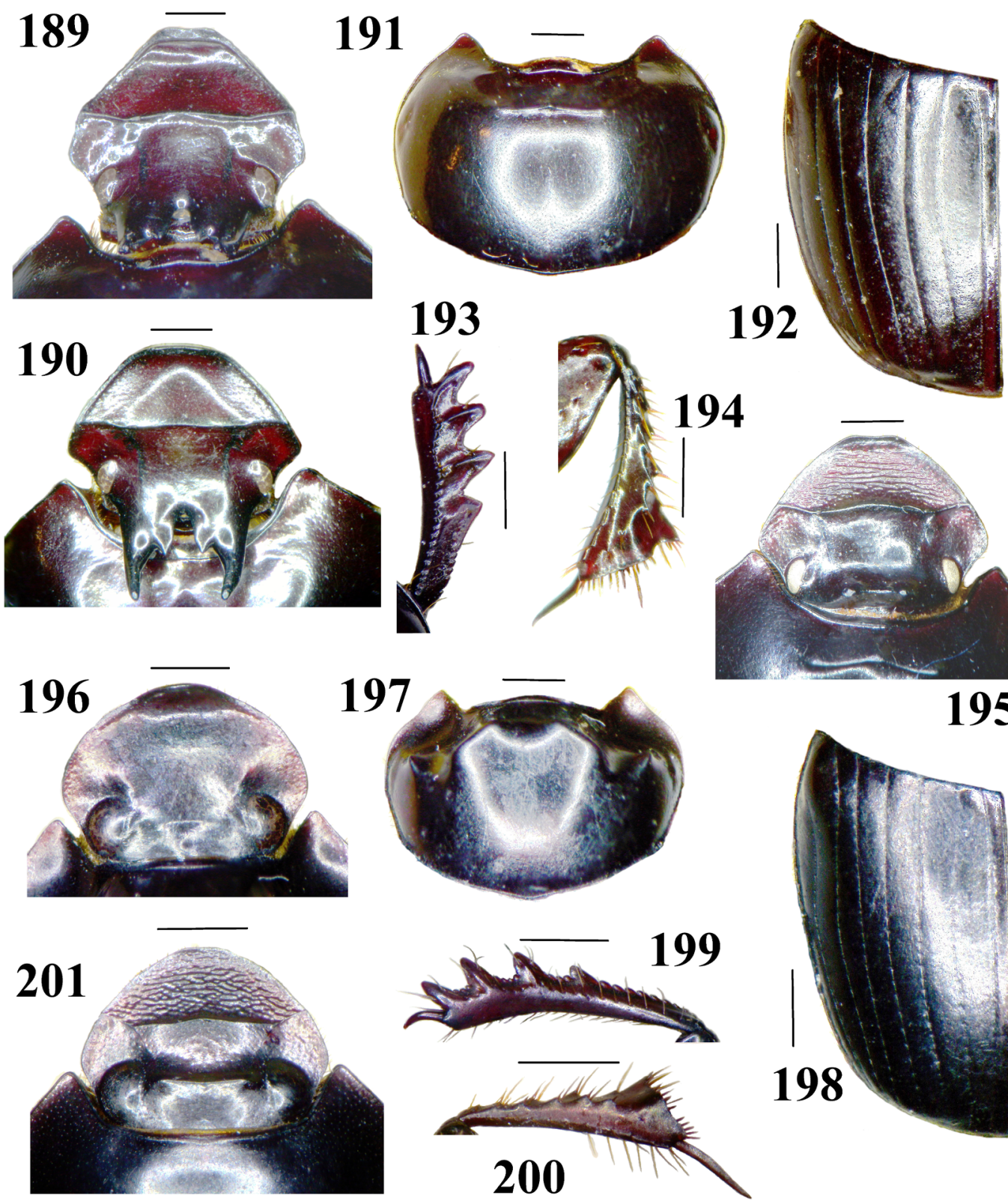

194

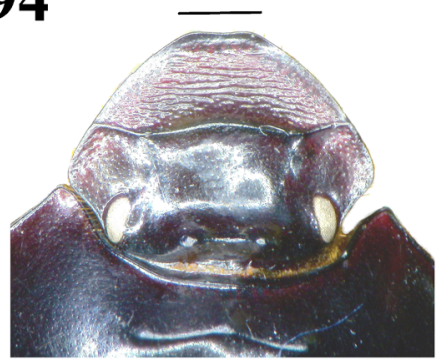

195

Figs 189-201. Onthophagus species, body parts. 189-195, O. papuplicatus, male holotype, female paratype E Pt Moresby (195); 196-201, sylvipapuanus, male holotype, female paratype Mt Hagen (201). - Contours of head fullface view $(189,195,196,201)$, head frontal (190), pronotum dorsal view (191, 197), left elytron dorsal view (192, 198), protibia upper side $(193,199)$, metatibia underside $(194,200)$. Scale lines equal $1 \mathrm{~mm}$.

Description (holotype, male)

Body length ca $9.5 \mathrm{~mm}$. Habitus deplanate. Colour generally black, largely shining, some parts darkbrown. Dorsum glabrous (micro-stubbles aside), ventral side and legs with numerous long light-brown setae.
Clypeal border widely, evenly rounded to slightly reflexed, shallowly bisinuate apical margin; clypeogenal suture ridged, running onto frons; clypeofrontal ridge distinct, weakly arcuate. Frons between eyes with short transverse ridge (about a third of interocular distance), ends on either side pointed, 

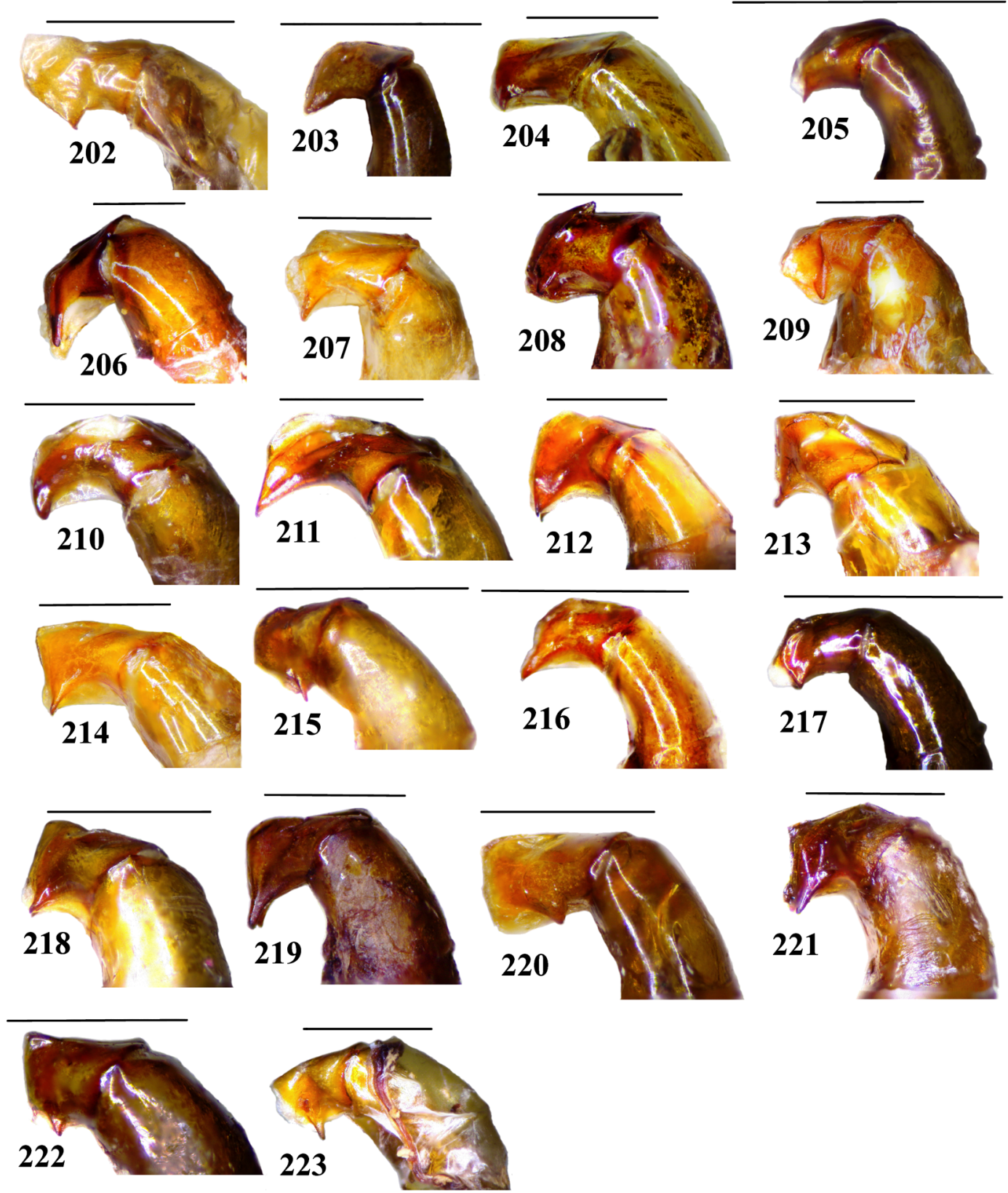

Figs 202-223. Onthophagus species, parameral contours, lateral view (holotypes, others specified). Scale lines (on top of relevant parameres) equal $1 \mathrm{~mm}$. 202, O. kokoiorus; 203, solomonensis; 204, mokwamensis; 205, tarasovi paratype N Pt Moresby; 206, tauroides E Pt Moresby; 207, opacotaurus; 208, costifer Jayapura; 209, pseudocostifer; 210, ioranus; 211, ubaidillahi; 212, francoisgenieri; 213, alaindrumonti; 214, andrewsmithi; 215, yifer; 216, papurugosus; 217, ioramaculatus paratype E Kagi; 218, papuater; 219, peotoxus; 220, hagenmontis; 221, papuplicatus; 222, sylvipapuanus; 223, toxopeus.

conically elevated. Genal border rounded, border finely marginate in front, transition to clypeus at border slightly indented. Head shining, clypeus strongly rugulate-punctate, frons and genae abundantly, finely punctate. Eye foramina narrowly elliptic, with ca 14 facet rows across widest point. Ra- 
tio interocular distance/maximum (transverse, single) eye width 7-8.

Pronotum shining, generally slightly deplanate, lacking midline impression; anterior declivity shallowly depressed, anteromedially with subconical protrusion, lower subconical protrusion on either side, at some distance and slightly behind anteromedian one. Pronotal disc very finely, sparsely to abundantly punctate, on lateral declivities punctation denser, punctures larger, more distinct. All pronotal borders finely marginate, base widely, evenly rounded; lateral border widely, evenly rounded in front (dorsal view), almost straight (full-face view), anterolateral angle rounded, rectangular; posterolateral section of lateral border slightly sinuate (full-face view), posterolateral angle vague, rounded off.

Elytra black, humeral umbone shining, interstriae moderately shiny due to fine microreticulation; scutellum indistinct, shape of elytral base and apex unmodified; epipleuron with row of setae in front. Elytra broad, with 8 straight to slightly curved, narrow, distinct striae; stria 7 evenly, slightly curved in front, ending at humeral umbone; strial punctures distinct, very fine, mostly separated by over 8 puncture diameters, hardly crenulating interstrial edges. Interstrial surfaces slightly convex, all with numerous poorly defined, very fine, evenly scattered punctures.

Antennal club brown; scapus unmodified. Mentum shallowly emarginate in front. Propectoral sides with fine, short, distally straight coxal-marginal ridge (not reaching border), surface abundantly punctatesetose. Anterior lobe of metasternum evenly, slightly convex, abundantly punctate-setose, disc shining, micropunctate, with midline impression almost effaced; metasternal flanks matt, abundantly (annulate-)punctate-setose. Abdominal ventrites matt, from ventrite 2 laterally each with basal row of (annulate) seta-bearing punctures. Pygidium black, matt, finely, densely punctate; surface evenly slightly convex, base with transverse ridge.

Legs robust, generally shining black. Protibia with $3+1$ large external denticles (distal 3 larger, more or less acuminate), separated by minimal serration; proximal serration consisting of 3 small denticles; apico-external denticle oblique to tibial axis; protibial apex unmodified, with robust elongateacuminate, slightly curved spur; protibial underside with low longitudinal crest; protarsus unmodified. Profemoral underside with numerous setabearing punctures and inconspicuous micropunctation; meso- and metafemoral underside with very few seta-bearing punctures and inconspicuous micropunctation. Meso- and metatibia robust, strongly dilated distad to transversely subelliptic crest, which is fringed with long fossorial spines and setae; external side of tibiae with 3-4 sets of slight, spine-bearing fossorial protrusions. Tarsi robust, with fine sickleshaped claws; meso- and metatarsomeres 1 robust, long, straight, unmodified. Terminal spurs on mesoand metatibiae long, apically tapering. Approximate length proportions terminal spur//metatarsomeres 1-5: 14//14/5/3/2/4.

Parameres tapering to slightly divergent, somewhat spatuliform tip, Fig. 219.

Measurements in mm (dorsal view). Maximum width of head 3.2. Median length of pronotum 3.5, maximum width 5.2. Sutural length of elytra 4.1, maximum width combined 5.6.

\section{Variation and sexual dimorphism}

Only male holotype available.

\section{Distribution}

West New Guinea: C mountain region: $\mathrm{N}$ side.

\section{Etymology}

Name is an anagrammatized form of the collector's name, see above, under $O$. toxopeus sp. n.; to be treated as masculine noun.

\section{Onthophagus papuater sp. $\mathrm{n}$.}

Figs 55-56, 173-172, 218

\section{Material examined}

Holotype male only (CMNC), from Papua New Guinea: Iora Creek, 17 km S Kokoda, Kokoda Trail, 1400 m, 3-6.viii.1976, O. Kukal, carrion, montane rainforest.

\section{Identification}

At first sight this Onthophagus looks a minor male, or a female, having no conspicuous forebody ornamentation at all (horns, whatever), and its deplanate, completely matt black, inconspicuously microsculptured dorsum precluding any obvious connection to other Papuasian congeners, or it should be $O$. peotoxus, described above. Anterior margin of clypeus bisinuate. Head with slightly arcuate clypeofrontal ridge and with short transverse ridge between relatively narrow eyes. Pronotum weakly convex, lacking protrusions, lateral margin with series of distinct large punctures. Tibiae robust. Body length ca $7 \mathrm{~mm}$.

\section{Description (holotype, male)}

Body length ca $7 \mathrm{~mm}$. Habitus deplanate. Colour generally black, matt (microreticulate), legs shiny brown. Dorsum glabrous (micro-stubbles aside), ventral side and legs with numerous long light-brown setae. 
Clypeal border widely, evenly rounded to slightly reflexed, shallowly bisinuate apical margin; clypeogenal suture ridged, running onto frons; clypeofrontal ridge distinct, very weakly arcuate. Frons between eyes with short transverse ridge (about half interocular distance), ends on either side in slight angle (axial view). Genal border rounded, virtually immarginate, transition to clypeus at border very slightly indented. Clypeus strongly rugulate-punctate, frons and genae abundantly, distinctly punctate; punctation sparser, finer behind interocular ridge. Eye foramina narrowly elliptic, with ca 11 facet rows across widest point. Ratio interocular distance/maximum (transverse, single) eye width ca 7 .

Pronotum slightly convex, slightly deplanate, lacking midline impression; anterior declivity unmodified. Pronotal disc very finely, sparsely to abundantly punctate, on lateral declivities punctures denser, larger, more distinct. Anterior and lateral pronotal borders marginate; base widely, evenly rounded; lateral border widely, evenly rounded in front (dorsal view), almost straight (full-face view), anterolateral angle shortly rounded, rectangular; posterolateral section of lateral border slightly sinuate (full-face view), posterolateral angle rounded off completely. Lateral edge bordered by series of larger punctures, posteriorly contiguous (almost canaliculate).

Elytra black, interstriae all with microreticulation; scutellum indistinct, shape of elytral base and apex unmodified; epipleuron with row of setae in front. Elytra broad, with 8 straight to slightly curved, narrow, distinct striae; stria 7 evenly, slightly curved in front, ending at humeral umbone; strial punctures fine, mostly separated by over 8 puncture diameters, very slightly crenulating interstrial edges. Interstrial surfaces slightly convex, all with sparse, evenly scattered, inconspicuous micropunctation.

Antennal club yellow; scapus unmodified. Mentum shallowly emarginate in front. Propectoral sides with fine, short, distally straight coxal-marginal ridge (not reaching border), surface abundantly punctatesetose. Anterior lobe of metasternum evenly, slightly convex, abundantly punctate-setose; disc shining, with shallow midline impression, rather densely, finely punctate; metasternal flanks matt, abundantly (annulate-)punctate-setose. Abdominal ventrites matt, from ventrite 2 laterally each with basal row of (annulate) seta-bearing punctures. Pygidium black, matt, finely, abundantly punctate; surface evenly slightly convex, base with transverse ridge.

Legs robust. Protibia with $3+1$ large external denticles (distal 3 larger, more or less acuminate), separated by minimal serration; proximal serration consisting of 3 small denticles; apico-external denticle oblique to tibal axis; protibial apex unmodified, with robust elongate-acuminate, curved spur; protibial underside with low longitudinal crest; protarsus unmodified, slender. Profemoral underside with numerous large seta-bearing punctures and many fine punctures; meso- and meta femoral underside with very few seta-bearing punctures and numerous much finer punctures. Meso- and metatibia robust, strongly dilated distad to transversely subelliptic crest, which is fringed with long fossorial spines and setae; external side of tibiae with 3 sets of slight, spine-bearing fossorial protrusions. Tarsi slender, with fine sickle-shaped claws; meso- and metatarsomeres 1 robust, long, straight, unmodified. Terminal spurs on meso- and metatibiae long, apically tapering. Approximate length proportions terminal spur//metatarsomeres 1-5: 17//16/7/5/4/7.

Parameres (Fig. 218) tapering to sclerotized divergent lateral tip (full-face view).

Measurements in mm (dorsal view). Maximum width of head 2.2. Median length of pronotum 2.3, maximum width 3.5. Sutural length of elytra 3.3, maximum width combined 4.0 .

\section{Variation and sexual dimorphism}

Only male holotype available.

\section{Distribution}

Papua New Guinea: SE region: Kokoda Trail.

\section{Etymology}

Name is a contraction referring to the New Guinea origin and the fully black appearance of this species.

\section{Onthophagus sylvipapuanus sp. $\mathrm{n}$.}

Figs 51-52, 196-201, 222

\section{Material examined}

Holotype male (CMNC) from Papua New Guinea: Western Highlands, 6000 ft, Mt. Hagen, S. Peck, 58.vii. 1974, dung, T24-25, oak forest. Paratypes in Appendix 1.

\section{Identification}

Combination of primary features of this species includes: a strongly, broadly protruding anterior pronotal declivity, a short, broad head, with an upright apicomedian clypeal lobe (subtriangular, tip rounded) and a low, transverse interocular ridge; border behind acute anterolateral pronotal angle (dorsal view) distinctly concave; and elytra more elongate than usual in most congeners $(O$. hagenmontis, described below, also has elongate elytra). Clypeogenal and clypeofrontal ridges absent in male, distinct in female. For detailed shape of male pronotum, see 
pictures. Elytral interstriae lacking distinct punctation (micropunctation present). Body length usually 9-9.5 mm.

\section{Description (holotype, male)}

Body length ca $9 \mathrm{~mm}$. Habitus convex, more elongate than most congeners. Colour generally black, largely shiny (microreticulation mostly vague, some parts of ventral side more matt). Ventral side and legs with numerous long brownish setae.

Head broad. Clypeogenal border widely, evenly rounded to reflexed, subtriangular anteromedian lobe, its tip rounded; clypeogenal suture hardly indented at border, widely curvilinear onto frons, almost effaced; clypeofrontal transition lacking any elevation. Frons with low, transverse elevation extending between eyes. +Genal border rounded, immarginate. Head shiny, almost entirely with sparse, scattered, fine punctures, punctation more distinct and abundant on margins of clypeus and gena. Eye foramina large, very broadly elliptic, with very numerous facet rows across widest point. Ratio interocular distance/maximum (transverse, single) eye width ca 3 .

Pronotum generally strongly convex, disc slightly convex, lacking midline impression; anteromedian protrusion with very steep declivity from approximately W-shaped antediscal rim (medially concave, between paramedian protrusions, in dorsal view); lateral protrusions angular separated from paramedians by concave depression extending to anterolateral service. Almost entire pronotal surface sparsely micropunctate, marginal surface of lateral declivities abundantly, distinctly punctate; base laterally lined with row of annulate punctures. All pronotal border marginate, base very finely marginate, medially with hardly distinct angle; anterior section of lateral border slightly sinuate (dorsal view), straight (full-face view), anterolateral angle distinct, slightly acute; posterolateral section of lateral border straight, posterolateral angle vague, rounded off.

Elytra black, shiny (vaguely microreticulate), humeral umbone distinctly shining; scutellum indistinct, shape of elytral base and apex unmodified. epipleuron punctate-setose. Elytra more elongate than usual, with 8 straight to slightly curved, narrow, distinct striae; stria 7 evenly curved in front, ending at humeral umbone; strial punctures distinct, fine, mostly separated by 4-6 puncture diameters, slightly crenulating interstrial edges. Interstrial surfaces virtually flat (interstria 1 apically slightly convex), lacking distinct punctation, micropunctation present.

Antennal club grey-brown; scapus unmodified. Mentum shallowly emarginate in front. Propectoral sides with simple coxal-marginal ridge, surface abundantly (hemi) punctate-setose. Anterior lobe of metasternum evenly, slightly convex, abundantly annulate-punctate-setose, disc smooth (some micropunctation present), with superficial midline impression extending caudad; metasternal flanks abundantly, distinctly annulate-punctate-setose. Abdominal ventrites each with basal row of annulate setabearing punctures. Pygidium black, slightly matt, finely, abundantly to densely punctate, surface evenly slightly convex; base with transverse ridge.

Legs generally shiny black-brown. Protibia with $3+1$ large external denticles (distal 3 larger, more or less acuminate), separated by fine serration; proximal serration consisting of 9 small denticles; apicoexternal denticle oblique to tibial axis; protibial apex shortly angular, with elongate-acuminate, distally curved spur; protibial underside with low longitudinal crest; protarsus unmodified. Profemoral underside with several seta-bearing punctures and inconspicuous sparse micropunctation; meso- and meta femoral underside with few seta-bearing punctures and inconspicuous sparse micropunctation. Mesoand metatibia robust, dilated distad to transversely subelliptic crest, which is fringed with fine fossorial spines and setae; external side of tibiae with ca 3 sets of slight, spine-bearing fossorial protrusions. Tarsi generally slender, with fine sickle-shaped claws; meso- and metatarsomeres 1 slender, long, straight, unmodified. Terminal spurs on meso- and metatibiae long, tapering. Approximate length proportions terminal spur//metatarsomeres 1-5: 20//24/8/5/4/7.

Parameres tapering to spatuliform tip, Fig. 222.

Measurements in mm (dorsal view). Maximum width of head 3.0. Median length of pronotum 3.3, maximum width 5.0. Sutural length of elytra 4.7, maximum width combined 5.5.

\section{Variation and sexual dimorphism}

Known from both Papua New Guinea and West New Guinea, no taxonomically significant differentiation noticed, lobe on clypeal apex of West New Guinea males narrower, more slender. Female with widely rounded clypeal border, transversely rugulate clypeus, straight clypeofrontal ridge, and robust interocular ridge; pronotum virtually evenly convex.

\section{Distribution}

Papua New Guinea: Western Highlands. West New Guinea: SC region.

\section{Etymology}

Name of this species refers to both forest occurrence and faunal region; to be treated as masculine noun. 
Onthophagus hagenmontis sp. $\mathbf{n}$.

Figs 45-46, 158-163, 220

\section{Material examined}

Holotype male (CMNC) from Papua New Guinea: $30 \mathrm{mi}$ W Mount Hagen, 8000 ft, 7-12.vii.1974, H.F. Howden. Paratype in Appendix 1.

\section{Identification}

The pronotal shape, with its anteromedially pointed, in dorsal view broad, quasi-triangular anterior protrusion, and the unusually elongate elytra, constitute a unique character combination of this Onthophagus species. Clypeofrontal crest widely arcuate. Vertex with upright, internally dentate horns. Eye foramina large, widely elliptic. Dorsum shining. Parameres characteristic, with large angular protrusion on underside (lateral view). Body length 10.5-11.5 mm. Apparently an upland species.

\section{Description (holotype, male)}

Body length ca $11.5 \mathrm{~mm}$. Habitus convex, more elongate than most congeners. Colour generally shining black. Dorsum glabrous (micro-stubbles aside), ventral side and legs with numerous long yellow-brown setae.

Clypeogenal border widely, evenly rounded to broad, reflexed anteromedian lobe, its tip roundedtruncate; clypeogenal suture fine, vaguely running onto frons, almost effaced; clypeofrontal ridge with fine crest, widely arcuate between clypeogenal sutures on either side. Vertex with pair of virtually upright, distally (on cross-section) roundish, paraocular horns connected by slight transverse ridge, with denticle on internal side at ca 0.4 from base, tip abruptly bent inward, apex blunted. Genal border almost straight in front, rounded posteriorly, immarginate, transition to clypeus at border continuous. Head shining, disc with sparse, scattered micropunctures, punctation more distinct, larger, and abundant on lateral margins of clypeus and gena. Eye foramina broadly elliptic, with ca 17 facet rows across widest point. Ratio interocular distance/maximum (transverse, single) eye width ca 4.5 .

Pronotum very shining, generally strongly convex, disc very slightly convex, midline impression hardly distinct; anteromedian protrusion sharply triangular, with very steep declivities from antediscal rims on either side; surface behind vertexal horns shallowly concave. Almost entire pronotal disc and anterior declivities sparsely micropunctate, marginal surface of lateral declivities abundantly, more distinctly punctate. All pronotal borders finely marginate, base medially with very obtuse angle; lateral border widely, evenly rounded (dorsal view) in front, almost straight (full-face view), anterolateral angle shortly rounded, subrectangular; posterolateral section of lateral border slightly sinuate (full-face view), posterolateral angle vague, rounded off.

Elytra very shining; scutellum indistinct, shape of elytral base and apex unmodified. epipleuron punctate-setose in front. Elytra elongate, with 8 straight to very slightly curved, narrow, fine striae $(3+4$ and $5+6$ joined on distal declivity); stria 7 almost straight in front, ending on distinct humeral umbone; strial punctures distinct, fine, mostly separated by $4-8$ puncture diameters, very slightly crenulating interstrial edges; punctures in juxtepipleural stria larger than in striae 1-7. Interstrial surfaces slightly convex, all interstriae with fine, scattered punctation.

Antennal club yellow-brown; scapus unmodified. Mentum shallowly emarginate in front. Propectoral sides with fine, short, slightly curved coxalmarginal ridge (not reaching border), surface abundantly (hemi)punctate-setose (puncture size varies). Anterior lobe of metasternum evenly, slightly convex, abundantly punctate-setose, disc shining, with midline impression almost effaced; metasternal flanks shiny, abundantly annulate-punctate-setose. Abdominal ventrites shiny, laterally each with basal row of annulate seta-bearing punctures. Pygidium shining black between dense, fine punctation, with microstubbles only; surface evenly slightly convex; base with transverse ridge.

Legs generally shining dark-brown (profemora black). Protibia with $3+1$ large external denticles (distal 3 larger, more or less acuminate), separated by some serration; proximal serration consisting of 5-7 small denticles; apico-external denticle oblique to tibial axis; protibial apex broadly angular, with elongate-acuminate, distally strongly curved spur; protibial underside with low longitudinal crest; apico-internal angle with short, acute, accrete spine; protarsus unmodified. Profemoral underside with numerous seta-bearing (hemi-)punctures and inconspicuous micropunctation; meso- and metafemoral underside with very few seta-bearing punctures and inconspicuous micropunctation. Meso- and metatibia proximally slender, strongly dilated in distal part to transversely subelliptic crest, which is fringed with fine fossorial spines and setae; external side of tibiae with 3-4 sets of slight, spine-bearing fossorial protrusions. Tarsi generally rather robust in relation to tibiae, with fine sickle-shaped claws; meso- and metatarsomeres 1 slender, long, straight, unmodified. Terminal spurs on meso- and metatibiae long, tapering. Approximate length proportions terminal spur//metatarsomeres 1-5: 12//13/5/4/3/6.

Parameres with angular roof and downward angular paramerite (the actual tip) halfway on underside (all lateral view, Fig. 220), base broad (full-face view). 
Measurements in $\mathrm{mm}$ (dorsal view). Maximum width of head 3.4. Median length of pronotum 5.4, maximum width 5.4. Sutural length of elytra 5.8, maximum width combined 6.1 .

\section{Variation and sexual differentiation}

Two males seen. Body length 10.5-11.5 mm.

\section{Distribution}

Papua New Guinea: Western Highlands.

\section{Etymology}

Name refers to the Papua New Guinea type locality of this species.

\section{Acknowledgements}

The continued support of the collection institutions and their staff (listed above) is greatly appreciated. The following colleagues and friends (in alphabetic order) have been very helpful, each of them in their own way: A. Drumont (IRSNB), F. Génier (CNMC), J. Hájek (NMPC), M.A. Hielkema (Netherlands), H.F. Howden (CMNC), D. \& A. Huizing (Belgium), A.B. Smith (CMNC), R. Ubaidillah (MBBJ), S. Tarasov (Natural History Museum, Oslo, Norway), J. van Tol (RMNH). Prodigious field collectors were O. Kukal and S.B. Peck.

\section{References}

Archbold, R., A.L. Rand \& L.J. Brass, 1942. Results of the Archbold Expeditions No. 41. Summary of the 1938-1939 New Guinea Expedition. - Bulletin of the American Museum of Natural History 79: 197-288.

Arrow, G.J., 1941. A few new species of the genus Onthophagus from New Guinea and Japen Island. - Annals and Magazine of Natural History 11(8): 48-55.

Balthasar, V., 1969. Neue Onthophagus-Arten von NeuGuinea und den benachbarten Inseln. - Acta Entomologica Musaei Nationalis Pragae 38: 361-408.

Bornemissza, G.F., 1971. Mycetophagous breeding in the Australian dung beetle, Onthophagus dunningi. - Pedobiologia 11: 133-142.

Boucomont, A., 1914. Les Coprophages de l'Archipel malais (Coléopt.). - Annales de la Société Entomologique de France 73: 238-350.

Cassis, G. \& T.A. Weir, 1992. Scarabaeinae. - Zoological Catalogue of Australia 9: 108-173.

Emlen, D.J., J. Marangelo, B. Ball \& C.W. Cunningham, 2005. Diversity in the weapons of sexual selection: horn evolution in the beetle genus Onthophagus (Coleoptera: Scarabaeidae). - Evolution 59: 1060-1084.

Gillet, J.J.E., 1930. Onthophagides de Nouvelle Guinée. Nova Guinea (Zoologie) 15(1929): 411-434.
Harold, E. von, 1877. Énumération des Lamellicornes coprophages rapportés de l'Archipel malais, de la Nouvelle-Guinée et de l'Australie par MM. J. Doria, O. Beccari et L. d'Albertis. - Annali del Museo Civico di Storia Naturale Genova 10: 38-109.

Holthuis, L.B. \& A.M. Husson, 1973. Jonkheer Drs. Willem Cornelis van Heurn (1887-1972). - Zoologische Bijdragen Leiden 16: 1-67. [Biography, in Dutch.]

Huijbregts, J. \& J. Krikken, 2009. Sulawesi Onthophagus with paraocular protrusions: ten new species, with a key (Coleoptera: Scarabaeidae: Scarabaeinae). - Tijdschrift voor Entomologie 152: 209-236.

Huijbregts, J. \& J. Krikken, 2012. Taxonomy of Moluccan Onthophagus, including eight new species (Coleoptera: Scarabaeidae: Scarabaeinae). - Tijdschrift voor Entomologie 155: 29-55.

Krikken, J., 1977. Some new and otherwise noteworthy species of Onthophagus Latreille from the IndoAustralian archipelago (Coleoptera: Scarabaeidae). Zoologische Mededelingen Leiden 52: 169-184.

Krikken, J. \& J. Huijbregts, 2008. Sulawesi large-eyed Onthophagus and their relatives: seven new species, with a key (Coleoptera: Scarabaeidae: Scarabaeinae). Tijdschrift voor Entomologie 151: 155-171.

Krikken, J. \& J. Huijbregts, 2011. New Southeast Asian Onthophagus species in the deflexicollis group (Coleoptera: Scarabaeidae: Scarabaeinae). - Tijdschrift voor Entomologie 154: 203-213.

Krikken, J. \& J. Huijbregts, 2011. Taxonomy of Sulawesi Onthophagus with an immarginate pygidial base: (Coleoptera: Scarabaeidae: Scarabaeinae). - Tijdschrift voor Entomologie 154: 229-268.

Matthews, E.G., 1972. A revision of the scarabaeine dung beetles of Australia. I. Tribe Onthophagini. - Australian Journal of Zoology Supplement 9: 1-330.

Paulian, R., 1937. Sur quelques nouveaux Onthophagides africains et australiens (Coleoptera: Lamellicornia). Arbeiten über morphologische und taxonomische Entomologie 4: 336-346.

Paulian, R., 1972. Récoltes de M.P. Jolivet en NouvelleGuinée. Coléoptères Scarabaeidae Onthophaginae. Bulletin de la Société Entomologique de France 77: 215-217.

Ridsdill-Smith, T.J. \& P.B. Edwards, 2011. Biological control: ecosystem functions provided by dung beetles. In: L.W. Simmons \& T.J. Ridsdill-Smith (eds.), Ecology and evolution of dung beetles. Wiley-Blackwell, Chichester, UK, 245-266.

Scholtz, C.H., A.L.V. Davis \& U. Kryger, 2009. Evolutionary biology and conservation of dung beetles. Pensoft, Sofia, 567 pp.

Steenis-Kruseman, M.J. van, 1950. Malaysian plant collectors and collections, being a cyclopaedia of botanical exploration. - Flora Malesiana (1) 1(1948-1954), i-clii, 1-639.

Storey, R.I., 1977. Six new species of Onthophagus Latreille (Coleoptera: Scarabaeidae) from Australia. - Journal of the Australian Entomological Society 16: 313-320. 
Storey, R.I. \& T.A. Weir, 1990. New species of Onthophagus Latreille (Coleoptera: Scarabaeidae) from Australia. - Invertebrate Taxonomy 3: 783-815.

Tarasov, S.I. \& A.Y. Solodovnikov, 2011. Phylogenetic analyses reveal reliable morphological markers to classify mega-diversity in Onthophagini dung beetles (Coleoptera: Scarabaeidae: Scarabaeinae). - Cladistics 27: $1-39$.

Toxopeus, L.J., 1940. Nederlandsch Indisch Amerikaansche Expeditie naar Nederlands Nieuw Guinea. (3e Archbold Expeditie naar Nieuw Guinea 1938-1939). Lijst van verzamelstations [List of collecting stations]. Treubia 17: 271-279.

Received: August 27, 2012

Accepted: September 24, 2012

\section{Appendix 1. Material of Papuasian Onthophagus examined}

Grand totals:

30 species, 58 records, 404 specimens.

Species in alphabetic order.

Current country names given.

\section{Onthophagus alaindrumonti}

Papua New Guinea: Kokoda Trail, Iora Creek, 03-06/viii/ 1976, Kukal, 1400 m, montane rainforest: carrion, male Holotype, in CMNC. -1 record.

\section{Onthophagus andrewsmithi}

Papua New Guinea: Kokoda Trail, Iora Creek, Templeton Cross, 03-06/viii/1976, Kukal, 1900 m, upper montane rainforest: dung trap, 10, incl. Holotype, paratypes, in CMNC. 06-08/viii/1976, Kukal, 1900 m, upper montane rainforest: dung trap, 2 paratypes, in CMNC.

Subtotal 12 males and females, in 2 records.

\section{Onthophagus coprimorphus}

Indonesia: West New Guinea: Idenburg River, Prauwenbivak, xi/1920, Van Heurn, 4 male and female SYNTYPES, in SDEI. - 1 record.

\section{Onthophagus costifer}

Papua New Guinea: $10 \mathrm{mi}$ N Wau, 26-28/vi/1974, Peck, $900 \mathrm{~m}$, dung, 2 spms, in CMNC. Indonesia: West New Guinea: Hollandia [Jayapura], ex coll. Van Doesburg, $1 \mathrm{spm}$, in RMNH. Mamberamo River, Pionierbivak, xii/1920, Van Heurn, male Lectotype (designated this paper), in IRSNB. NEW GUINEA [unspecified], 1 female paralectotype in IRSNB.

Subtotal 5 males and females, in 4 records.

\section{Onthophagus eliptaminus}

Papua New Guinea: Eliptamin Valley, 01-15/vii/1959, Brandt, $1200-1350 \mathrm{~m}, 1$ paratype, in NMPC. Indonesia:
West New Guinea: Star Range, Sibil, 08/iv/1959, 1260 m, at light, 1 spm, in RMNH.

Subtotal 2 males, in 2 records.

\section{Onthophagus francoisgenieri}

Papua New Guinea: Madang: Baitabag, $608^{\prime} 19^{\prime \prime} S-145$ $46^{\prime} 34^{\prime \prime} \mathrm{E}, 30 / \mathrm{i} / 2000$, Anderson, $100 \mathrm{~m}$, rainforest litter, 26 spms, incl. Holotype, male and female paratypes, in CMNC. 1 record.

\section{Onthophagus hagenmontis}

Papua New Guinea: 20 mi E Mount Hagen, 12/vii/1974, Howden, $6000 \mathrm{ft}, 1$ paratype in CMNC. $30 \mathrm{mi} \mathrm{W}$ Mount Hagen, 07-12/vii/1974, Peck, $8000 \mathrm{ft}, 1$ Holotype, in CMNC.

Subtotal 2 males, in 2 records.

\section{Onthophagus ioramaculatus}

Papua New Guinea: Kokoda Trail, 5 km E Kagi, 0811/viii/1976, Kukal, 2000 m, upper montane rainforest: dung, 114 paratypes, in CMNC. Kokoda Trail, Iora Creek, Templeton Cross, 06-08/viii/1976, Kukal, 1900 m, upper montane rainforest: dung trap, 65, incl. Holotype, paratypes, in CMNC.

Subtotal 179 males and females, in 2 records.

\section{Onthophagus ioranus}

Papua New Guinea: Kokoda Trail, Iora Creek, 03-06/viii/ 1976, Kukal, 1400 m, montane rainforest: carrion, male Holotype, in CMNC. -1 record.

\section{Onthophagus kokoiorus}

Papua New Guinea: Iora Creek, 17 km S Kokoda, Kokoda Trail, $1400 \mathrm{~m}, 03-06 / \mathrm{viii} / 1976$, Kukal, 1400 m, montane rainforest: carrion, 5, incl. Holotype, paratypes, in CMNC. Western Highlands, Mt. Hagen, 05-08/vii/1974, Peck, $6000 \mathrm{ft}$, oak forest, 4 paratypes, in CMNC.

Subtotal 9 males and females, in 2 records.

\section{Onthophagus labdacus}

Indonesia: West New Guinea: Mamberamo, 1956, male Holotype, in NMPC. -1 record.

\section{Onthophagus mokwamensis}

Indonesia: West New Guinea: Mokwam Birdahead, 27/vii/ 2007, Withaar, male Holotype, in RMNH. - 1 record.

\section{Onthophagus opacotaurus}

Papua New Guinea: Kokoda Trail, Iora Creek, Templeton Cross, 06-08/viii/1976, Kukal, 1900 m, upper montane rainforest: dung trap, 2, incl. male Holotype, female paratype, in CMNC. -1 record.

\section{Onthophagus papuater}

Papua New Guinea: Kokoda Trail, Iora Creek, 03-06/viii/ 1976, Kukal, 1400 m, montane rainforest: carrion, male Holotype, in CMNC. -1 record. 


\section{Onthophagus papuplicatus}

Papua New Guinea: Kokoda Trail, 30-34 mi E Port Moresby, 16-17/vii/1974, Peck, 2200 ft, 1 Holotype, in CMNC. Kokoda Trail, 34 mi E Port Moresby, 17-18/vii/1974, Peck, $2200 \mathrm{ft}, 4$ paratypes, in CMNC. 17-18/vii/1974, Peck, $2200 \mathrm{ft}, 19$ paratypes, in CMNC. 16-17/vii/1974, Peck, 2200 ft, 16 paratypes, in CMNC. Kokoda Trail, Kauai River, Manari, 12-14/viii/1976, Kukal, 700 m, rain forest: dung, 2 paratypes, in CMNC. Indonesia: West New Guinea: Freeport Concession, 4 26'21" S-136 52'59" E, 11/iii/1997, Ubaidillah, $300 \mathrm{ft}$, dry lowland forest: dung pitfall trap, 3 paratypes, in MBBJ.

Subtotal 45 males and females, in 6 records.

\section{Onthophagus papurugosus}

Papua New Guinea: Oro Bay, 20 mi S Buna, xi-ii/1943-1944, Helfer, male Holotype, in AMNH. - 1 record.

\section{Onthophagus parapedisequus}

Papua New Guinea: Edie Creek, 5-10/x/1961, Sedlacek, 2000-2100 m, 1 male paratype, in NMPC. - 1 record.

\section{Onthophagus pedisequus}

Papua New Guinea: Eliptamin Valley, 01-15/vii/1959, Brandt, $1200-1350$ m, 1 male paratype in NMPC. Indonesia: West New Guinea: Rattan Camp, ii-iii/1939, Toxopeus, $1000 \mathrm{~m}, 1 \mathrm{spm}$, in RMNH.

Subtotal 2 males, in 2 records.

\section{Onthophagus peotoxus}

Indonesia: West New Guinea: Araucaria Camp, iii/1939, Toxopeus, 800 m, male Holotype, in RMNH. - 1 record.

\section{Onthophagus platalea}

Indonesia: West New Guinea: Timika, Freeport Concession, $416^{\prime} 99^{\prime \prime}$ S-137 00'86"E, 09/iii/1997, Ubaidillah, $1950 \mathrm{ft}$, hill forest: dung pitfall trap, $1 \mathrm{spm}$, in MBBJ. $416^{\prime} 99^{\prime \prime} \mathrm{S}-137$ $00^{\prime} 86^{\prime \prime} \mathrm{E}, 09 / \mathrm{iii} / 1997$, Ubaidillah, $1950 \mathrm{ft}$, heath forest: dung pitfall trap, 2 spms, in MBBJ.

Subtotal 3 males and females, in 2 records.

\section{Onthophagus pseudocostifer}

Papua New Guinea: Kokoda Trail, Iora Creek, 03-06/viii/ 1976, Kukal, 1400 m, montane rainforest: carrion, Holotype, 23 male and female paratypes, in CMNC. -1 record.

\section{Onthophagus signifer}

Papua New Guinea: $18 \mathrm{mi}$ N Port Moresby, Brown River, 14-15/vii/1974, Peck, $10 \mathrm{ft}$, forest: dung, $1 \mathrm{spm}$, in CMNC. Kokoda Trail, 30-34 mi E Port Moresby, 16-17/vii/1974, Peck, 2200 ft, 3 spms, in CMNC. Kokoda Trail, $34 \mathrm{mi}$ E Port Moresby, 17-18/vii/1974, Peck, 2200 ft, 2 spms, in CMNC. Wareo-Finschhafen, Wagner, $1 \mathrm{spm}$, in NMPC.

Subtotal 7 males and females, in 4 records.

\section{Onthophagus solomonensis}

SOLOMONS: British Solomons, Lever, Holotype, in BMNH. -1 record.

\section{Onthophagus sylvipapuanus}

Papua New Guinea: Western Highlands, Mt. Hagen, 0508/vii/1974, Peck, $6000 \mathrm{ft}$, oak forest, 2, incl. Holotype, paratype in CMNC. Indonesia: West New Guinea: Timika: Tembagapura, Freeport Concession, $414^{\prime} 22^{\prime \prime} \mathrm{S}-13702^{\prime} 25^{\prime \prime} \mathrm{E}, 17-$ 20/iii/1997, Ubaidillah, 1500 m, mossy mid-montane forest: dung pitfall trap, 3 paratypes, in MBBJ.

Subtotal 5 males and females, in 2 records.

\section{Onthophagus tarasovi}

Papua New Guinea: 30 mi N Port Moresby, Brown River, 15-16/vi/1974, Peck, 900 m, 1 Holotype, in CMNC. 1415/vi/1974, Peck, $10 \mathrm{ft}$, forest: dung, 4 paratypes, in CMNC. 16-18/vi/1974, Peck, $10 \mathrm{ft}$, forest: dung, 4 paratypes, in CMNC.

Subtotal 9 males and females, in 3 records.

\section{Onthophagus tarsius}

Papua New Guinea: $8 \mathrm{~km}$ SW Nadro, Ofi Creek, 0306/viii/1976, Kukal, 650 m, lowland rainforest: dung, 1 spm, in CMNC. Baiyer River, 35 mi N Mt Hagen, 06-11/vii/1974, Howden, $4000 \mathrm{ft}, 1 \mathrm{spm}$, in CMNC. Kokoda Trail, Kauai River, Manari, 12-14/viii/1976, Kukal, 700 m, rain forest: dung, $1 \mathrm{spm}$, in CMNC.

Subtotal 3 males and females, in 3 records.

\section{Onthophagus tauroides}

Papua New Guinea: $8 \mathrm{~km}$ SW Nadro, Ofi Creek, 1518/viii/1976, Kukal, 650 m, lowland rainforest: dung, 4 spms, in CMNC. Kokoda Trail, 30-34 mi E Port Moresby, 1617/vii/1974, Peck, $2200 \mathrm{ft}, 1 \mathrm{spm}$, in CMNC. Kokoda Trail, $34 \mathrm{mi}$ E Port Moresby, 17-18/vii/1974, Peck, 2200 ft, 19 paratypes, in CMNC. 16-17/vii/1974, Peck, 2200 ft, 23 paratypes, in CMNC. Kokoda Trail, Kauai River, Manari, 1214/viii/1976, Kukal, $700 \mathrm{~m}$, rain forest: dung, $3 \mathrm{spms}$, in CMNC.

Subtotal 50 males and females, in 5 records.

\section{Onthophagus toxopeus}

Indonesia: West New Guinea: Mist Camp, 19/i/1939, Toxopeus, $1800 \mathrm{~m}$, rotting carrion, male Holotype, in RMNH. 1 record.

\section{Onthophagus ubaidillabi}

Indonesia: West New Guinea: Freeport Concession, 4 $26^{\prime} 21^{\prime \prime}$ S-136 52'59"E, 11/iii/1997, Ubaidillah, $300 \mathrm{ft}$, dry lowland forest: dung pitfall trap, male Holotype, in MBBJ. 1 record.

\section{Onthophagus yifer}

Indonesia: West New Guinea: Timika, Freeport Concession, $416^{\prime} 99^{\prime \prime} \mathrm{S}-13700^{\prime} 86^{\prime \prime} \mathrm{E}, 09-12 / \mathrm{iii} / 1997$, Ubaidillah, $1950 \mathrm{ft}$, mossy heath forest: dung pans trap, 2, incl. Holotype, paratype, in MBBJ. $417^{\prime} 93^{\prime \prime} \mathrm{S}-13659^{\prime} 98^{\prime \prime} \mathrm{E}, 09-12 / \mathrm{iii} / 1997$, Ubaidillah, $1900 \mathrm{ft}$, mossy heath forest: dung pitfall trap, 2 paratypes, in MBBJ.

Subtotal 4 males and females, in 2 records. 
